- SAND86-7083

TTC -0574

Unlimited Release

UC -71

\title{
Railroad Transportation of Spent Nuclear Fuel
}

Donald G. Wooden

Transportation Consultant

St. Albans, VT 05478

Prepared by Sandia National Laboratories Albuquerque, New Mexico 87185 and Livermore, California 94550 for the United States Department of Energy under Contract DE-AC04-76DP00789

Printed March 1986 


\section{DISCLAIMER}

This report was prepared as an account of work sponsored by an agency of the United States Government. Neither the United States Government nor any agency Thereof, nor any of their employees, makes any warranty, express or implied, or assumes any legal liability or responsibility for the accuracy, completeness, or usefulness of any information, apparatus, product, or process disclosed, or represents that its use would not infringe privately owned rights. Reference herein to any specific commercial product, process, or service by trade name, trademark, manufacturer, or otherwise does not necessarily constitute or imply its endorsement, recommendation, or favoring by the United States Government or any agency thereof. The views and opinions of authors expressed herein do not necessarily state or reflect those of the United States Government or any agency thereof. 


\section{DISCLAIMER}

Portions of this document may be illegible in electronic image products. Images are produced from the best available original document. 
Issued by Sandia National Laboratories, operated for the United States Department of Energy by Sandia Corporation.

NOTICE: This report was prepared as an account of work sponsored by an agency of the United States Government. Neither the United States Government nor any agency thereof, nor any of their employees, nor any of their ment nor any agency thereof, nor any of their employees, nor any of their contractors, subcontractors, or their employees, makes any warranty, ex-
press or implied, or assumes any legal liability or responsibility for the accuracy, completeness, or usefulness of any information, apparatus, product, or process disclosed, or represents that its use would not infringe privately owned rights. Reference herein to any specific commercial product, process, or service by trade name, trademark, manufacturer, or otherwise, does not necessarily constitute or imply its endorsement, recommendation, or favoring by the United States Government, any agency thereof or any of or favoring by the United States $G$. The views and opinions expressed heretheir contractors or subcontractors. The views and opinions expressed here-

in do not necessarily state or reflect those of the United States Government,
any agency thereof or any of their contractors or subcontractors.

Printed in the United States of America Available from

National Technical Information Service

U.S. Department of Commerce

5285 Port Royal Road

Springfield, VA 22161

NTIS price codes

Printed copy: A06

Microfiche copy: A01

\section{DO NOT MICROFILM COVER}


CONTRACTOR REPORT

SAND86-7083

TTC-0574

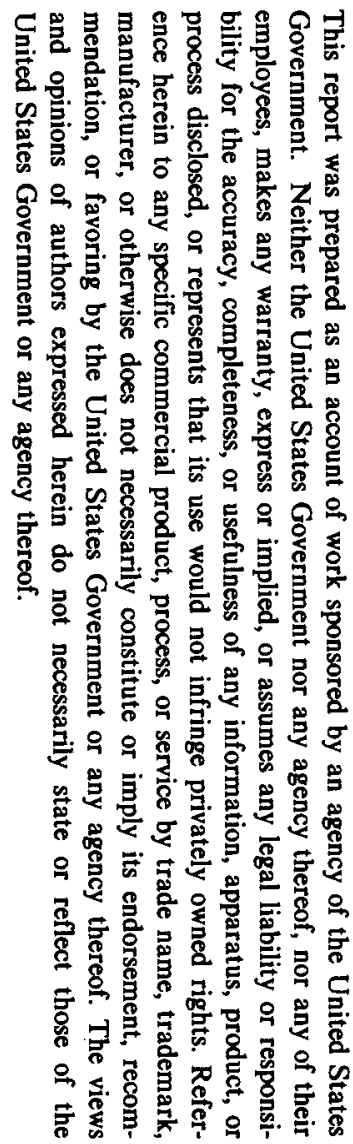

RAILROAD TRANSPORTATION

OF SPENT NUCLEAR FUEL

불

Donald G. Wooden

Transportation Consultant

St. Albans, VT 05478

March 1986
Distribution

Category UC-71

This cocument is

PUBLICL7? PELEASABL跑 Larng E. Prilliam

Authorizing Ofticial

Date: $12 / 22 / 2005$

ABSTRACT

This report documents a detailed analysis of rail operations that are important for assessing the risk of transporting high-level nuclear waste. The major emphasis of the discussion is towards "general freight" shipments of radioactive material. The purpose of this document is to provide a basis for selecting models and parameters that are appropriate for assessing the risk of rail transportation of nuclear waste.

*Prepared for Division 6321, Sandia National Laboratories under PR52-3642 by DGW Services, Inc. 
This page left intentionally blank 
1.0 Introduction 7

2.0 "Typical" Transcontinental Rail Shipment Operations 8

2.1 Origin pickup 8

2.2 Inter-train classification 8

2.3 Road haul 11

2.4 Block exchange 12

2.5 Interchange Transfer 12

2.6 Enroute Repair 13

2.7 Destination Delivery 14

3.0 Classification Terminal Characteristics 15

4.0 Analysis of Parameters Important to Waste Transportation Risk 21

4.1 Velocity Between Terminals 21

4.2 Exposures to Crewmen on a Shipment 23

4.2.1 Number of Crewmen on a Shipment 23

4.2.2 Estimate of Exposure to Crews During Shipment 24

$\begin{array}{lll}4.3 & \text { Stop Time Per Trip } & 27\end{array}$

4.3.1 General Description 27

4.3.2 Development of Factor 29

4.4 Employee Close Proximity Exposure at
Classification Points

4.4.1 Description of Exposures 33

4.4.2 Estimation of Close-Proximity Exposures 41

4.5 Employee General Area Exposure at Intermediate
Classification Points

4.6 Population Exposure at Intermediate
Classification Points

4.7 Frequency of Classification 93

4.7.1 The Route Base 94

4.7.2 Railroad Request and Responses 94

4.7.3 Route Analysis 95

4.8 Exposure of Passengers and Crew of Other Trains Sharing Route $\quad 96$

$$
-2-/-3-
$$


4.8.1 Amtrac Trains 96

4.8.2 Other Freight Trains 98

4.8.3 Passing Train Exposure $\quad 99$

4.9 Rail Accident Rates $\quad 99$

4.9.1 The Data Base 99

4.9.2 Superiority of Using Only Severe Accidents 100

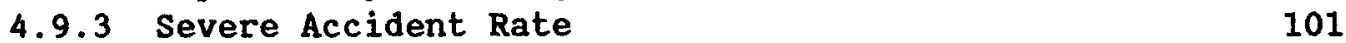

5.0 Summary of Incident-Free Exposure Hodels 104

Appendix A Units of Calculations 106

Appendix B Factors for Exposure From Adjoining Cars 108

Appendix C Generic Population Density Estimates 109

Appendix D Classification Frequency Study Letter 110

Appendix E Study of the Incidence of classification

in Rail Shipments of Merchandise 
1. Baily Yard Photo

2. East Deerfield Yard Diagram

3. Silvis Yard Photo

4. Denver Yard Photo

5. Carman Inspecting Car

6. St. Paul Yard Photo

7. Sevier Yard Hump Photo

8. Carman Repairing Car

9. Rol1-By Car Inspection Photo

10. "Rep" Track Photo

11. Photo of Interior of "One-Spot"

12. Receiving Yard Repair Tracks Photo

13. Receiving Yard Diagram

14. Classification Yard Diagram 
LIST OF TABLES

Page

1. Integrated Dose Rates to Areas Adjacent to Railroad Perimeters... . . . . . . . . 88

2. Dose Factors for Receiving Yard . . . . . . . . 89

3. Number of Routes vs. Number of Classifications by Mileage Blocks . . . . . . . . . . . . . . 97 


\subsection{Introduction}

This report documents a detailed analysis of rail operations that are important for assessing the risk of transporting high-level nuclear waste. The major emphasis of the discussion is towards "general freight" shipments of radioactive material. The purpose of this document is to provide a basis for selecting models and parameters that are appropriate for assessing the risk of rail transportation of nuclear waste.

The report contains four major sections: a section which describes transcontinental shipments of material; a section that describes classification terminals and operations; a section that contains detailed analyses of parameters that are important for assessing the risk of rail transport of nuclear waste; and a summary section that outlines the findings of the work. The first two sections are intended to provide the reader with a general background on rail operations that would be involved during the transport of high-level nuclear waste. The third section documents a detailed analysis of those rail operations that are considered important for assessing the incident-free radiological risk of waste transportation. 


\section{0 "Typical" Transcontinental Rail Shipment Operations*}

As the U. S. railroad industry is presently configured, there is no literally transcontinental railroad. To complete a transcontinental rail shipment, meaning a shipment between a point substantially east of the Mississippi River and a point west of the lower Missouri or Red Rivers, requires at least two carriers. A transcontinental shipment is necessarily an interline shipment. The operations that must be performed to complete such a shipment can be categorized as: origin pickup, intertrain classification, road haul, block exchange, interchange transfer, enroute repair, and destination delivery.

\subsection{Origin pickup}

A rail shipment is picked up by either an industrial switcher (if the shipper's siding is located within the limits of a rail terminal) or a local train (if the siding is along the line of road, including branches). After ascertaining that the car is ready and safe to be moved, the crew will couple the car to the train or draft of cars being handled by the switcher. If it is a local train, or a switcher that must operate with functioning air brakes, the brakes will be connected. If the car is a radioactive shipment (RA), it may not be placed next to the locomotive or caboose or any hazardous shipment in the train. In some cases, this rule will apply to cars picked up by switchers. After pickup of the shipment, the local train or switcher will proceed to the classification terminal, possibly stopping several times on the way to pick up and/or set out other cars. In a very large or complex industrial terminal, a car picked up at an origin by a switcher may be set off at some point by that switcher to be picked up later by a second switcher for transfer to the classification terminal.

\subsection{Inter-train classification}

The part of the classification terminal where the car will be placed by the incoming train or switcher is usually the receiving or arrival yard.

*This description does not apply to intermodal shipments. 
Along with the other cars that have been brought there by the switcher or local train, the car will be inspected to make sure it meets the mechanical requirements for moving in a train. If the defect can be remedied in the receiving yard (e.g., worn brake shoes, broken air hose), the defect will be repaired by the inspectors or car repairmen working with them. If it cannot be remedied in the receiving yard, the car will be designated to go to a repair facility in the terminal rather than in the train in which it would otherwise have been forwarded (see enroute repair below).

In due course, the draft or group of cars which includes the RA car will be picked up for classification or marshalling, a process of sorting cars according to the next handling they are to receive. Cars with identical next handling are called "blocks" which are designated by names or alphanumeric codes. For example, all cars designated to go to Denver on train number six might be called the DEN 6 block.

The classification or sorting process can take place in either a flat or a gravity yard. Either yard has an array of parallel tracks fanning out from switches along a "lead" track which perform the same function as pigeonholes in a post office. In the flat yard, the draft of cars (with the switch engine at their rear) could be shoved down the lead and into the proper track for the $\operatorname{car}(s)$ at the head end of the draft. These could then be uncoupled and the remainder of the draft pulled back to the lead. The process could be repeated until the entire draft is classified. Unless there is a reason to follow this time-consuming procedure, however, the entire draft will not be shoved all the way into each classification track. Instead, after the switches are lined up for the proper classification track, the draft will be accelerated, and the car(s) at the head end to be classified will be uncoupled in motion and allowed to coast into the track as the rest of the draft is brought to a halt. As the "cut" coasts, the draft may be drawn back, the switches realigned for the next "cut," and the process repeated. This process, which is called "kicking to clear," saves a great deal of time and energy. One drawback is that it is hard to control the speed with which the coasting cut meets the $\operatorname{car}(s)$ already standing in the track. If the speed is too low, the $\operatorname{car}(s)$ may stop short and/or fail to couple; worse, if the speed is too high 
when the cars meet, the freight contents and even the cars may be damaged. Because of this, cars containing certain dangerous or fragile commodities will not be kicked, but instead are classified by the process earlier described of shoving the whole draft into the classification track. This process is called "shoving to rest." It must also be followed with the next car(s) to be classified into the track with the "shove to rest" car, unless the latter is already "covered" by a non-hazardous or non-fragile shipment. While not presently mandatory, some roads voluntarily shove RA cars to rest and it will be the usual practice for spent fuel cask cars.

In a gravity yard, the classification process is similar to kicking in a flat yard, except that it is unnecessary to accelerate the draft and to stop it after uncoupling the cut. The engine shoves the draft up an artificial hill called a "hump" over which the lead is located, at a moderate but steady speed. The cuts are made at the crest of this hill, and the cuts accelerate away from the draft by gravity. The same sorts of cars that may not be kicked also may not be humped. The hump engine may shove these cars to rest over the hump, or they may be picked up at the crest by another switch engine coming from the other direction, and shoved to rest in the other end of the proper track from the other end of the "bowl," as the array of classification tracks below the hump is called.

Sometimes the capacity of the bowl is so taxed, or the number of blocks to be made is so great, that all blocks cannot be assembled on a once-through basis. Cars may be reswitched or rehumped before they are ready to be placed in their outbound trains.

After all its constituent blocks are complete, the outbound train is "built" by assembling them. This takes place at the opposite end of the bowl called the "trim" end. Frequently, some of the cars which were kicked or humped stop short of coupling, and it is necessary for the trim switcher assembling the train to close these gaps by shoving the drafts together. When the train is assembled it is moved to the departure or forwarding yard. Here the air hoses are connected, another car inspection performed, and the brakes on each car checked after the appropriate brake line pressure is achieved. 
Any car which does not pass inspection at this point and cannot be repaired in the departure yard must be switched out of the assembled train. The locomotive and caboose are then coupled, the train crew boards, and the train departs.

In some very large terminals, all trains and switchers may not arrive and depart from the same classification yard. This may have resulted because of a merger of separately built lines, each of which had its own yards in the terminal area. Or it could simply reflect the size and complexity of that carrier's terminal operations. In such a case, a car may have to be handled by two or more classification yards before it is able to depart on a train. At the first yard, it will be classified for transfer to the next yard, and instead of being assembled into a train, will be assembled into a transfer run (another form of switcher which moves between yards in the same terminal area), which may not require the same mechanical inspection as the train would. At the next yard, the classification process could be repeated, this time moving the car into an outbound train.

\subsection{Road haul}

Road haul refers to the movement over the road in trains. Normally, the cars in the train will receive no attention from the time they leave one terminal until they arrive at the next. Train positioning restrictions apply to RA cars. However, this will have been taken care of by the switching crew which assembled the train at its departure yard.

If a car is discovered to be or becomes unsafe enroute, and cannot be repaiced by the train crew, it may have to be switched out of the train at an intermediate point in the train run to be repaired before further movement or given special handling to a repair facility. This may also be a consequence of a train accident, such as a derailment, grade crossing collision, fire, mechanical failure, etc.

It is a statutory requirement that the cars in a train be inspected every 1000 miles. For most trains, this distance exceeds their run, so the rule 
doesn't come into play. The cars are given another inspection before they depart on their next train. Some train runs are longer than 1000 miles and the cars in these trains are inspected either by the train crew enroute, or by inspectors at a terminal short of its 1000-mile limit. The difficulty with an enroute inspection by the train crew is that if a defective car that cannot be repaired is discovered, it must be set off there whereas the terminal has greater facility for making repairs.

\subsection{Block exchange}

When the block arrives at its destination (which may or may not be the destination of the train), it could be classified again in the same manner as previously described to prepare it for its next handling. It could also be held as a block to be picked up by another train, transfer or industry switcher. Block exchanges can occur at a terminal where classification is also performed, at smaller terminals, or even at stations and sidings along the line of road. In block exchange, inter-train handling is accomplished without classification activity. To utilize block exchanges, a more complicated blocking plan is required, because the cars in the blocks must initially be classified into finer categories which will avoid additional classification "down the road." However, it has great potential to save both switching expense and car delays, which improves service quality (i.e., speed and reliability).

\subsection{Interchange transfer}

If the destination of the "block" is the point where the car is to be turned over to a connecting railroad, the car could be classified to a transfer run to the other carrier's terminal, which is similar to the intra-railroad terminal transfer described under inter-train classification. There it would be subject to the receiving carrier's classification handing. To expedite service and save expenses, a number of carriers have arranged to have the trains of one carrier run directly into or out of terminals of the other carrier, eliminating one and sometimes two classification handlings (if the cars can be preblocked by the delivering carrier at its departing 
terminal). Another improvement is to execute block exchanges at the junction point, whether or not either carrier's trains originate or terminate there. Finally, even an individual car can be interchanged directly from one road train to another if the junction is along the lines of road, and not at a point where either carrier conducts terminal operations.

Interchanges at very large gateways, Chicago and St. Louis in particular, are sometimes accomplished via intermediate switching railroads whose function is to provide connections between carriers that do not directly connect with each other, and to consolidate interchange classifications and transfers in multicarrier terminals in the process. At worst, these switching carriers can constitute an additional set of handings that take place on the two roads connected by them. At best the switching carriers can function as clearing houses that reduce handlings by consolidating or even obviating blocks and transfers and providing common terminals for the line-haul carriers.

\subsection{Enroute repair}

If a car is found to be defective in a receiving yard, it will be repaired there if at all possible. Certain repairs, such as changing brake shoes and air hoses, are routinely performed there. Repairs requiring only portable tools and materials can often be accomplished there also. If the car cannot 
be repaired in the receiving yard it will be classified to a repair facility in the terminal, usually called the "rip track." There are also requirements that a car's brake equipment be cleaned, oiled, and tested at prescribed intervals; this is also done on the "rip" if scheduled maintenance is nearly due. After being repaired, the car will be switched back to the receiving yard to be reclassified to its next move.

\subsection{Destination delivery}

When the shipment arrives at the terminal from which the consignee's siding is served, the final classification will be to the local train or industrial switcher which will place it there. This operation is the exact reverse of the origin pickup.

The foregoing description does not apply to intermodal shipments, unit trains and multiple car shipments, specialized services (perishables, bulk terminals, motor vehicles), and large volume bulk routes (coal, ore, grain, phosphate rock).

A more detailed description of "generic" railroad operations can be found in $\mathrm{Ar}-78$.

REFERENCE FOR SECTION 2.0

Ar-78 John H. Armstrong, The Railroad--What It Is, what It Does, Simmons-Boardman Publishing Corp., Omaha, Nebraska, 1978. 


\subsection{Classification Terminal Characteristics}

Terminals at which cars spend most of their stop time usually contain the following components: receiving tracks, departure tracks, classification tracks (flat or gravity), car repair tracks or facility, engine servicing tracks and facilities, car cleaning tracks, and miscellaneous tracks (cabooses, wreck train, stores). If the traffic volume handled is high enough, some of these components may have subcomponents for traffic in each direction, for intermodal traffic, for servicing/inspecting run-through trains, etc. If there is a traffic originating or terminating terminal there may also be an intermodal loading facility, and industrial sidings. If at a junction point, there may be several interchange tracks. At some locations, there will be large back shops for heavy repairs on rolling stock, or even manufacture or reconstruction, materials depots for fuel, track components, etc. There is always an office building for supervisors and facilities for crews.

These components can be arranged in any number of ways. The most obvious arrangement is a linear sequence of receiving-classification-departure (end-to-end). In another arrangement, the receiving ( $R$ ) and departure (D) tracks are parallel to the classification tracks, either to one side or straddling it (push-pul1). Bailey Yard, a very large intermediate terminal on the Union Pacific Railroad exhibits both these arrangements in its directionalized layout. In addition, it has a separate "van" (intermodal) yard, and run through tracks (see Figure 1 ). Boston and Maine's East Deerfield yard is a much smaller and less sophisticated terminal with combined $R$ \& $D$ tracks (Figure 2). Dimensionally, classification terminals range from $1.5 \times 0.5 \mathrm{~km}$ up to $11-12 \times 1.5 \mathrm{~km}$. In a small terminal, employment averages 80 persons around the clock (three shifts), not counting train crews that begin or end their runs in the terminal. A very large terminal might have up to 500 . These figures include employees of departments which have no responsibility for running the terminal itself. Most of the employees who are not crewmen (including car inspectors and repairmen) work indoors. 


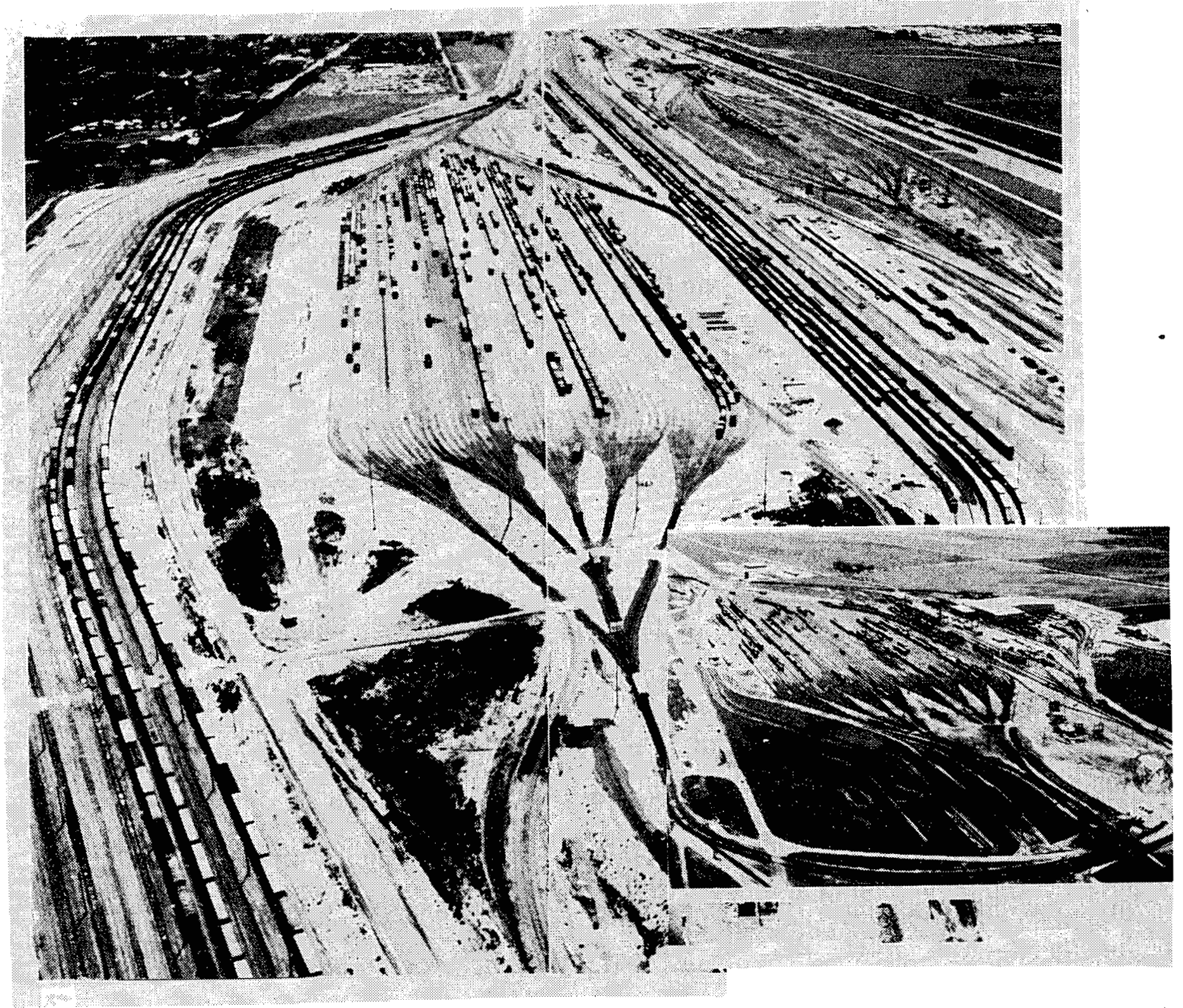

Figure 1. Bailey Yard Photo. (The large photo shows the westward yard. The eastward yard is shown by the inset. 


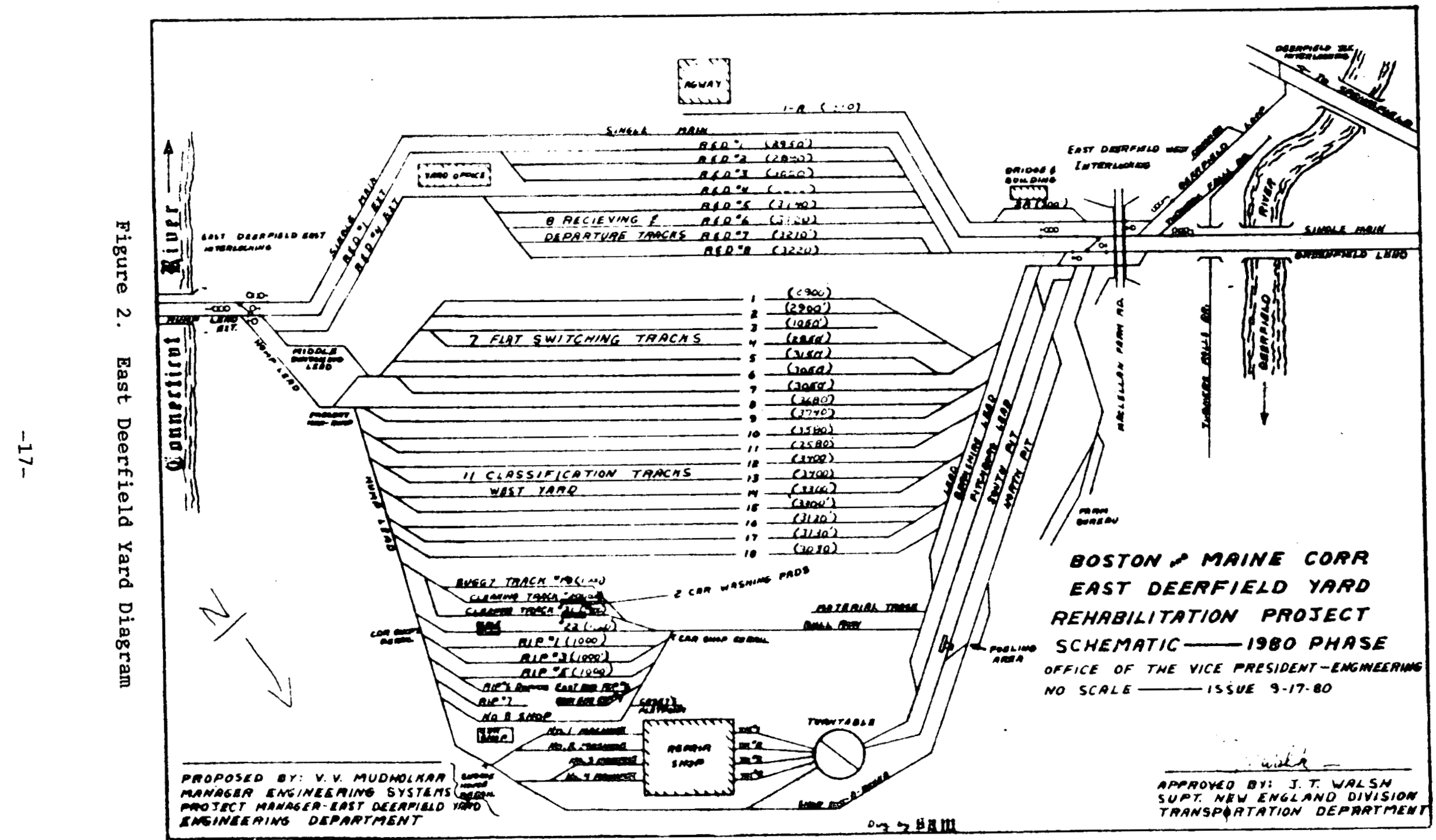


By their nature, terminals have a large number of cars reposing in them much of the time. The average inventory would range from 500 to 2500 . Approximately half the cars at any time would be loaded.

On average, an individual car might be in the terminal from 12 to 24 hours. If it has to be sent to the repair facility, it could be delayed 2-3 days or more. Only 2 or 3 percent of cars passing through terminals are sent to the repair facility.

During their stop time in the terminal, cars that are classified will repose in several general locations for hours at a time without being moved. Within the general locations, the particular spot where the car will repose is random (except for shove-to-rest cars in a hump yard, as will be described later). Likewise, the cars, both loaded and empty, which repose around them are continuously subject to random change.

The population characteristics of the area surrounding a classification terminal can range from entirely rural (former Rock Island Yard in Silvis, IL) to entirely urban (UP's yard in Denver) (Figures 3 and 4). A detailed population study of one large terminal was made; this can be considered representative of a terminal that is not at either extreme of population density. 


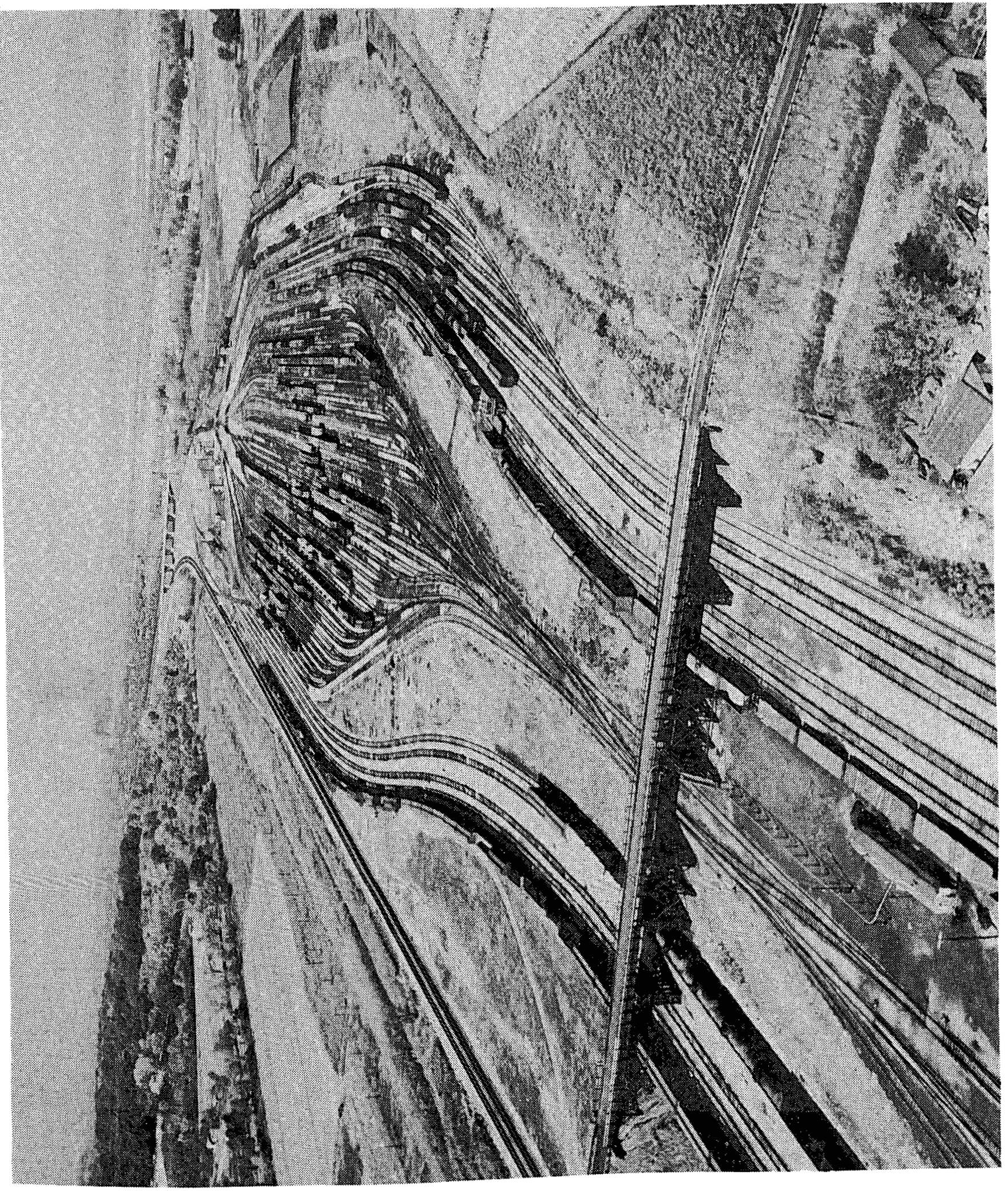

Figure 3. Silvis Yard Photo 


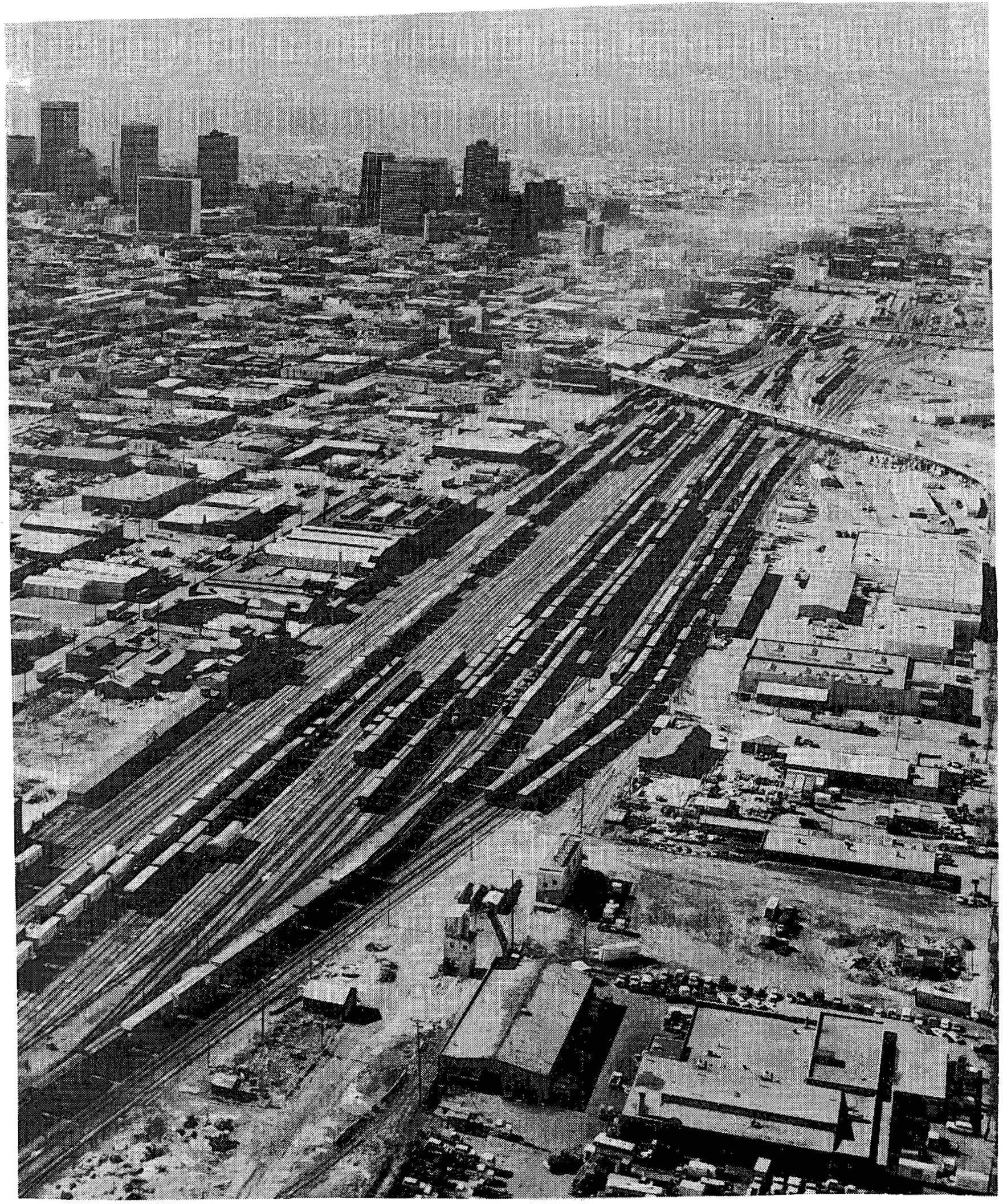

Figure 4. Denver Yard Photo 


\subsection{Analysis of Parameters Important to Waste Transportation Risk}

This section contains detailed analyses of parameters that are considered important for assessing the radiological risk of transporting nuclear waste. These parameters include train velocity between terminals, train crew exposures to radiation, train stop time per trip, exposures to rail crews and non-rail populations during train stops and classifications, exposures to individuals in other trains sharing the route, and severe accident rates for trains.

\subsection{Velocity Between Terminals}

Velocity ( $\mathrm{m} / \mathrm{s})$ during travel does not include stop times. This concept requires stop time during a train trip to be segregated from the time while actually in motion.

Stop time during train trips is a significant portion of total train time.* It is caused by the need to set out or pick up cars enroute, to change crews and motive power, add fuel, to undergo mandatory inspections, and by mechanical failure, by line interruptions, and most frequently by interference from other trains and activities.

There are good reasons to expect that train running velocities are higher than average in rural zones and lower than average in suburban and urban ones. Many municipalities have speed limits within their boundaries, and it frequently happens that railroads limit train speeds over public crossings in built-up areas where crossings are close together and of ten have visibility limitations. Speeds are also reduced over grade crossings with other railroads, and when passing by or through yards and other terminal facilities where employees may be present.

\footnotetext{
* One train run which was observed on 10 different days had a scheduled stop at an intermediate terminal that ranged from a low of 2.17 hours to a high of 5.68 hours with a median of 3.30 hours. This did not include other stop time on the run which had an elapsed time ranging from 23 to 39 hours, with a median of 29 .
} 
Unfortunately, the concept of train running velocity by population zone is difficult to measure. Observation of actual train trips is required, either by observers riding them, or by means of trip recorder tapes that already exist for other reasons, or are collected for this purpose. Mile-by-mile data on population characteristics of each route analyzed would also have to be available also. Again, this could be obtained through observation, or perhaps with the aid of large-scale maps having population detail. In any event, it is a large, costly proposition.

A concept that is simpler to implement is average road haul velocity, or distance divided by all train hours. This will include not only stop time enroute, but also delays in leaving the origin terminal and time held out of the destination terminal. The railroads report statistics on both train miles and train hours. For U.S. railroads as a whole (excluding short lines) road haul velocity averages about $32 \mathrm{~km} / \mathrm{hr}$. Because of its operational attributes, the Northeastern region* has an average velocity of only $22 \mathrm{~km} / \mathrm{hr}$, whereas that for the rest of the U.S. is $40 \mathrm{~km} / \mathrm{hr}$.

Without the extensive field studies mentioned above, it is not possible to differentiate average road haul speed by population zone. Some part of the Northeastern region's lower average road haul velocity is probably due to a higher proportion of nonrural train time.

There is a very wide variation in road haul velocity, even over the same route. Three routes that were checked for 10 or more trips had variations in individual trip velocities of 40 to 60 percent of their median velocities. There is also a wide variation between different routes. One railroad uses two routes between the same major terminals. One route is 20 percent longer than the other, yet has about 30 percent shorter road haul time. The longer route not only has higher speed limits, it has far greater traffic density. Because of the heavy traffic it has much more double track and more ample passing track capacity, which helps to reduce stop time waiting for opposing trains to clear.

*The Northeastern region is defined as Virginia and west virginia and all territory to the north of these states and north of the ohio River as far west as the Illinois Waterway and the Mississippi River.

$$
-22-
$$




\subsection{Exposures to Crewmen on a Shipment}

\subsubsection{Number of Crewmen on a Shipment}

Until recently, the number of crewmen in a train crew was either four or five men (depending on whether a locomotive fireman was present), except under special circumstances. In a few states, an additional brakeman was mandated by law for trains in excess of a specified length, but this is being phased out. If the railroad were nonunion, and only short lines are, the crew could be any size, even one, but the incidence of short lines handling irradiated fuel will be small. The largest railroad having generally less than four-man crews has been the Florida East Coast. Elsewhere, the usage of firemen has been declining through attrition, but labor agreements would have kept a significant number of five-man crews in use for some time to come.

Under the combined pressure of a shrinking rail industry and increasing highway competition, rail unions have been "trading off" the traditional train manning on an ever-widening basis. The mandatory use of cabooses has been broached and in time they will disappear. With no caboose, the entire crew will be accommodated on the locomotive. Thus, the crew will eventually be no more than three men, and may become two, at least under specific circumstances * *

The size of switching crews is also impacted by the current rail environment, although there is somewhat more pressure to retain the fireman as a locomotive lookout, with three of the crew frequently being on the ground on either or both sides of the engine.

Flat classification switching can hardly be envisioned with fewer than three or four crewmen, but hump classification could be performed with only two.

Although the downward trend seems clear, using an average of 4.5 crewmen per train crew is recommended for the present; 2.5 men will be on the

* This is a personal conclusion that would not be concurred in by rail labor negotiators. In 1984 , national rail labor agreements were under negotiation. Unions have initially demanded the restoration of firemen and cabooses, and the reversal of some of the manning concessions they made in recent years. 
locomotive and 2 on the caboose. Switch crews are covered by individual terminal employee exposure estimates.

\subsubsection{Estimate of Exposure to Crews During Shipment}

Because of the conclusion reached in this research that spent fuel cask cars will be handled as shove-to-rest cars in classification switching, all possible car locations in the train will not have an equal probability. After the classification process is complete in automated hump yards, cask cars will tend to be located at the end of drafts they were classified into. When trains are assembled, cask cars will have an enhanced probability of being at the very head end or rear end of the train, and a diminished probability of being randomly located. It was assumed in the terminal exposure studies (see below) that a train would typically be made up of three drafts. This means that there is up to a one-third probability that a RA car at the end of a draft will be located next to the locomotive or caboose in the departing train. Safety regulations, however, require that there be at least one car between a RA car and either locomotive or caboose. This cover car will be placed by the yard crew assembling the train. The other probabilities are that the end-of-draft car more often than not will be one-third of the length of the train in from one end or the other. With trains averaging about $1100 \mathrm{~m}$ in length, this will be too far away to constitute a significant exposure to the train crew, and will be disregarded.

In the terminal exposure studies, it was also assumed that about one-fourth of the shove-to-rest cars classified will be located at the trim end of their drafts. The remaining three-fourths would be randomly located within their drafts, and therefore within their departing trains, except for the locations next to locomotive and caboose, of course.

\section{Car at head end}

With one cover car, the center point of a RA car is $25 \mathrm{~m}$ from the locomotive (i.e., $1.5 \times 16.5 \mathrm{~m}$ ). The average locomotive has more than 3 units. If each unit is $16.5 \mathrm{~m}$ in length, the head end of the locomotive will 
be 50 meters ahead of the first car in the train. The cab of the lead unit will be about $5 \mathrm{~m}$ back from this point. Thus, the head end crew (2 $1 / 2 \mathrm{men})$ is 70 meters away from the center of a RA car at the head end of the train.

When the train is on tangent (straight) track, the locomotive units furnish complete shielding to the crew in the cab. Only when the train is going around a curve will any of the crew be significantly exposed.

Typically, the engineer will ride on one side of the cab, another crewman on the other side, and if there is a fireman, the third person will ride between the two. It will be assumed that the third person and the person on the outside of the curve continue to be effectively shielded by the locomotive while going around curves. Only the crewman riding on the side of the cab on the inside of the curve will be exposed.

Curved track represents about 20 percent of all roadway, so only one head end crew member will be exposed 20 percent of the time. This fraction is multiplied by the probability of a RA car being at the head end of the train. The probability is assumed to be one-sixth, which is one half of the probability that would exist if all $\mathrm{RA}$ cars were shoved-to-rest at the trim ends of their drafts in the classification yard, and the typical train is made up of three drafts. This exposure is too high since crews will be shielded somewhat on the inside of some curves when the train is in hilly terrain. With a $70 \mathrm{~m}$ distance to source, the head end dose rate (allowing for air attenuation) is

$\mathrm{TI} \times .79 \mathrm{~K} / 4900 \times .2 / 6=.000005 \mathrm{~K} \times \mathrm{TI} \mathrm{mrem} / \mathrm{hr}$ per rail cask.

See Appendix A for specifics on dose calculations and for definitions of $K$ and TI. The factor of 0.79 accounts for air attenuation and buildup.

\section{Car at rear end}

The exposure to rear end crew is similar to that above when the cover car is loaded, thereby providing shielding when the train is going straight ahead. With a typical caboose length of $10 \mathrm{~m}$, the average exposure distance 
is $30 \mathrm{~m}$. Again, only one of the two-man rear end crew is assumed to be exposed 20 percent of the time. The dose rate is

$\mathrm{TI} \times .91 \mathrm{~K} / 900 \times .2 / 6=.000034 \mathrm{~K} \times \mathrm{TI} \mathrm{mrem} / \mathrm{hr}$.

The factor 0.91 accounts for air attenuation and buildup. However, when the cover car is empty, providing no shielding to the rear end crew, exposure is continuous and the dose rate is

TI $\times .91 \mathrm{~K} / 900 \times 2 / 6=.000337 \mathrm{~K} \times \mathrm{TI} \mathrm{mrem} / \mathrm{hr}$.

Assuming half loaded and half empty cover cars, the average crew dose rate for trim end locations is

$\mathrm{TI} \times(.000337 \mathrm{~K} \times .5+.000034 \mathrm{~K} \times .5+0.000005)=.00019 \mathrm{~K} \times$ TI mrem/hr per rail cask.

\section{Car randomly located}

The cumulative air-attenuated dose rate from the second, third, fourth, etc., cars from the locomotive is $.00068 \mathrm{~K} \times \mathrm{TI}(\mathrm{mrem} / \mathrm{hr})$.* The average freight train has about 68 cars. Therefore the average dose rate for the locomotive crew is TI $\times .00068 \mathrm{~K} / 68 \times .2=.000002 \mathrm{~K} \mathrm{TI} \times \mathrm{mrem} / \mathrm{hr}$. This dose incorporates the impact of air attenuation and buildup.

The dose rate to the crew in the caboose is more complex to calculate. For the second position, the calculation is similar to that for the trim end dose rate. This dose is

TI $\times .91 \mathrm{~K} / 900 \times(2 \times .5+.2 \times .5) / 68=.0000163 \mathrm{~K} \times \mathrm{TI} \mathrm{mrem} / \mathrm{hr}$.

* This is calculated with the dose rate from the second position included twice, to conservatively cover the probability of the RA car being randomly located in the position next to the locomotive, in which case it would be switched to the second position by a cover car. 
Doubling this dose to conservatively cover the probability of a location next to the caboose yields $.0000327 \mathrm{~K} \times \mathrm{TI} \mathrm{mrem} / \mathrm{hr}$.* For the third position, there is a $75 \%$ probability that the RA car will be shielded by the two cars between it and the caboose. Thus, the dose for the third position is

$\mathrm{TI} \times .856 \mathrm{~K} /(46.5 \times 46.5) \times(2 \times .25+.2 \times .75) / 68=.0000038 \mathrm{~K} \times \mathrm{TI} \mathrm{mrem} / \mathrm{hr}$.

From the fourth position, the shielding factor is $87.5 \%$, etc. The cumulative dose rate for the caboose crew is $.000039 \mathrm{~K} \times \mathrm{TI} \mathrm{mrem} / \mathrm{hr}$. The dose rate is $.000041 \mathrm{~K} \times \mathrm{TI} \mathrm{mrem} / \mathrm{hr}$ for locomotive and caboose crews together.

Combining the dose for rate end-of-train locations (25\%) with the dose rate for random car locations (75\%) results in a composite dose rate of $.000078 \mathrm{~K} \times \mathrm{TI} \mathrm{mrem} / \mathrm{hr}$ per rail cask. These calculations incorporate the impact of air attentuation and buildup. At an average train velocity of 32 $\mathrm{km} / \mathrm{hr}$, the dose-rate is $0.0000024 \mathrm{~K} \times \mathrm{TI} \mathrm{mrem} / \mathrm{km}$.

The foregoing estimates reflect conditions while the train is running. When it is stopped, the crew may be on the ground for a number of reasons, thus increasing their exposure to the RA car. They may walk past it during stop times to get to and from the locomotive or caboose. On the other hand, the percentage of stop time on curves should be somewhat less than running time on curves, so if the crew stays aboard, they will receive less exposure.

\subsection{Stop Time Per Trip}

\subsubsection{General description}

Since it is impractical without extensive field research to identify the stop time that takes place while shipments are in trains (see Velocity Between Terminals), stop time discussed here is confined to stop time not in trains, i.e., in terminals* and other stopover points between trains. Most of this occurs in terminals where the cars are classified or marshalled, a process

\footnotetext{
*obviously, stop time in terminals includes minor intervals of time during which the car actually is in motion as it is switched from one place to another.
} 
similar to sorting mail as it moves from sender to addressee. Cars arriving in trains are sorted or classified in a yard, or array of tracks, into batches or drafts that have a common destination. The drafts are subsequently assembled into departing trains. The stop time of an individual car being classified at a particular terminal can vary widely, from as little as 3-4 hours to well over a day, although the time is seldom less than 12 hours. The time depends upon the frequency and scheduling of the inbound and outbound trains between which the car is connecting, and the productivity and work schedule of the classification yard.

At one very large intermediate yard, i.e., a yard which mainly handles cars between trains rather than serving customer tracks, stop times of cars travelling on one route varied from a low of 8 hours to a high of 32 , with a median of 19. Cars classified at the same yard that arrived from another origin ranged from 11 to 47 hours with a median of 18 hours.

Cars also experience stop time at stopover points between trains where they are not classified, but merely "block exchanged," i.e., dropped in a group (block) by one train and subsequently picked up in the same group by another train (usually going to a different destination than the first). Block exchange can occur at terminals which also perform classification, and it can occur at smaller locations or even side tracks along the road. The stop time can be much shorter than stops where the car is classified. One such location examined had stop times from $40 \mathrm{~min}$. to over 6 hours, with a median of $31 / 2 \mathrm{hrs}$.

Stop time also occurs at interchange points between railroads. It may be quite short if the interchange is accomplished by a run-through train, which merely requires a change of crew, and perhaps of power. Over half the cars interchanged between two specific carriers at one gateway had stop times of less than $11 / 2$ hours. At another junction where interchange was accomplished by block exchange the range was from $17 \mathrm{~min}$. to over 8 hours, the median being 7 hours.

If one or both carriers must classify the car, stop time will be longer at interchanges than at inter-train stop points because time is consumed moving 
from one carrier's yard to the other. At the same junction as the run-through train mentioned above, stop times for cars received from other roads ranged from 2 to 46 hours, with a median of 25 hours.

If the car originates or terminates at an industrial track within terminal switching limits, the time consumed by the industrial switch engine picking the car up and carrying it to the classification yard is counted as stop time, and will make the origin stop time greater than the classification stop time that occurs between trains. Moreover, the comparable situation at the destination terminal can be even longer because the train or switcher moving the car to the consignee's siding may be able to deliver the car only during the consignee's working hours. Also, the consignee may be unable to receive the car as soon as the railroad is able to deliver it, causing it to be held in the railroad terminal. At one major industrial terminal, terminating cars took as long as 150 hours to be delivered after arrival, the minimum was 11 hours and the median was 30 hours. At a smaller terminal, the median was 11 hours.

\subsubsection{Development of factor}

On a complete trip, stop time not in trains is a consequence of both the number of stops and their duration. The frequency of stops involving classification on a trip varies greatly, and most of the stop time not in trains occurs in conjunction with classification. The duration of stops varies greatly as well. Because of the variations in both frequency and duration of stops, a generic expression or equation of stop time not in trains can be at best only a very imprecise indication of general tendency. The variation of stop time not in trains around the measure of central tendency will be much greater than the variation of road haul velocity around the average velocity.

A generic expression of stop time should be based upon empirical data. A data base was available which seemed reasonably analogous to shipments of spent fuel. This was a tabulation of trips made by multilevel motor vehicle rack cars between their unloading point and the factory from which they would 
receive their next load. Because timely scheduled delivery of motor vehicles from factory to dealer is so important to the shippers (the manufacturers), no backup of vehicles can be permitted at factories. These empty rail cars are given a high priority of movement by the railroads, just as would spent fuel cars. They move over main line, high-density routes in expedited trains, as would spent fuel cars. The only differences these cars have with spent fuel cars is that they are not shoved to rest when switched, and they move in multicar volumes between loading and unloading ramps which are usually located close to large terminals.

The data base was generated by approximately 64,000 empty car trips involving 18 railroads. For each individual carrier, averages were calculated for the hours per car and the miles per car for trips on its lines.* There were about 130,000 such trip segments, which shows that most of the trips were interline. During the period studied, there were no transcontinental or other very long haul trips since the objective of the routing of the cars was to minimize unproductive empty trip costs.

The differences in origin and destination handing between spent fuel shipments and the multilevel cars as covered by the empty trip study will have to be allowed for. First, the car trip times in the data base do not cover any destination stop time. The trips were considered ended when the cars reached the rail terminal where the loading ramps are located. This is because the inventory of empty cars is held in the rail terminal rather than at the loading ramp, and empty cars are ordered in as needed. A particular empty auto-rack car might spend considerable time in the empty pool at the terminal.

Second, the origin terminal time of the empty auto-rack cars is less than would be expected of a loaded cask car. The trip times began when the cars left the unloading ramp, but ramps are usually located adjacent to the rail classification yard from which the empty cars depart in trains. The cars are switched in multiple-car lots from the ramps to these yards, requiring a minimal movement time. In contrast, the cask cars will usually originate at a reactor away from the switching limits of the origin terminal, requiring a 
local train movement that can take as much as 10-12 hours. (Because local trains spend most of their time switching, their mileage is too small to generate realistic trip time under the average road-haul velocity factor; instead it must be added to the classification terminal stop time.)

In recognition of the pronounced difference in average road haul velocity between railroads in the Northeastern region of the country and railroads elsewhere, the observations were first grouped into those for Northeastern railroads and into an "other" category. Least-squares lines were fitted to the average hours per trip on each road for each year as the dependent variables and the average miles per trip as the independent variables. The equations that resulted were

Hours per trip on each road $=26.5+0.10 \times$ miles (Northeast) and

$$
22.8+0.07 \times \text { miles (other). }
$$

These relationships are the expression of trip time on each handing road which excludes destination time, but includes time in trains. The time in trains can be deducted by means of the average road haul velocity of $14 \mathrm{mph}$ in the Northeast and $25 \mathrm{mph}$ elsewhere. When this is done, the equations represent stop time not in trains, and the mileage coefficients for both equations become .03 per mile. If the fixed times per trip are weighted in proportion to the number of observations underlying each ( 7 and 16), their composite is 23.9 hours. Rounding and converting to metric yields a generic relationship. That is,

Stop time $(h r)$ per trip on each road $=24+0.02 \times$ kilometer,

not including destination terminal time.

A reasonable allowance for the greater time at origin of spent fuel cars

\footnotetext{
*Two carriers were omitted, which were "outliers", i.e., they had highly unrepresentative characteristics. The average hauls on individual roads ranged from 120 miles to 770 miles; within these averages some repetitive trips were lower and some quite a bit higher.
} 
compared to the auto-rack cars in the data base is six hours. At the destination, the final classification can be estimated to add 24 hours, with another six hours for local train delivery. Additional stop time for the total spent fuel car trip will thus be 36 hours.

The above equation is an expression that applies to each road handling the shipment. If it is augmented by 36 hours to cover the stop time of spent fuel cars, it becomes

Total stop time (hr) per trip $=36+0.02 \times$ kilometer +24 per road.

This equation requires that the number of handling roads be specified to obtain the estimated stop time. If this is not known, the modal number of two could be used. However, it is known that the number of carriers handing a shipment tends to increase as the trip lengthens. The study that was made for the incidence of classification (see section 4.7) was based on a large number of routes between reactors and repository sites that were determined to be representative. This routing data base can be used to estimate the number of carriers to be expected in relation to the length of haul. There were 211 routes having the following distribution by number of carriers:

$\begin{array}{lr}\text { one carrier } & 12 \text { routes } \\ \text { two carriers } & 119 \text { routes } \\ \text { three carriers } & 69 \text { routes } \\ \text { four carriers } & 9 \text { routes } \\ \text { five carriers } & 2 \text { routes }\end{array}$

(Intermediate switching carriers at gateways are not counted.) The mode and the median of this distribution are both two carriers. An analysis was made of the variation in the number of additional carriers (one is the minimum, obviously) in relation to the length of the route. To do this, the routes were grouped into 100-mile mileage blocks (e.g., 50-149, 150-249, etc.), the number of carriers of all routes in each block was averaged, except blocks with fewer than four routes. The block averages in excess of one were fitted to a least-squares curve. The relationship that resulted is

$$
\text { Carriers over one }=0.37 \times(\text { mileage block number })^{0.46} \text {. }
$$


Converted to metric, the equation becomes

\author{
Carriers over one $=0.036 \times$ (Kilometers) 0.46 . \\ Applying this equation to the stop time relationship yields \\ Total stop time $(\mathrm{hr})$ per trip $=60+0.02 \times$ kilometer $+0.86 \times$ \\ (kilometer) 0.46 .
}

\title{
4.4 Employee close Proximity Exposure at Classification Points
}

\subsubsection{Description of exposures}

When cars arrive at a classification point, interchange transfer, or industry switch run, they usually stop in a portion of the terminal called a receiving or arrival yard. Most often, they are inspected there by carmen, who "bleed" the air pressure from the brake cylinders so that the cars will roll freely when switched, inspect the cars for mechanical defects, make minor repairs as the cars stand in the track, and attach defect cards to those cars which must be sent to repair tracks for more extensive repairs. Occasionally in a hump yard, the inspection will be made by carmen at a pit alongside the hump approach track. Carmen get close to each car during the inspection process (see Figure 5).

After inspection, the cars are sorted or classified to reassemble them into the next set of trains, transfers, and switch runs that will advance them to their destination. Classification can take place over a hump or by flat switching.

A hump classification yard has an artificial hill over which the draft of coupled cars being sorted is pushed. At the crest of the hill, individual cars, or groups of cars having a common classification, are uncoupled and allowed to roll by gravity into the proper classification track, the switches being reset between each such "cut." The speed of the cuts is usually 
regulated by mechanical retarders during their descent to insure proper coupling speed when they encounter the cars already present in the assigned track.

The photograph of the St. Paul Yard of the Milwaukee Road in Figure 6 shows a cut of cars coming over the hump. The crest is at the top center at the control tower. The cut is passing over the primary retarder, which is located down from the crest but before the first switch. Two secondary retarders are just beyond the first switch, and five tertiary retarders are opposite the tower from which they are all controlled (left center). A moving cut of two tank cars can be seen at center of the photo. The "dynamite" track whose function will be described below holds two cars and is to the right and just off the hump approach. The main lines are to the left of the retarder control tower. The tracks to the right of the classification tracks appear to be a receiving and/or departure yard.

In a flat classification yard, the same sorting process takes place. However, the rolling momentum of the cuts is imparted by the locomotive. pushing the string of coupled cars to the necessary speed, at which point a switchman uncouples the cars to be separated and signals the engineer to stop, thereby "kicking" the cut into its assigned track. If the cut is unusually long, or the kicking distance short, or a hazardous material car is involved, the cut may be shoved all the way into its assigned track and coupled to the cars already there, rather than kicked.

Flat switching requires much more back-and-forth movement of the locomotive and cars being sorted than does hump switching. Cutting does not take place at one location in the tracks, as at the hump crest. The switchmen performing the uncoupling (pin-pullers) in either type of yard are quite close to both cars being uncoupled, and are close to the entire draft of cars during the classification process (see photo of hump crest of Sevier Yard, Knoxville, TN in Figure 7).

At the other end of the classification yard, switch engines "trim" the classified cars, pushing together any that may not have coupled, and 


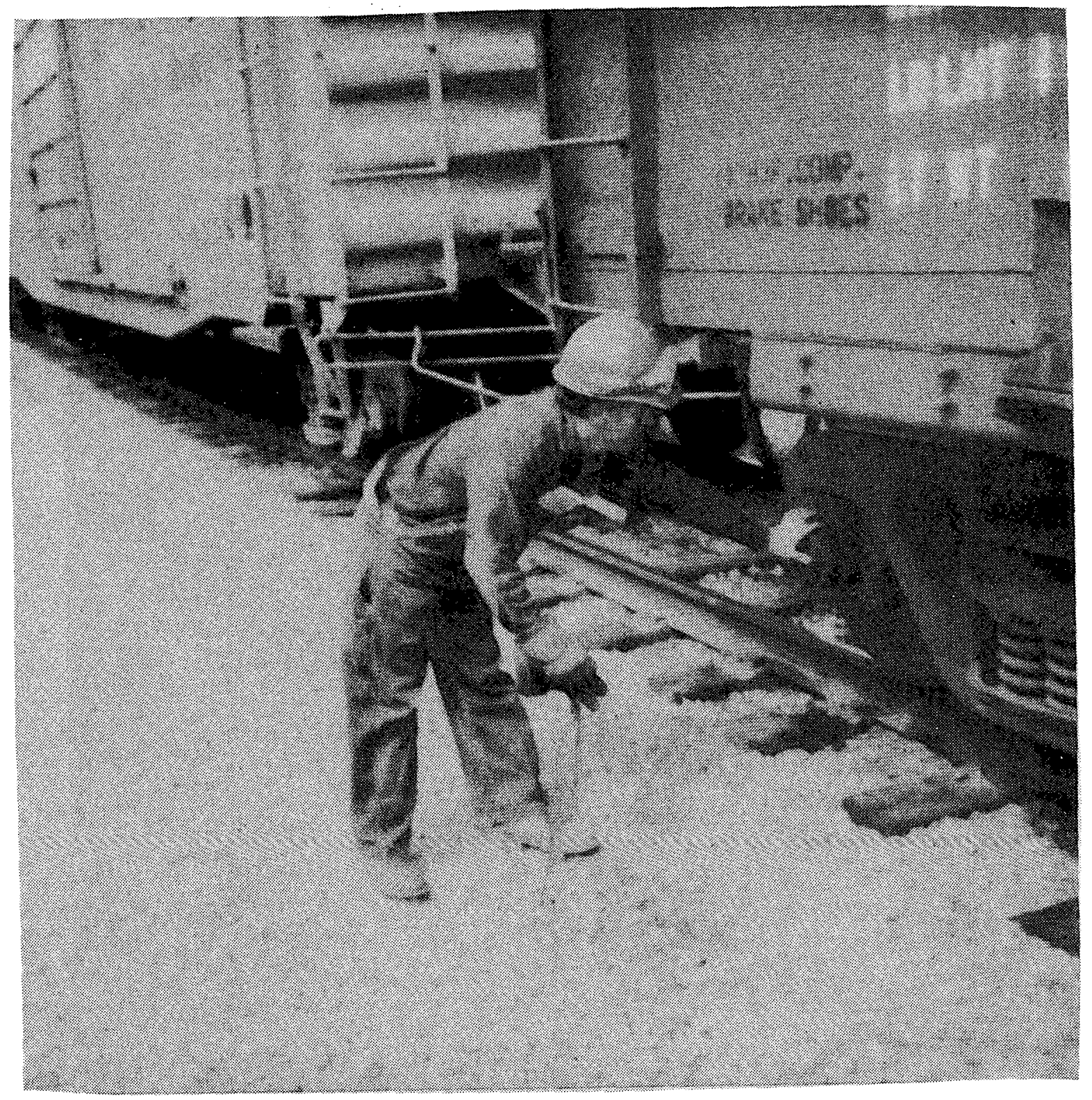

Figure 5. Carman Inspecting Car 


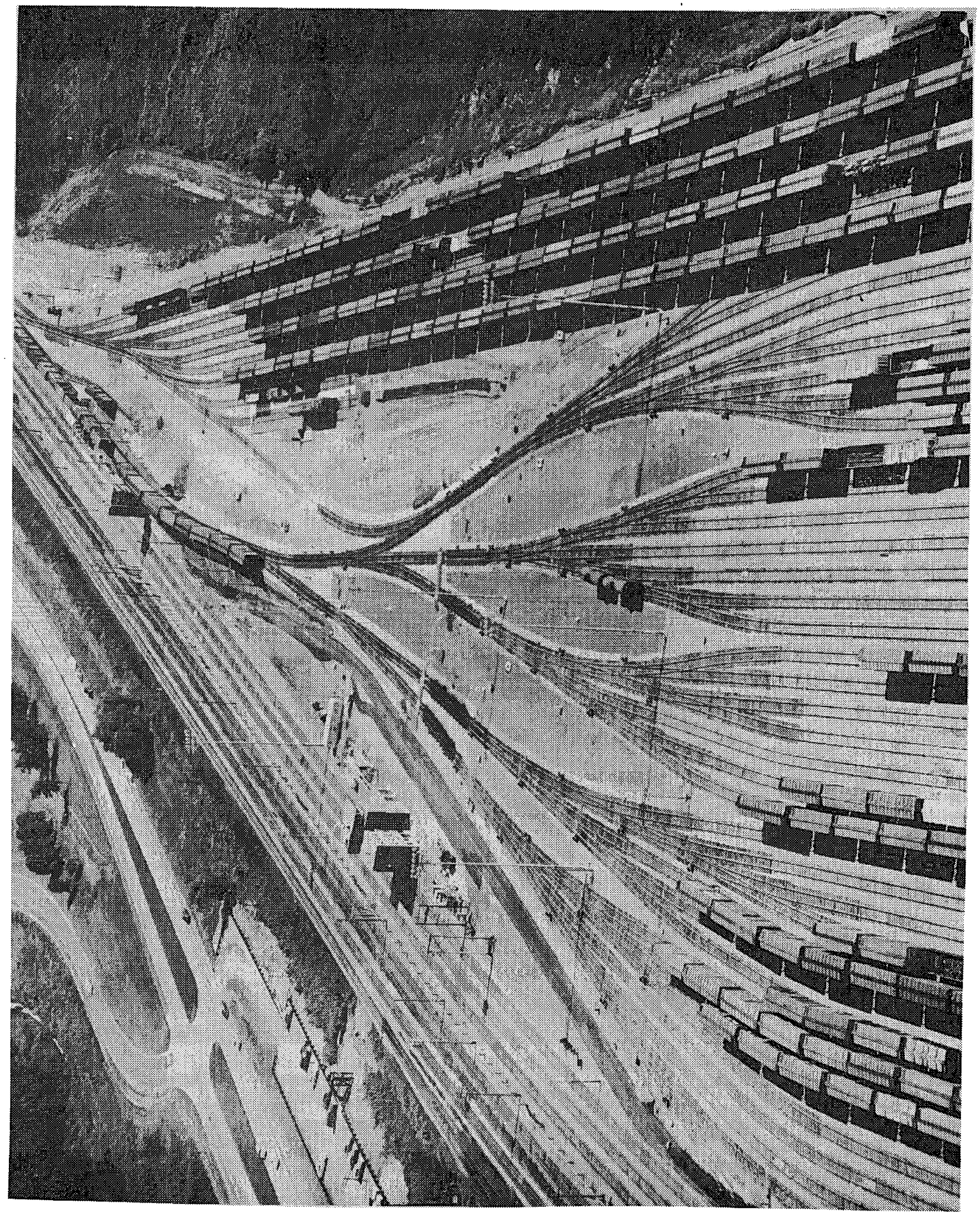

Figure 6. St. Paul Yard Photo 
assembling the drafts of classified cars into trains, transfers, and switch runs. They may perform flat classification from the trim end from time to time when it is simpler than normal classification, when the hump is out of service, or when humping capacity is exceeded. If the number of classifications that are required exceeds the capacity of the yard, some groups of cars may need to be reclassified or rehumped before being finally assembled into trains. Trim engine switchmen come close to cars which are being coupled or uncoupled, but are not in close proximity to every car which they process, except when they are classifying. The same is true of switchmen other than pin-pullers who are stationed on the classification engine, who throw switches in the yard, or who make shove-to-rest couplings, etc.

When the trains and transfers have been assembled by the trim engines, they may be pulled down or set over to a departure yard, or they may depart directly from the classification yard. In either location, carmen inspect the train for defects, couple air brake hoses, oil friction bearings, and after the air pressure has reached a working level, perform an air test and check the brake function on each car. Any defective cars detected at this time must either be repaired in place or switched out of the train. (Cars departing on most switch runs do not require air brakes, and thus no departure inspection would be made.) The exposure of carmen to cars is, if anything, greater during departure than during arrival inspections due to the need to couple air hoses.

Cars that are "bad-order," i.e., have defects which cannot be repaired in the arrival or departure tracks, will be classified to repair tracks. At these locations, carmen will be quite close to cars a substantial fraction of the time they are engaged in repairing them. (e.8., see photo of Chessie carman repairing car corner in Figure 8 ).

Certain hazardous material cars, viz., those containing explosives, poison gases, and by local option, RA cars, will be "shoved-to-rest." This means that they must neither be humped nor kicked, but must be handled coupled at all times, and not have any other cars humped or kicked directly against them. In the hump yard, such cars will be set over on a "dynamite" track 


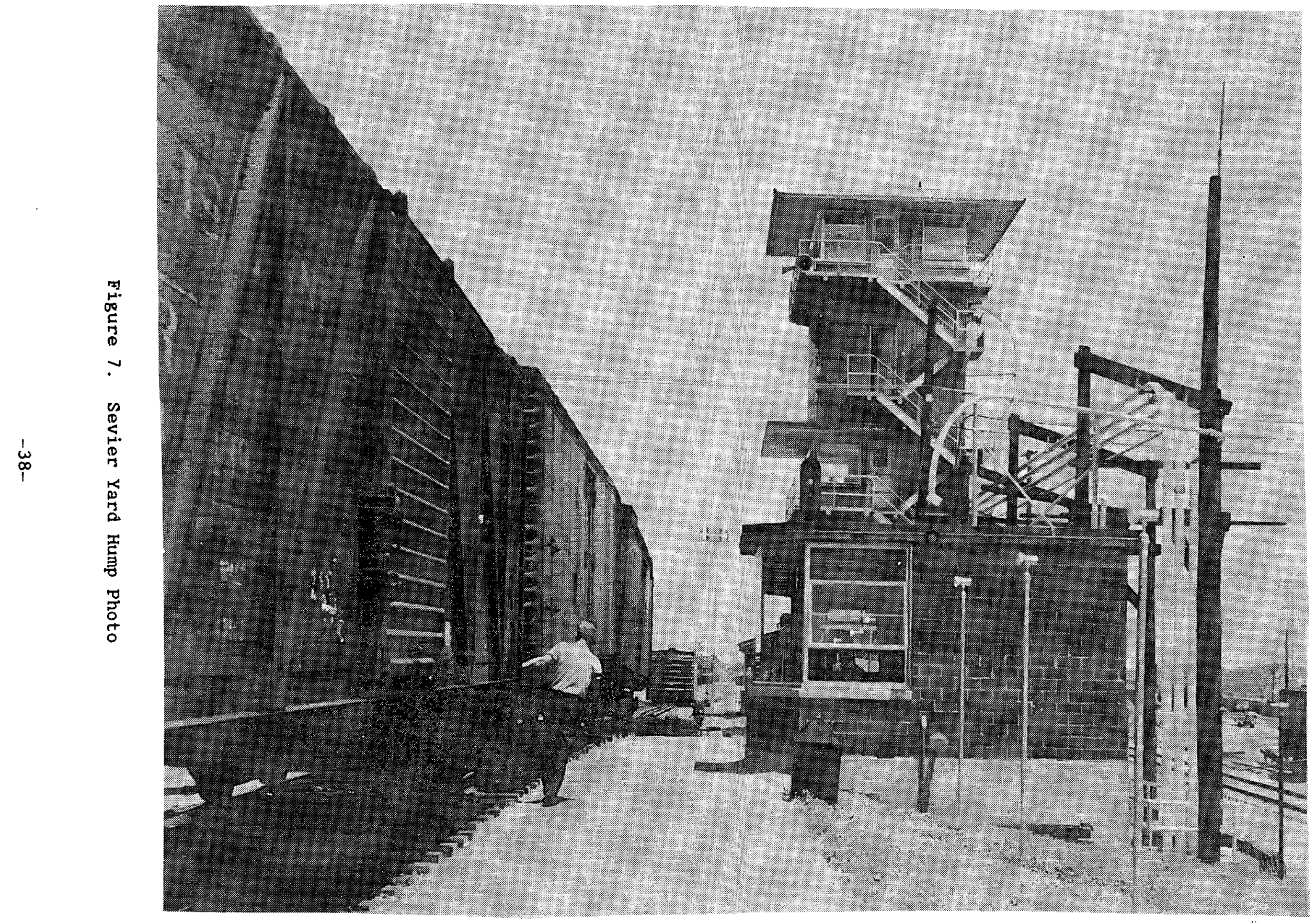




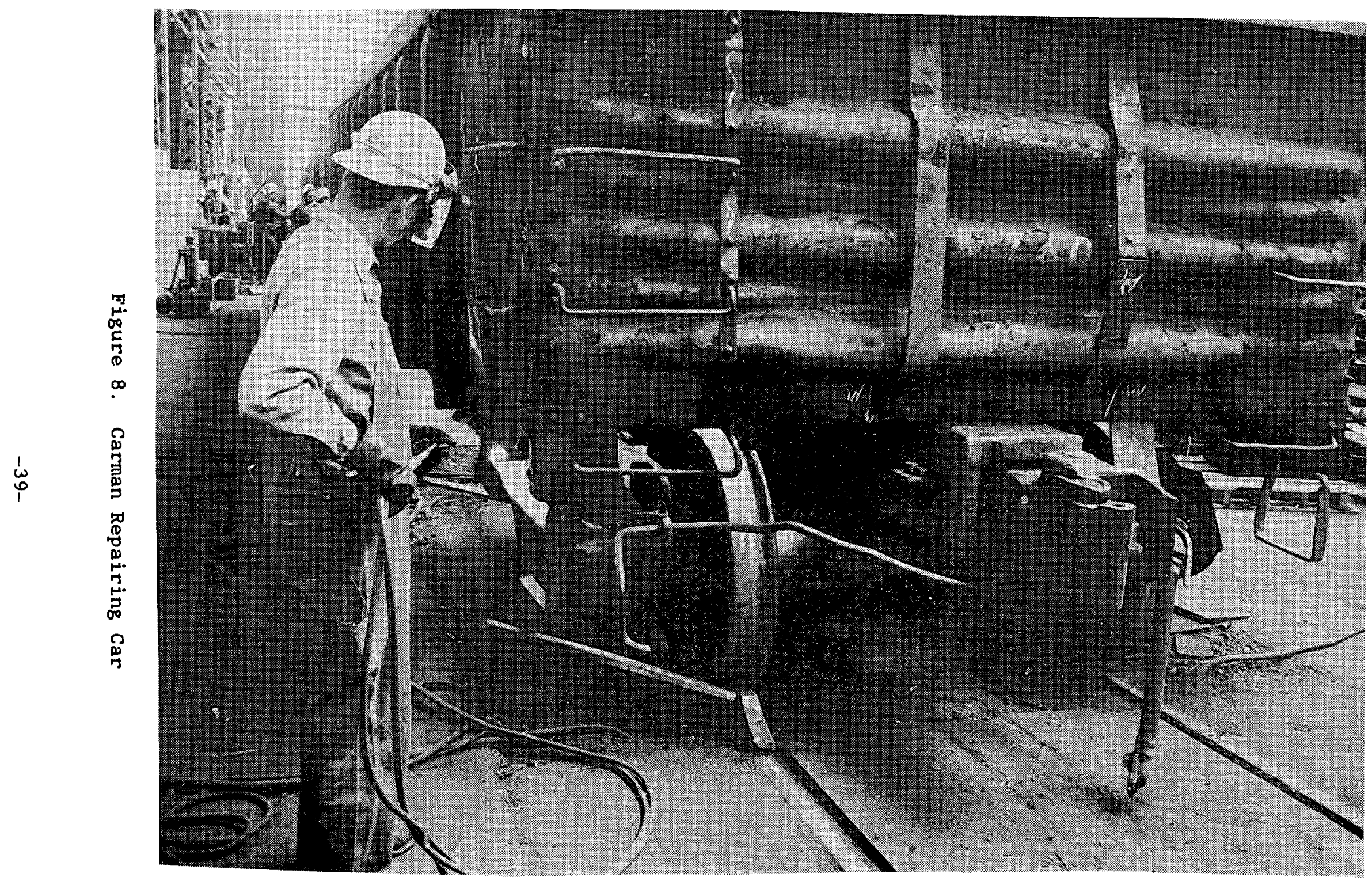


adjacent to the hump (if the hump has such a track), and subsequently shoved by the hump engine into their proper bowl track, or into a vacant track from whence trim engines will switch them to rest at the trim end of their assigned track. A "cover car" would be switched to rest against the RA cars if they are the end car of a train or transfer. In a flat yard, the radioactive (RA) cars would be shoved to rest into their assigned tracks and a cover car shoved against them. $*$

Most car inspections take place as part of the intermediate classification process described above. However, some inspections do occur at other points:

o When trains run through interline junctions, the train will be inspected by the receiving road to establish responsibility for defective cars, unless an interroad agreement has been reached to defer this to the next normal inspection point.

- Trains are required by regulation to be inspected at intervals of not more than 1000 miles. Most trains that are inspected under this rule are unit or dedicated trains that run long distances without alteration in their makeup. Single car shipments would rarely be subject to such inspections as they are obviated by the frequency of intermediate classification.

Apart from carmen inspecting and repairing cars and switch crews classifying cars, employees at classification points experience other exposures to RA shipments that are less in terms of frequency, duration, closeness and regularity. These exposures are difficult to quantify, but their magnitude is less than those previously described. They include

*A yet more stringent handling mode that may be adopted locally would be to isolate the RA car on a track location where it cannot be approached by other cars and locomotives until the time for its departure. This would be attractive if the yard experiences a good deal of rework/rehumping that would call for repeated shove-to-rest handling of the RA car. Crew exposure should be approximately the same as for a single shove-to-rest classification handling. 
- Employees occupying towers adjacent to humps (yardmasters, clerks, retarder operators, crew foremen) are exposed to all passing cars humped, but are further away than the pin-pullers, and shielded by the tower.

- Yard switch crews will pass cars on adjacent tracks as they move back and forth in their activities. The number of crewmen that pass close to a given car while it is in the terminal would be highly variable.

- Switch crewmen on engines are shielded from cars by the engine itself to an important extent.

- other employees working indoors and outdoors throughout the terminal in offices, shops, engine servicing and intermodal facilities (train, transfer and industry switching crews starting and finishing runs, etc.), may occasionally pass close to or be passed by a RA shipment.

These more remote and random exposures are best quantified by overall area average employee population densities rather than by individual exposure estimates appropriate for inspection, classification, and repair personnel.

\subsubsection{Estimation of Close-Proximity Exposures}

Field studies of terminals were made at four locations to assist in determining the exposures of railroad employees during classification. One of the locations was in the Northeast US and three were in the West. One location is a smaller intermediate (intertrain) terminal with a low-hump classification yard handling about 3500 cars per week, mostly cars belonging to other railroads. Another ( 6500 cars per week) is a flat classification switching facility located at a major interchange point. Another yard ( 8000 cars per week, mostly of system ownership) is at an intermediate location having a significant volume of locally generated traffic from industry and railroad shops, and both automated hump and flat (trim end) switching. The 
largest location ( 16,000 cars per week) is a very large intermediate terminal, with separate facilities for eastbound and westbound railcar traffic which utilize automated hump classification switching. The latter two locations also experience large volumes of run-through traffic, i.e., trains that stop at the terminal for servicing and inspection. The run-through traffic is not included in the weekly volumes cited, nor is intermodal traffic handled by a separate flat yard at the last location.

Not all of the activities were observed at each location, because some were not taking place during the visits. However, the inactive facilities were observed and their operations were discussed with local personnel. In this way, the extent to which the results of the activities that were observed could be applied to the locations not observed could be estimated.

The discussion of close-proximity dose is broken down into four categories: inspection doses, normal classification doses, doses for shove-to-rest classification, and car repair doses.

\section{Car inspection}

Inspection of cars upon arrival was observed at two locations. Beforedeparture inspection was also observed at two locations. Based upon the observations, inspection exposures have been estimated for two contrasting situations; "traditional" and "motorized" modes.

The traditional mode of conducting inspections is exemplified by the smallest terminal visited. Two carmen walk the length of trains after arrival, one starting from each end, bleeding air, repairing minor defects, and designating larger defects for the repair tracks. When they meet in the middle of the train, they cross over, reverse direction, and inspect the other side of the same cars on the return walk. Their time in close proximity to the cars averages one man-minute per car.

Departing trains take about two man-minutes per car because air hoses must be coupled, air pressure buildup must be awaited, and a second round-trip walk 
is necessary to check brake functions. Both processes take place within three meters of the RA car centerlines. Thus, the combined arrival and departure inspection dose is

TI $\times K^{\prime} / 3 \times 3 / 60 \times 1.10 *=.0183 \mathrm{~K}^{\prime} \times \mathrm{TI}$ mrem per rail cask.

The approach to calculating "close-proximity" dose is discussed in Appendix A. This estimate is based upon a somewhat idealized situation in that no time is allowed for occasional delays due to leaky air hoses and malfunctioning brakes, very low temperatures, larger defects that must be repaired or the car switched out, slow down from snow and ice in winter, etc. To compensate for all such contingencies, an allowance of 20 percent has been added, for a dose of $.0220 \mathrm{~K}$ ' $\mathrm{x}$ TI mrem. That is, the dose was adjusted by a "contingency" factor of 1.2 .

Carmen inspecting trains on adjacent (parallel) tracks will also receive radiation doses. Their distance from the RA car will be about 4 meters when they are on the side of the track next to the RA car, and about 8 if they are on the other side of the cars being inspected. (Inspection time is equal on the two sides.) In the latter case, the cars in the train being inspected will provide shielding from the RA car if they are loaded, which can be assumed to be the case about half the time. Inspecting a train on the next parallel track beyond the adjacent track involves exposures at 9 and 13 meters, etc.

There will not be inspection of cars on adjacent tracks every time a RA car is in the receiving/departure yard. At the small terminal, the average occupancy of the eight-track receiving/departure yard is less than one-third. However, allowance must be made for bunching (fluctuations in occupancy from hour to hour) which raises the effective joint occupancy factors; that is to say, whenever a particular track is occupied, the probability that a nearby track will also be occupied is greater than one-third. Using one-half as a joint occupancy factor, the dose to carmen inspecting other trains in the yard

* Factor used to increase exposure calculated for a person while he is immediately next to the RA car to include exposures while he is next to adjoining cars in the same track. See Appendix B for derivation. 
may be calculated.

Adjacent Track:

TI $\times K^{\prime} \times$ (1.2-contingency factor)

$x 1 /(4-d i s t a n c e$ to near side of adjacent cars)

$x$ (1.18-adjoining factor, Appendix B)

$x$ (1.5/60-exposure time)

$=.0089 \mathrm{~K}^{\prime} \mathrm{TI}$ on near side and

TI $\times K^{\prime} \times 1.2 /(8-d i s t a n c e$ to far side)

$\times 1.54 \times 1.5 / 60 \times$ (1/2-shielding factor)

$=.0029 \mathrm{~K}^{\prime} \times \mathrm{TI}$ on far side.

In an eight-track yard, there are 14 possible locations for a car being on a track adjacent to a car on one of the eight tracks (the two outside tracks have only one possibility each).

Therefore, the adjacent track dose is

$\mathrm{K}^{\prime} \times \mathrm{TI} \times(.0089+.0029) \times 14 / 8 \times(1 / 2$-joint occupancy factor $)=$ $.0103 \mathrm{~K}^{\prime} \times \mathrm{TI}$ mrem.

Car two tracks äway:

$\mathrm{TI} \times \mathrm{K} \times 1.2 / 9 \times 1.61 \times 1.5 / 60 \times[1-(1 / 2 \times 1 / 2)] \times 12 / 8 \times 1 / 2=$ $.0030 \mathrm{~K}^{\prime} \mathrm{TI}$ mrem.

Exposures for inspections at greater distances and with increasing shielding become insignificant. Total dosage from this traditional inspection mode is thus

$\mathrm{TI} \times \mathrm{K}^{\prime}(.0220+.0103+.0030)=.035 \mathrm{~K}^{\prime} \times \mathrm{TI}$ mrem per rail cask.

A motorized mode of inspection is employed at the largest terminal visited; this is an improvement that can be adopted where volume is large and there is ample space. 
As in the traditional mode, carmen work in pairs to perform arrival inspection, but one drives a truck stocked with parts and tools, while the other one walks along the other side of the train. Two or more pairs inspect a train simultaneously. They also change brake shoes as needed using a supply of shoes scattered along the tracks. Each man may cross under a car to assist the other with repairs. One pass completes the arrival inspection. The rate is two cars per minute per pair (comparable speed to the smaller terminal). The carmen on foot are within 3 meters of the car centerline at all times, whereas the man in the truck gets out only when a repair or closer check is needed. Repairs and close checks account for about one-third of the elapsed time for the man in the truck, while in the truck the second man is about 5 meters from the cask centerline. After completion of inspection, each pair drives back at a speed of $24 \mathrm{~km} / \mathrm{hr}$ and a distance of 7 meters from the cask centerline. Doses for the motorized mode are determined as follows.

Inspection on foot:

$\mathrm{TI} \times 1.2 \mathrm{~K}^{\prime} / 3 \times .5 / 60 \times 1.10=.0037 \mathrm{~K}^{\prime} \times \mathrm{TI}$ mrem

Inspection in truck:

$\mathrm{TI} \times 1.2 \mathrm{~K} / 3 \times .5 / 60 \times 1 / 3 \times 1.10=.0012$

$\mathrm{TI} \times 1.2 \mathrm{~K} / 5 \times .5 / 60 \times 2 / 3 \times 1.27=.0017$ $.0029 \mathrm{~K}^{\prime} \times \mathrm{TI}$ mrem

Inspectors returning:

$\mathrm{TI} \times 1.2 \mathrm{~K} / 7 \times 16.5 * / 24000 \times 1.46 \times 2 \mathrm{men}=.0003 \mathrm{~K}^{\prime} \times \mathrm{TI} \mathrm{mrem}$

Total arriving inspection:

$\mathrm{TI} \times \mathrm{K}^{\prime}(.0037+.0029+.0003)=.0069 \mathrm{~K}^{\prime} \times \mathrm{TI} \mathrm{mrem}$.

Departing train inspection is fully motorized. Truck-riding carmen working on one side of the train connect air hoses and report all but minor defects by radio to a repair truck. Others concentrate on repairing defects 
and oiling friction bearings. (Defects on departing trains are much less frequent and severe than on arriving trains, but it is much more important to repair them in the train.) Three "airmen," each working a third of the train, progress at the rate of three cars per minute, one-fourth of their time is at $3 \mathrm{~m}$ away from the cask centerline as they connect air hoses and examine defects, and three-fourths at $5 \mathrm{~m}$. After air pressure is up, the airman at the far end of the train drives back on the other side of the train, checking brake function and reporting defects. The rate is 5 cars per min. at a $5 \mathrm{~m}$ distance. Travel alongside the train to and from inspection and repair takes place at $24 \mathrm{~km} / \mathrm{hr}$ and at a distance of $7 \mathrm{~m}$. Assuming an average train of about 100 cars, and a total repairman time of 20 minutes, the repairman averages 6 seconds per car at $3 \mathrm{~m}$ plus 6 seconds at $5 \mathrm{~m}$. The total dose for inspecting the train departing with a RA car, including travel, can now be calculated.

Connecting air hoses:

$$
\begin{aligned}
& \mathrm{TI} \times 1.2 \mathrm{~K}^{\prime} \times 20 / 3600(1.10 / 3 \times 1 / 4+1.27 / 5 \times 3 / 4)=.0019 \mathrm{~K}^{\prime} \times \\
& \text { TI mrem }
\end{aligned}
$$

Travel to and from segment inspected:

TI $\times 1.2 \mathrm{~K} / 7 \times 16.5 / 24000 \times 1.46 \times$ (2-passings per car) $=.0003 \mathrm{~K}^{\prime} \times$ TI mrem

Checking brakes on return to near end of train:

TI $\times 1.2 \mathrm{~K}^{\prime} / 5 \times 12 / 3600 \times 1.27=.0010 \mathrm{~K}^{\prime} \times \mathrm{TI}$ mrem

Repairman:

TI $\times 1.2 \mathrm{~K}^{\prime} \times 6 / 3600(1.10 / 3+1.27 / 5)=.0012 \mathrm{~K}^{\prime} \times \mathrm{TI}$ mrem

Total departing inspection:

$\mathrm{TI} \times \mathrm{K}^{\prime}(.0019+.0003+.0010+.0012)=.0044 \mathrm{~K}^{\prime} \times \mathrm{TI} \mathrm{mrem}$ 
Tracks in the arrival and departure yards are spaced $13.5 \mathrm{~m}$ apart. The inspection process on adjacent tracks occurs at 10 and $17 \mathrm{~m}$ (arrivals) and 9 and $18 \mathrm{~m}$ (departures) from the cask centerline, with the travel alongside being at a distance of $7 \mathrm{~m}$ in both cases. The activities at 17 and $18 \mathrm{~m}$ are shielded half of the time. Arrival inspection dose in adjacent tracks (2 groups of three tracks, separated by 2 runner tracks, average occupancy of one-third, increased to one-half to allow for bunching) is determined as follows :

Inspection:

TI $\times 1.2 \times / 10 \times .5 / 60 \times 1.68 \times(1 / 2$-joint occupancy factor $)=$ $.0008 \mathrm{~K}^{\prime} \times \mathrm{TI}$ mrem.

In a three-track yard, there are four possible locations for a car to be on the next adjacent track to a car on one of the three tracks. (Exposure across runner tracks is insignificant.) Thus, the dose is given by

$\mathrm{TI} \times .0008 \times 4 / 3=.0011 \mathrm{~K}^{\prime} \times \mathrm{TI}$ mrem.

Return:

TI $\times 1.2 \mathrm{~K} / 7 \times 16.5 / 24000 \times 1.46 \times 2$ men $\times 1 / 2 \times 4 / 3 \times(1 / 2-$ probability that return will be on near side of train inspected) $=.0001 \mathrm{~K}^{\prime} \times \mathrm{TI}$ mrem.

Total arrival inspection dose:

$\mathrm{TI} \times \mathrm{K}^{\prime}(.0011+.0001)=.0012 \mathrm{~K}^{\prime} \times \mathrm{TI}$ mrem.

Departure inspection dose in adjacent tracks (one group of seven tracks, average occupancy one-fourth, increased to one-third) is determined as follows. Inspecting and repairing:

TI $\times 1.2 \mathrm{~K}^{\prime} / 9 \times(20+12+6+6) / 3600 \times 1.61=.0026 \mathrm{~K}^{\prime} \times \mathrm{TI}$ mrem. 
Travel:

$\mathrm{TI} \times 1.2 \mathrm{~K}^{\prime} / 7 \times 16.5 / 24000 \times 1.46 \times 2=.0003 \mathrm{~K}^{\prime} \times \mathrm{TI}$ mrem.

Total departure inspection dose:

$T I \times K^{\prime}(.0026+.0003) \times 1 / 3 \times 12 / 7 \times(1 / 2$-probability that above activities will be on near side of train inspected) $=.0008 \mathrm{~K}^{\prime} \mathrm{x}$ TI mrem.

The combined arrival and departure inspection dose for the large terminal is $.0133 \mathrm{TI} \times \mathrm{K}$ mrem per rail cask. The reduction in inspection dose in the large volume terminal is the result of motorization. This mode requires ample track spacing which is not feasible or economic in many smaller or more severely constricted locations. The wide spacing itself reduces adjacent track exposure. Few terminals can approach this low exposure rate.

Arrival car inspection was partially observed at the interchange terminal. At this location, carmen sometimes inspect cars as they roll into the receiving tracks in trains or transfers from connections (see photo in Figure 9). Having noted the cars with defects, they later use their repair truck to carry out in-train repairs and mark cars for the repair tracks. One such incoming movement that was observed travelled about 5 cars per minute past two carmen standing 5 meters away for a dose of

$\mathrm{TI} \times 1.2 \mathrm{~K} / 5 \times 12 / 3600 \times 1.27 \times 2=.0020 \mathrm{~K}^{\prime} \times \mathrm{TI}$ mrem per rail cask.

The subsequent repair of defective cars in the train was not observed. Even if these had required one-half a man-minute per car, this mode of inspecting arriving cars has only slightly higher exposure than the previously described motorized mode. However, not all arriving trains are handled this way, and no departing trains are.

Arrival inspections are conducted in two different ways at the fourth terminal. Some trains are inspected in arrival tracks designed to facilitate heavier than usual repairs on an in-yard basis. This mode was not observed. 
Some arriving trains and all departing trains, though not observed, appeared to be inspected in a mode similar to that for the smaller terminal. Thus, the inspection dose could reasonably be inferred. Inspections to comply with the 1000-mile rule were by truck riding inspectors.

The average car inspection dose would probably be closer to the smaller terminal dose of $.035 \mathrm{~K}^{\prime} \times$ TI mrem per car stopover than to the large terminal motorized dose of $.0133 \mathrm{~K}$ ' $x$ TI mrem. Until it is decided that further research is warranted on the frequency of the several variations in inspection mode, a dose of $.03 \mathrm{~K}^{\prime} \times \mathrm{TI}$ mrem per rail cask is suggested.

\section{Classification}

Classification was observed at an automated hump yard, at a flat yard, and at a low hump yard, which combines features of both hump and flat switching.

In the automated hump yard (an end-to-end layout), the draft to be classified moves up the hump at the rate of 4 average length cars per minute. Because of the length capacity of the retarders, the maximum size cut is three cars (two if cars are extra long), the average being 1.5 cars. The pin-puller is near the end of the car whose coupler he is opening $(3 \mathrm{~m}$ ) for about 8 seconds. Simultaneously, he is $4 \mathrm{~m}$ from the other car, which is the last car of the cut being made. After cutting, he walks back alongside the draft (at a distance of $4 \mathrm{~m}$ ) to the next cut point. The speed of the cut is restricted to $3 \mathrm{mph}(5 \mathrm{~km} / \mathrm{hr})$ by the retarders, which are computer controlled, but can be overridden by a retarder operator in a nearby tower. (The retarder operator's exposure is too small to be included here.) Pin-puller dose per car humped can now be calculated.

Cutting:

$\mathrm{TI} \times 1.2 \mathrm{~K}^{\prime} \times 8 / 3600 \times(1 / 3+1 / 4) \times(2 / 3$-cuts per car $)=.00104 \mathrm{~K}^{\prime} \times$ TI mrem. 


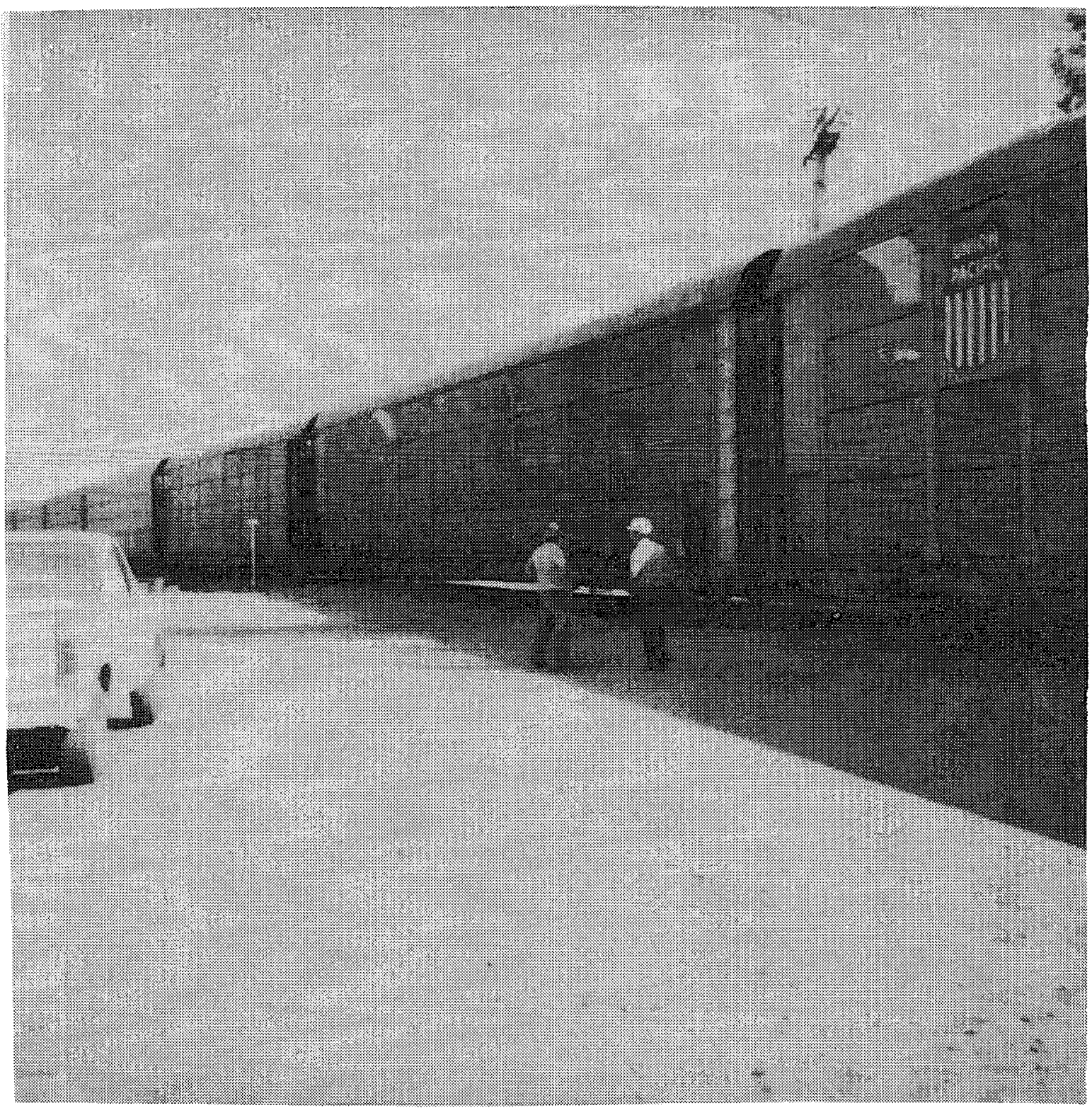

Figure 9. Roll-By Car Inspection Photo 
Walking back:

$T I \times 1.2 \mathrm{~K}^{\prime} / 4 \times 1.18 \times((60 / 4-8 \times 2 / 3) / 3600$-Total time per car less cutting time per car) $=.00095 \mathrm{~K} \cdot \mathrm{x}$ TI mrem.

Total pin-puller exposure:

$\mathrm{K}^{\prime} \times \mathrm{TI}(.00104+.00095)=.0020 \mathrm{~K}^{\prime} \times \mathrm{TI}$ mrem per rail cask.

Humping action is occasionally suspended for various reasons, resulting in additional pin-puller exposure to cars at or near the crest, but neither the added time nor the relative position of the pin-puller during suspension was observed.

The crew foreman directs the pin-puller from the track level of a control tower at the crest (see photo in Figure 7). He sits inside near a window. His seat is about $5 \mathrm{~m}$ from the centerline of the crest track closest to the tower and $9 \mathrm{~m}$ from the further crest track. Both tracks are used, but rarely simultaneously. In the upper level of the tower (4 $\mathrm{m}$ higher) behind all-around glass observation windows are stationed the yardmaster and his assistant (the latter being present two out of three shifts). It seems reasonable to assume that during suspension of humping the pin-puller will join the foreman inside the tower, especially during cold weather. Allowing for 10 percent suspension time, the dose to tower occupants would be

TI $\times 1.2 \mathrm{~K} \times 15 / 3600 \times((2.67+0.1)$ number of persons $) \times(1.27 / 5$ $+1.61 / 9) \times 1 / 2 \times(1.1$-suspension factor $)=.0033 \mathrm{~K}^{\prime} \times \mathrm{TI}$ mrem.

This calculation ignores any shielding that the tower structure may provide. Total humping dose is $.0053 \mathrm{~K}^{\prime} \times \mathrm{TI}$ mrem.

At the other end of this yard, trim engines assemble trains by coupling two or more drafts of cars that have been classified in the bowl tracks. First they shove together any cars that may have failed to couple after being humped. Then they pull the draft out of its track and shove it against the 
next draft in another track in the bowl which is to move in the same train. This process is repeated until the whole train is assembled, whereupon it is pulled into a track in the departure yard.

The trim engine crew will experience exposure when a RA car is at either end of a draft. When the car is at the end of the draft, the crewman making the coupling of one draft to the next will be within $3 \mathrm{~m}$ of the RA car for about one minute. The dose is

$\mathrm{TI} \times \mathrm{K}^{\prime} / 3 \times 1 / 60=.0056 \mathrm{~K}^{\prime} \times \mathrm{TI}$ mrem.

If the RA car is the first or trim end car of the first draft to be assembled into the train, or the last or hump end car of the last draft, additional exposure will occur. This is because in either case, the RA car would be the first or last car in the assembled train. Hazardous material handling rules prohibit a RA car from being next to a locomotive or occupied caboose in a train. When this happens, the trim engine crew must "bury" the RA car at least one car in from the end of the train. This maneuver may be done before the first draft is pulled from the bowl, or after the last draft has been pulled clear of it. The dose resulting from the burying maneuver is calculated as follows:

First, the engine is coupled to the RA car. The switchman making the coupling will be within $3 \mathrm{~m}$ of the car for one minute, plus an "adjoining factor," which includes walking back past the RA car to uncouple the second car from the draft. The dose is

$\mathrm{TI} \times \mathrm{K}^{\prime} / 3 \times 1.10 \times 1 / 60=.0061 \mathrm{~K}^{\prime} \times \mathrm{TI}$ mrem

Second, the engine pulls both cars back to the lead switch, at which point the second car is uncoupled; uncoupling takes about half a minute. This dose is

TI $\times .0056 \mathrm{~K}^{\prime} \mathrm{hr} \times 1 / 2=.0028 \mathrm{~K}$ ' TI mrem (no adjoining factor)

Third, after pulling the RA car through the switch, the switch is thrown and the $\mathrm{RA}$ car is shoved into the clear and uncoupled $(.0028 \mathrm{~K}$ ' $\times$ TI mrem). 
Fourth, the engine goes back and picks up the other car, returns and is coupled to the RA car again $(.0028 \mathrm{~K}$. TI mrem).*

Finally, now in the reverse order, the two cars are shoved back against the draft and coupled, and the crewman returns past the RA car once again for a dose of $.0061 \mathrm{~K}, \mathrm{TI}$ mrem.

During this process, the engine has been next to the RA car perhaps five minutes, and with the cover car, about three more minutes. The probability that the cover car will be loaded and shield the engine occupants from exposure is .5 , and the number of crew aboard is three. The exposure of the cab occupants depends on whether the car is coupled to the short or long end of the engine. When it is coupled to the long end, the cab is about $16 \mathrm{~m}$ away from the car, and the occupants receive shielding from the motor under the long hood. Therefore, long-end exposure will be disregarded, and 50 percent of short-end exposure will be calculated. The dose is

No cover car ( $4 \mathrm{~m}$ distance):

$\mathrm{TI} \times \mathrm{K}^{\prime} / 4 \times 3 \times 5 / 60=.0625 \mathrm{~K}^{\prime} \times \mathrm{TI}$ mrem.

Cover car ( $20 \mathrm{~m}$ distance):

$\mathrm{TI} \times \mathrm{K} /(20 \times 20) \times 3 \times 3 / 60 \times(.5$-shielding $) \times(.94-$ air attenuation $)$ $x\left(3.5\right.$-conversion to $\left.\mathrm{K}^{\prime}\right) \star=.0006 \mathrm{~K}^{\prime} \times \mathrm{TI}$ mrem.

Total cover car placement dose:

$\mathrm{TI} \times(.0625+.0006) \times 50 \%+2 \times .0061+3 \times .0028+.0056=$ $.0522 \mathrm{TIX} \mathrm{K}^{\prime}$ mrem.

Having buried the RA car at the trim end of the first draft, the engine crew will experience radiation exposure ( $20 \mathrm{~m}$ distance), with shielding by the

\footnotetext{
*Even though this is a coupling move, the half-minute exposure is applied because the cars involved were coupled only moments before.
} 
cover car (50\%) throughout the assembly and pull down process, lasting about one half hour. The dose is

$\mathrm{TI} \times \mathrm{K} /(20 \times 20) \times 3 \times 30 / 60 \times .5 \times(1 / 2$-cover car shielding $)$ $x\left(3.5\right.$-conversion to $\left.K^{\prime}\right) \times(.94-a i r$ attenuation factor $)=$ $.0031 \mathrm{~K}$ ' TI mrem.

The number of bowl track drafts which are assembled to make up a departing train or transfer is at least two unless it is a local train or a low-volume interchange. Using three as a conservative representation, the composite trimming dose alternatives are as follows:

first draft

second draft

third draft
Car at trim end

$\frac{\text { Car at trim end }}{(.0031+.0522)}$ K' TI mrem
.0056 K' TI mrem
.0056 K' TI mrem

Car at hump end $.0056 \mathrm{~K} \cdot \mathrm{TI}$ mrem $.0056 \mathrm{~K}^{\prime} \mathrm{TI}$ mrem $.0522 \mathrm{~K}$ TI mrem

Each of the above represents the dose that would occur if a RA car is located at the indicated end of any of the above drafts in the bowl. The average of these six possibilities, multiplied by the 1.2 contingency factor, is $.0260 \mathrm{~K}^{\prime}$ $x$ TI mrem per rail cask.

The six exposure alternatives represent six of the bowl location possibilities that a car could experience during classification into its next train. If the train is composed of 100 cars, then the calculated dosage has a 6-percent probability (all other location possibilities having minimal exposure).

On this basis the average dose would be

$\mathrm{TI} \times .0260 \mathrm{~K}^{\prime} \mathrm{hr} \times .06=.0016 \mathrm{~K}^{\prime} \times \mathrm{TI}$ mrem per rail cask

*See Appendix A. 
for an end-to-end yard total dose, including humping, of .0069 K' $x$ TI mrem. If the train were much longer, the number of drafts would probably also be greater, but the net effect would be to reduce trim end dosage.

The very large intermediate terminal included another automated hump yard having a push-pull layout which was observed but not operating. This yard was identical in its exposure characteristics to the previous one with the following exceptions :

a. There are two pin-pullers, the second one pulling the pin on the car at the end of the cut to be uncoupled, thereby opening its knuckle and reducing the incidence of cars failing to couple in the bowl. The second pin-puller is on the other side of the hump draft, but his exposure is practically identical to that for the first pin-puller. Therefore, the pin-puller exposure is double that of the end-to-end yard.

b. There is only one track over the hump, spaced about as far from the tower as the farther track at the other yard. (There is also no retarder operator.) This reduces the exposure of the tower occupants. Humping dose is

Pin-pullers: $\quad$ TI $\times \mathrm{K}^{\prime} 2 \times .0020=.0040 \mathrm{~K}^{\prime} \times \mathrm{TI}$ mrem.

Tower occupants: TI $\times 1.2 \mathrm{~K}^{1 / 9} \times 15 / 3600 \times((2.67+0.2)$-number of persons) $\times$ (1.61-adjoining car factor) $\times$ (1.1-suspension factor) $=.0028 \mathrm{~K}^{\prime} \times \mathrm{TI}$ mrem.

Total: $(.0040+.0028) \mathrm{TI} \times \mathrm{K}^{\prime}=.0068 \mathrm{~K}^{\prime} \times \mathrm{TI}$ mrem per rail cask.

c) Trimming exposure is greater because this yard has a push-pull configuration rather than the end-to-end one described above. In such a yard, the trim crew accumulates the train in the departure yard. The first draft from a bowl track is pulled out of the bowl, then 
shoved into a departure track parallel to the bowl. Each succeeding draft is coupled to the one that preceded it in the departure track, and the train is shoved deeper into the track until it clears. Any RA car at the trim end of a draft remains coupled to the engine ( $4 \mathrm{~m}$ crew exposure distance) for about 10 minutes. Thus, the dose is

$\mathrm{K} / 4 \times 3 \times 10 / 60 \times(50 \%$-probability of locomotive short end $) \times \mathrm{TI}=$ $.0625 \mathrm{~K}^{\prime} \times \mathrm{TI}$ mrem per rail cask.

A coupling exposure occurs when the next draft is added $\left(.0056 \mathrm{~K}^{*} \times \mathrm{TI}\right.$ mrem). The exception is a RA car at the trim end of the last draft, which must be buried (.0522 $\mathrm{K}^{*} \times \mathrm{TI}$ mrem). Assuming that the car is buried while the draft is still in the bowl, there would be an additional TI $\times .0010 \mathrm{~K}^{\prime}$ mrem dose to the locomotive crew.

With incorporation of the 20-percent contingency factor, the average of all push-pull trimming alternatives is $.0506 \mathrm{~K}^{\prime} \times \mathrm{TI}$ mrem. This average is based on the following possibilities:

\begin{tabular}{|c|c|c|}
\hline & Car at trim end & Car at hump end \\
\hline first draft & $(.0056+.0625) \mathrm{K}^{\prime} \times \mathrm{TI}$ mrem & $.0522 \mathrm{~K}^{\prime} \times \mathrm{TI}$ mrem \\
\hline & $(.0056+.0625) \mathrm{K}^{\prime} \times \mathrm{TI}$ mrem & $.0056 \mathrm{~K}^{\prime} \mathrm{x} \mathrm{TI}$ mrem \\
\hline third draft & $(.0010 *+.0522) \mathrm{K}^{\prime} \times \mathrm{TI}$ mrem & $.0056 \mathrm{~K}^{\prime} \times \mathrm{TI}$ mrem \\
\hline
\end{tabular}

The average dose is multiplied by 6 percent $(.0030)$. The product is added to the humping dose. The total dose for this push-pull yard is $.0098 \mathrm{~K}^{\prime} \times \mathrm{TI}$ mrem.

In the flat yard classification, two members of the crew work along the lead tracks to throw switches as the cuts coast into the body of the yard. Moving cuts roll past the crew at about $3 \mathrm{mph}(5 \mathrm{~km} / \mathrm{hr})$ at varying distances. For these calculations, it is assumed that the average switch handler exposure

* The dose would be increased to $.0652 \mathrm{~K}^{\prime} \times$ TI mrem if cover maneuver occurs in departure yard. 
could be represented by a classified car moving past one switch handler at a 5 m distance.

The pin-puller position during the cutting action is identical to that assumed for the hump yard, but the pin-puller stays longer due to the need to walk or run alongside, holding up the uncoupling lever until kicking speed is reached. (On the hump, he merely has to hold the pin up until gravity accelerates the cut away from the crest.) Pin-puller time at the cut point is about 20 seconds and the average cut has $21 / 2$ cars. This means that in classifying 100 cars, the pin-puller will make 40 cuts. Each cut will expose the pin-puller to two cars, the car whose coupler he is opening (exposure distance of $3 \mathrm{~m}$ ) and the car at the end of the cut being kicked (exposure distance of $4 \mathrm{~m}$ ). Therefore, he will have been exposed to 80 cars for a duration of 20 seconds each or 1600 "car-seconds." This averages 16 seconds per classified car, 8 seconds at a $3 \mathrm{~m}$ distance and 8 seconds at a $4 \mathrm{~m}$ distance.

After the kick, the draft may be moved while the pin-puller walks back to the next cut point at a relative rate of six cars per minute (exposure distance of $4 \mathrm{~m}$ ). On the other hand, the next cut may have to wait until previous cuts have cleared the switches, or the draft may have to be backed up to gain access to another switch or to recover room to accelerate. When the pin-puller is engaged in neither making cuts nor walking back alongside the next cut, he is assumed to be within $9 \mathrm{~m}$ of the head (cutting) end of the draft. Total exposure time is 8 seconds per car cutting, 10 seconds walking back, and 12 seconds for waiting and backing up. Including the 20-percent contingency factor, the pin-puller dose is

Making cuts:

TI $\times 1.2 \mathrm{~K}^{\prime} \times 8 / 3600 \times(1 / 3+1 / 4)=.00156 \mathrm{~K}^{\prime} \times \mathrm{TI}$ mrem.

Walking back:

TI $\times 1.2 \mathrm{~K} / 4 \times 10 / 3600 \times(1.09-1 / 2$ adjoining car factor $)=$ $.00091 \mathrm{~K}^{\prime} \times \mathrm{TI}$ mrem. 
Waiting :

TI $\times 1.2 \mathrm{~K}^{\prime} / 9 \times 12 / 3600 \times 1.30=.0058 \mathrm{~K}^{\prime} \times \mathrm{TI}$ mrem.

Total pin-puller dose:

$\mathrm{K}^{\prime} \times \mathrm{TI} \times(.00156+.00091+.00058)=.00305 \mathrm{~K}^{\prime} \times \mathrm{TI}$ mrem per rail cask.

With switch handlers receiving a dose of $K^{\prime} / 5 \times 12 / 3600 \times 1.27=.00085 K^{\prime} \times$ TI mrem, a total flat yard classification dose of .0039 $\mathrm{K}^{\prime} \times \mathrm{TI}$ mrem per car can be calculated.

Flat classification is most efficiently performed with smaller than train size drafts, such as are usual on humps. Long drafts in flat switching are cumbersome and waste both time and fuel in repetitive starting, accelerating, stopping, and backing of long drafts of cars. The flat switching engine therefore batches smaller drafts that can be classified more briskly and returns more frequently to the yard for successive drafts before a whole train has been classified. Crew exposure during this "fetching" phase of the flat yard classification process has not been estimated.

However, smaller (less than train size) drafts in flat switching means that the probability exists that a RA car that was in the middle of an inbound train will become the end car of a flat yard classification draft, and thereby expose the locomotive cab occupants throughout the classification of that draft. Assuming the typical flat yard draft would be one-fourth of a 100-car train, the probability that a RA car would be next to the classification locomotive is three percent.* The time for classifying this draft would be about 12 minutes at 2 cars per minute. Including the time to pick up the draft in the arrival yard and move it into position to begin classification would raise the exposure time to at least 24 minutes. With three crewmen in the cab during the pickup, and two during the classification, and with disregarding exposure when the locomotive is oriented long end to the RA car, 
the cab dose totals to

$\mathrm{TI} \times 1.2 \mathrm{~K}^{\prime} / 4 \times(3+2) \times 12 / 60 \times 50 \% \times 3 \%=.0045 \mathrm{~K}^{\prime} \times \mathrm{TI} \mathrm{mrem}$.

The trim end exposure in the flat yard should be similar to the large hump yard previously quantified. Since trim end exposure is of the push-pull configuration, we can add $.0030 \mathrm{~K}^{\prime}$ TI mrem for a total of $.0114 \mathrm{~K}^{\prime} \times \mathrm{TI}$ mrem per rail cask for flat yard classification.

The low hump yard observed has characteristics of both hump and flat yards. Long drafts are classified with continuous forward engine movement, but crew members handle switches below the crest. There are no retarders, and the body of the yard is laid out like a flat yard, viz., a "pinnate" configuration with long leads rather than a "palmate" one with the crest track fanning out through a series of branches. As a result of this flat yard configuration, the low hump yard has a classification rate about the same as the flat yard, but without the periodic interruptions to pick up a series of short drafts, and without the backing up time.

The pin-puller spends 20 seconds making the cut plus 10 seconds walking forward with the cut to center and open the retreating car's coupler knuckle (exposure distance is $3 \mathrm{~m}$ ). As in the flat yard, the 20-second cut time represents exposure to two cars. The walk back to the next cut takes another half minute, plus about 10 seconds for each additional car over one in the cut. The exposure distance is $5 \mathrm{~m}$. The average cut is $21 / 2$ cars, so the classification rate averages about two cars per minute. The pin-puller's dose is

Making cuts:

same as flat yard $=.00156 \mathrm{~K}^{\prime} \times \mathrm{TI}$ mrem.

\footnotetext{
*Because of train positioning requirements, the RA car will never be the very first or very last car in a train. Therefore, it will never be the first car in the first classification draft in a flat yard.
} 
Walking forward:

$\mathrm{TI} \times 1.2 \mathrm{~K}^{\prime} / 3 \times 10 / 3600 / 2.5=.00044 \mathrm{~K} \times \mathrm{TI}$ mrem.

Walking back:

$\mathrm{TI} \times 1.2 \mathrm{~K}^{\prime} / 5 \times 45 / 3600 / 2.5 \times 1.14=.00137 \mathrm{~K}^{\prime} \times \mathrm{TI}$ mrem.

Total pin-puller:

$\mathrm{TI} \times \mathrm{K}^{\prime}(.00156+.00044+.00137)=.00337 \mathrm{~K}^{\prime} \times \mathrm{TI}$ mrem.

A switch handler dose of $.00085 \mathrm{~K}^{\prime} \times \mathrm{TI}$ mrem is also added to yield a dose of $.0042 \mathrm{TI} \times \mathrm{K}^{\prime}$ mrem.

Unlike the other yards observed, the low hump yard has insufficient capacity to perform all classifications on a once-through basis. This yard reprocessed 80 percent of all cars. This would increase classification dose to $.0076 \mathrm{~K}^{\prime} \times \mathrm{TI}$ mrem per car. Additionally, three percent of the time, the $R A$ car would be on the end of the rehumped draft next to the engine for perhaps half an hour, exposing the engineer (the only occupant of the locomotive $c a b$ ) to a dose of

$\mathrm{TI} \times 1.2 \mathrm{~K} / 4 \times 30 / 60 \times 50 \% \times .03 \times 80 \%=.0018 \mathrm{~K} \cdot \mathrm{TI}$ mrem.

Since this is a push-pull yard, trimming dose would be $.0030 \mathrm{~K}$ ' $\mathrm{x}$ TI mrem were it not for there being only an engineer occupying the locomotive cab rather than three crewmen. Instead, the dose is $.0015 \mathrm{~K}^{\prime} \times$ TI mrem for a total of $.0109 \mathrm{~K}^{\prime} \times \mathrm{TI}$ mrem per rail cask for the low hump yard.

The remaining terminal (classification was not observed) has an automatic hump yard, but also performs flat classification from the trim end of the hump. This hump is similar to the hump in the other large terminal, but with only one crest track which is closer to the tower. There are three retarder towers about $10 \mathrm{~m}$ from their respective tracks. A humped car passes by two of the three towers. This terminal is of the end-to-end configuration. 
Shove-to-rest-classification

Exposure rates appropriate for classification of general traffic, such as have been developed above, may not be appropriate for evaluating carload shipments of irradiated fuel. At least one major railroad has adopted a rule prohibiting the humping, kicking, cutting off while in motion, or striking by another car moving under its own momentum of any car placarded "Radioactive Material." It is probable that many other railraods, or even the industry as a whole will adopt such a rule, at least in so far as irradiated fuel loads are concerned.* This will be done not only to reduce the risk of a release of radioactive material, which may be quite small, but also to obviate the political consequences of an accident involving high-level waste, even without a release. Even if such a rule were not in force for a particular carrier, local supervision in the terminals could very well observe it anyway, just to avoid any possibility of an incident which could only have negative connotations. The shipments through any particular terminal will be infrequent enough that the extra cost of shove-to-rest handling will seem a trivial price to pay for peace of mind. Therefore, the evaluation of accident-free movement exposure should be based upon the shove-to-rest mode of handling in terminals between trains.

The shove-to-rest mode of handling occurs infrequently at the locations of field visits. None was actually observed. The following estimates of exposure are based on discussions with local managers.

For flat or low hump classification activities, shoving RA cars to rest means that the entire draft of which they are at the head must be shoved through all the leads, and down the assigned bowl track to the end of the track, or until the cars that are already in the track are reached. The draft cut must then be coupled gently to the first car already there, or if the

\footnotetext{
*This prediction is supported by the fact that a number of the roads handling flammable compressed gas, chlorine, and phosphorous shipments require them to be shoved to rest even though this is not mandatory under the Hazardous Materials Regulations of the Department of Transportation.
} 
track is empty, cut off and left standing. If the RA car is not the car left standing at the hump end of the cut after uncoupling, but is covered by another car, the draft can be pulled back to the hump or lead track and normal classification resumed. If the RA car is the hump end car in the track, then the next cut classified into that track must also be shoved to rest against it.

During the shoving move, one switchtender will ride the head car of the draft. Assuming this takes five minutes ( $1 / 4 \mathrm{mile}$ at $3 \mathrm{mph}$ ), the switch tenders' dose would be TI $\times 1.2 \mathrm{~K}^{\prime} / 3 \times 5 / 60=.0333 \mathrm{~K}^{\prime} \times \mathrm{TI}$ mrem plus $.0056 \times$ $1.2 \times 1.10 \times \mathrm{TI} \times \mathrm{K}^{\prime}=.0074 \mathrm{~K}^{\prime} \times \mathrm{TI}$ mrem for coupling if the head car is the RA car. The probability that this occurs is about 50 percent.* Thus, the dose is

$\mathrm{TI} \times \mathrm{K}^{\prime}(.0333+.0074) \times 50 \%=.0204 \mathrm{~K}^{\prime} \times \mathrm{TI}$ mrem per rail cask.

There is also a 50-percent probability that the car at the hump end of the cut will be the RA car, resulting in dose when the draft is uncoupled from it, and again, when the next cut must be coupled to it. The dose is

$$
\mathrm{TI} \times(.0028+.0056) \mathrm{K}^{\prime} \times 1.2 \times 1.10 \times 50 \%=.0055 \times \mathrm{TI} \times \mathrm{K}^{\prime} \mathrm{mrem} .
$$

In the event that the $\mathrm{RA}$ car is the last car in the flat yard draft next to the locomotive, the cab occupants' exposure time during normal classification will be increased by the time of the shove-to-rest move ( 5 minutes) plus the time for coupling and uncoupling ( 2 minutes). Thus, the dose is

$\mathrm{TI} \times 1.2 \mathrm{~K} / 4 \times(3 \times 12+2 \times 19) / 60 \times 50 \% \times 3 \%=.0056 \times \mathrm{TI} \times \mathrm{K} \cdot \mathrm{mrem}$.

Since the shove-to-rest handling of RA cars in flat and low hump yards results in the cars being placed in the same location within the classification yard

*The average cut of $21 / 2$ cars can be represented by equal proportions of one, two, three, and four car cuts. The probability of a RA car being on a given end of these cut sizes is one, $1 / 2,1 / 3$, and $1 / 4$, respectively, with an average of .52 . 
that they would have occupied had they not been shoved-to-rest, there is no difference in the trimming exposures because of shove-to-rest handing. Thus, the classification dose is

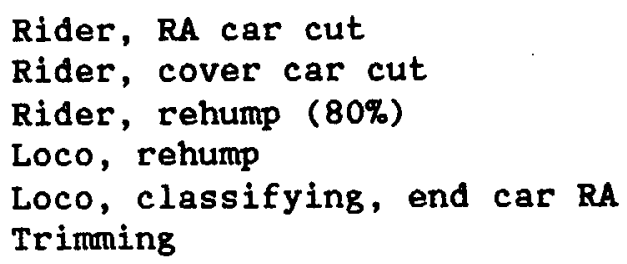

$\begin{array}{ll}\text { Flat } & \text { Low hump } \\ .0204 & .0204 \\ .0055 & .0055 \\ & .0207 \\ & .0018 \\ .0056 & \\ .0030 & \frac{.0015}{.035 \times \mathrm{TI} \times} \\ \text { K'mrem } & \text { K'mrem }\end{array}$

In an automated hump yard, the exposure for shove-to-rest handling consists of two components, the exposure of the crew moving the car into the bowl, and the exposure of of all employees at the hump crest while the car is set off on the dynamite track. This is a short side track located on the hump approach which is used to park cars in the draft which cannot be humped in sequence. (See photo of Milwaukee's St. Paul Yard hump in Figure 6.) Not all hump yards have a dynamite track.

On a shoving move over the automated hump, the exposures would be similar to those in the flat yard or low hump except that the shoving distances are greater, so car rider exposure would increase. With doubling the distance, the dose is

TI $\times \mathrm{K}^{\prime} \times(.0333 \times 2+.0074) \times 50 \%+.0055=.0425 \times \mathrm{TI} \times \mathrm{K}^{\prime} \mathrm{mrem}$, not including tower occupants*.

A shove-to-rest move over the hump can be a time- and energy-consuming maneuver if the hump cut is very long. Because of the cut length, the speed will be kept low ( $3 \mathrm{mph}$ ) to retain control, and the pull-back move (which entails no exposure) will take about as long. A subsequent covering shove-to-rest move will be equally lengthy. Altogether, such "handlings" greatly delay the humping operation and downgrade classification productivity.

*.0033 K' $\times$ TI mrem in the end-to-end yard, and $.0028 \mathrm{~K} \cdot \times$ TI mrem in the push-pull yard. 
There are two ways in which the holdup of the classification process can be reduced. One is to have a trim engine come to the hump crest through an empty bowl track, pick up the shove-to-rest cut, pull it back through the bowl, and shove it to rest in its proper bowl track from the trim end. In this way, humping is interrupted only briefly, which may be of more importance than the interruption to the trim engine's activities. With only one or two cars in tow, $* *$ the trim engine can move faster ( $6 \mathrm{mph}$ ).

If it is assumed that the entire trim engine exposure time is 17.8 minutes (one minute coupling, ten minutes pulling through the bowl, five minutes placement at trim end, and 1.8 minutes coupling and uncoupling), the dose is

Rider:

1. Couple to RA cut at crest:

TI $\times .0056 \mathrm{~K}^{\prime} \mathrm{hr} \times 1.2 \times(75 \%$-probability that end car is $\mathrm{RA})=.0050$ $\mathrm{K}^{\prime} \mathrm{X}$ TI mrem.

2. Shove RA cut from trim end into bowl: $1.2 \times \mathrm{TI} \times \mathrm{K}^{\circ} / 3 \times 5 / 60 \times 75 \%=$ $.0250 \mathrm{~K} \cdot \mathrm{X}$ TI mrem.

3. Couple and uncouple in bowl: TI $\times \mathrm{K}^{\prime}(.0028+.0056) \times 1.2 \times 1.10 \times$ $75 \%=.0083 \mathrm{~K}^{\prime} \times \mathrm{TI}$ mrem.

\footnotetext{
**Cuts in hump drafts can be expected to have about the same average size ( $21 / 2$ cars) as they have in flat or low hump yards. However, it will be recalled that retarder length limits the actual cut lengths at the crest to three cars (two if the cars are long), resulting in a $11 / 2$ car average actual cut at the hump. If the trim engine comes to the hump to pull down a shove-to-rest car, it would seldom handle more than two cars in this move, even if the natural "cut" (cars in sequence having the same bowl track assignment) were larger. One car in addition to the shove-to-rest car is useful as a cover car, but more cars act to encumber the maneuver, which is disruptive to yard activity in any case. For a one- or two-car cut, the probability of the RA car being at any given end is 75 percent.
} 
Total rider dose:

$\mathrm{TI} \times \mathrm{K}^{\prime}(.0050+.0250+.0083)=.0383 \times \mathrm{TI} \times \mathrm{K}^{\prime} \mathrm{mrem}$.

Crew on locomotive:

$1.2 \times \operatorname{TI} \times\left(\mathrm{K}^{\prime} / 4\right) \times(10 / 60 \times 4 *+7.8 / 60 \times 3) \times 75 \% \times(50 \%$-probability of locomotive short end) $=.1189 \mathrm{~K}^{\prime} \times \mathrm{TI}$ mrem.

Total exposure of trim engine crew:

$\mathrm{TI} \times \mathrm{K}^{\prime}(.0383+.1189)=.1572 \times \mathrm{TI} \times \mathrm{K}^{\prime}$ mrem per rail cask.

When the trim engine comes to the hump as just described, the personnel at the hump will receive a dose as the RA car approaches and reaches the crest, and as the car is cut off by the pin-puller after the trim engine has coupled to it. Over and above this, the pin-pullers and tower occupants will be exposed during the time the trim engine is coupling (one minute) and perhaps another minute waiting for the trim engine to climb the hump after the preceding cut has been released. This dose is

End-to-end hump:

$1.2 \times \mathrm{TI} \times \mathrm{K}^{\prime} \times 2 / 60 \times(3.67$-number of persons $) \times((1.27 / 5+1.61 / 9) \times$ $1 / 2$-average distance) $=.0106 \mathrm{~K}^{\prime} \times \mathrm{TI}$ mrem (plus $.0053 \mathrm{~K}$ ' TI mrem humping dose).

Push-pull hump:

$1.2 \times \mathrm{TI} \times \mathrm{K}^{\prime} \times 2 / 60 \times 4.67 \times 1.61 / 9=.0334 \mathrm{~K}^{\prime} \times \mathrm{TI}$ mrem (plus $.0068 \mathrm{~K}^{\prime} \times$ TI mrem).

The other way to avoid holding up the classification process when a shove-to-rest car is in the hump cut is to have a "dynamite" track. When the

*Includes rider when pulling from crest to trim end. 
hump cut has been completed, the "dynamiter(s)" can be shoved to rest over the hump by the hump engine, but at a greater speed, and without the necessity of a slow backup or subsequent cover car shove.* After completing the shove to rest of the RA car, the crew can proceed without returning to the hump, where another draft may be ready to roll. Alternatively, the hump engine might shove the car through the bowl for handling by a trim engine, as previously described. Shoving just the dynamiter cut (including a cover car) into the hump end of the bowl will reduce the shoving time by half for the rider. Thus, the dose is TI $\times \mathrm{K}^{\prime}(.0333+.0074) \times 75 \%=.0305 \mathrm{~K}^{\prime} \times \mathrm{TI}$ mrem. The locomotive cab occupants will now receive a dose of $1.2 \times \mathrm{TI} \times \mathrm{K}^{\prime} /(20 \times 20) \times$ $7 / 60 \times 4 * \star \times .5 \times .94 \times 3.5 \times 50 \%=.0012 \mathrm{~K}^{\prime} \times \mathrm{TI}$ mrem for a total of $.0317 \mathrm{~K}^{\prime} \times$ TI mrem per rail cask.

Shoving-to-trim-end-dose will be

$\mathrm{TI} \times 1.2 \mathrm{~K} / 3 \times 10 / 60 \times 75 \%=.0500 \mathrm{TI} \times \mathrm{K}^{\prime} \mathrm{mrem}$ (rider)

$\mathrm{TI} \times 1.2 \mathrm{~K}^{\prime} / 4 \times 10 / 60 \times 75 \% \times 4 * * * \times 50 \%=.0750 \mathrm{TI} \times \mathrm{K}^{\prime} \mathrm{mrem}(\mathrm{cab}$ occupants) or

$\mathrm{TI} \times \mathrm{K}^{\prime}(.050+.075)=.125 \times \mathrm{TI} \times \mathrm{K}^{\prime} \mathrm{mrem}$.

to which must be added a trim engine handling dose of

$\mathrm{TI} \times 1.2 \mathrm{~K} / 4 \times 7.8 / 60 \times 3 \times 75 \% \times 50 \%=.0439 \times \mathrm{TI} \times \mathrm{K}^{\prime} \mathrm{mrem}$ for cab occupants plus $.0383 \mathrm{TI} \mathrm{K}$ 'mrem for the rider. The total dose for shoving through to trim end is .2072 X TI $\times$ K'mrem per rail cask.

*This will be feasible only if the RA car is not on the hump end of the dynamiter cut. It is assumed that, if necessary to avoid having to make a subsequent cover car shove, the crew will place a cover car while the RA car is parked on the dynamite track. This means a hump-end shove cut will average $21 / 4$ cars. The RA car will be on the trim end of this cut $75 \%$ of the time.

**Assumes crew foreman will ride also as the locomotive will not return to the hump.

$* * *$ Includes rider when pulling from crest to trim end. 
In both versions of dynamite track handing, there will be exposure to the pin-puller while cutting the preceding hump cut, riding the RA cut from the hump crest to the dynamite track switch then forward into the dynamite track, and uncoupling the cut and setting the hand brakes. Later, when the dynamite cut is to be handled to the bowl, the pin-puller (rider) and cab occupants will be exposed while coupling to the RA cut and releasing hand brakes. For shoving to the trim end (where a hump end cover car need not be provided), doses are

Cutting :

$T I \times 1.2 K^{\prime} 1 / 3 \times 8 / 3600 \times 75 \%=.00067 K^{\prime} \times T I m r e m$.

Placement ( 3 minutes):

$\mathrm{TI} \times 1.2 \mathrm{~K}^{\prime} / 3 \times 3 / 60 \times 75 \%=.01125 \mathrm{~K}^{\prime} \times \mathrm{TI}$ mrem.

Pickup (2 minutes):

$\mathrm{TI} \times 1.2 \mathrm{~K}^{\prime} / 3 \times 2 / 60 \times 75 \%=.0075 \mathrm{~K}^{\prime} \times \mathrm{TI}$ mrem (rider);

TI $\times 1.2 \mathrm{~K}^{\prime} / 4 \times 3 \times 2 / 60 \times 75 \% \times 50 \%=.01125 \mathrm{~K}^{\prime} \times \mathrm{TI}$ mrem (cab occupants).

Total: $\mathrm{TI} \times \mathrm{K}^{\prime}(.00067+.01125 \times 2+.0075)=.0307 \mathrm{~K}^{\prime} \times \mathrm{TI}$ mrem.

When the RA car is to be shoved to the hump end of the bowl from the dynamite track, the cutting and placement exposure would be the same. However, it is assumed that the subsequent placement of a hump-end cover car on the dynamite track will be required $75 \%$ of the time. This will expose the rider. The rider dose is

$\mathrm{TI} \times .0056 \mathrm{~K}^{\prime} \mathrm{hr} \times 1.2 \times .75=.0050 \times \mathrm{TI} \times \mathrm{K}^{\prime} \mathrm{mrem}$. 
Pickup exposures are reduced due to the cover car; the rider spends one minute adjacent to the RA car releasing the brakes. The dose is

TI $\times 1.2 \mathrm{~K}^{\prime} / 3 \times 1 / 60=.0067 \mathrm{~K}^{\prime} \times \mathrm{TI}$ mrem.

The cab occupants' exposure is insignificant. Total dose for shoving to the hump end of bowl is

$\mathrm{TI} \times \mathrm{K}^{\prime}(.00067+.01125+.0050+.0067)=.0236 \times \mathrm{TI} \times \mathrm{K}^{\prime} \mathrm{mrem}$ per rail cask.

The shove-to-rest handling of RA cars in automated hump yards will affect the exposures received in the trimming portion of the classification process, which includes train assembly. To the extent that such cars are handled past the bowl and placed into the trim end of the bowl, the probability of a RA car being the trim end car in its draft is much greater than the 2-4 percent that applies to regular classification handling. If such by-pass moves average 1 $1 / 2$ cars each, the probability is 75 percent. At the other extreme, to the extent that RA cars are shoved to rest over the crest into the bowl, the probability of an end-of-draft location is the same as for a regular car. The trimming dose alternatives are as follows:

end-to-end push-pull

Shove over hump $.0016 \mathrm{~K}^{\prime} \times$ TI mrem $.0030 \mathrm{~K}^{\prime} \times \mathrm{TI}$ mrem Shove from trim end* .0199 .0568

Combining the classification and trimming exposure alternatives in the automated hump yard yields the following total shove-to-rest doses:

\begin{tabular}{|c|c|c|c|c|}
\hline Shove over hump & \multicolumn{2}{|c|}{ From hump crest: } & \multicolumn{2}{|c|}{ From dynamite track: } \\
\hline Hump engine crew & $.0 \overline{425 \mathrm{~K} \times \mathrm{TI}}$ & $.0425 \mathrm{~K}^{\prime} \times \mathrm{TI}$ &.$\overline{0553 \mathrm{~K}^{\prime} \times \mathrm{TI}}$ & $.0553 \mathrm{~K}^{\prime} \mathrm{x}$ \\
\hline Tower occupants & .0033 & .0028 & .0033 & .0028 \\
\hline Trim engine crew & .0016 & .0030 & .0016 & .0030 \\
\hline & $.047 \mathrm{~K}^{\prime} \mathrm{xTI}$ mrem & $.048 \mathrm{~K}^{\prime} \times \mathrm{XI} \mathrm{mrem}$ & $.060 \mathrm{~K}^{\prime} \times \mathrm{xI} \mathrm{mrem}$ & $.061 \mathrm{~K}^{\prime} \times \mathrm{XT}$ \\
\hline
\end{tabular}

*Average trim end location trimming exposure $x \quad 75 \%$. 


$$
\text { From hump crest: }
$$

Shove from trim end

Hump personnel

end to end

.0159

Trim engine crew

Classifying

Assembling

.1572

.0173 push-pull

.0402

.1572

.0480
From dynamite track:

end to end push-pull

.1590

.1585

.0822

.0822

$.193 \mathrm{~K}^{\prime} \times T I$ mrem .254K'xTI mrem .261K'xTI mrem .298K'xTI mrem

Only the shove over the hump produces doses as low as those developed for flat and low hump yards. The shove from trim end exposures are from three to six times as great.

The very significant impact of the shove-to-rest mode of handing upon the classification doses to terminal crews can be appreciated when these doses are compared to those that apply to $\mathrm{RA}$ cars receiving regular (humped or kicked) classification.

Regular

Automated hump yard

end-to-end

push-pull

Flat yard

Low hump yard ( $80 \%$ rehumping)
$.0069 \times T I X K '$ mrem

.0098

.0114

.0109
Shove-to-rest

.047 to $.261 \times T I x K^{\prime}$ mrem .048 to .298

.035 .050

The dose received by hump employees while the RA car is parked on the dynamite track should perhaps be added to any handling dose "variation" for a dynamite track. The length of exposure will be at least as long as it takes to complete humping the remainder of the draft. The RA car may be held there for one or more additional drafts, if its scheduled departure time from the terminal is sufficiently distant. There is an incentive to hold it until it can be the final cut into its classification track before the draft in that track is pulled down by a trim engine for train assembly. This results in the least time-consuming handing by switch engines. Thus there is a range of up to several hours in how long the hump employees will be exposed to a RA car parked on the dynamite track. 
There is also considerable range in the distance from where the car would be placed to employees at the crest from one hump yard to another. One yard at the largest terminal visited has a dynamite track only 10 meters from the hump track crest, whereas at the other yard in the same terminal the distance is $50 \mathrm{~m}$.* If these are representative variations, dynamite track doses would range downward from $.05 \mathrm{~K} \times \mathrm{TI}$ mrem per person to perhaps as little as 0.0005 $K \times$ TI mrem per person. Having more than one irradiated fuel carload in a single draft to be humped seems highly unlikely, but there could well be switch-to-rest loads of other hazardous commodities. In such a case, the spent fuel car might be handled together with the other hazardous cars after they are consolidated at the crest. $\star \star$ Such multicar handing could reduce crew RA exposures if the spent fuel car is neither at the forward end, which the switchman rides, nor next to the locomotive. However, the exposure could be increased if disposing of the non-RA switch-to-rest cars prolongs crew proximity to the spent fuel shipment.

Very extensive field studies would be required to establish the relative frequency of nonautomated yard classification and direct shoves into the bowl in automated yards. These handling variations are probably in the .035 to $.061 \times \mathrm{TI} \times \mathrm{K}$ 'mrem range of doses, whereas the other alternatives in automated hump yards are considerably higher (.19-.30 x TI X K'mrem). Moreover, the handling alternatives involving dynamite track set off would have a wide range of added exposure from that source as well, which can only be estimated by numerous field observations.

An estimate of $.05 \mathrm{~K}^{\prime} \times$ TI mrem for classification handling would certainly be about the minimum dose if it is to include any frequency of the

*The actual distance from a car on the dynamite track to the crest would also depend on how deep into the track the car is spotted. A single car would usually be spotted just far enough into the track to be in the clear (but more than one "dynamiter" can be in a single draft). In the case of the first yard cited, this results in the $10 \mathrm{~m}$ distance to the crest but the track itself is long enough to place the car up to $75 \mathrm{~m}$ away. At the other hump yard, spotting the car well into the dynamite track would place it closer to the hump than $50 \mathrm{~m}$. At the third automated hump visited, the maximum distance from "dynamite" car to crest is $15 \mathrm{~m}$.

**Handling RA shipments coupled to other hazardous material cars is improper in train service, but permissible in switching. 
higher trim end placement handling alternatives. The true average is probably higher, due to the rather frequent incidence of automated hump yards in the high-density routes traversed by most spent fuel shipments. How much higher is difficult to determine.

In the absence of field studies, it will be assumed that the lower dose cases (which result from random locations within classified drafts in the bowl) have triple the probability of trim end placement (which results in trim-end-of-draft locations in the bowl). The former group's dose is represented by the automated dose (.054 $\mathrm{x}$ TI $\left.\mathrm{X} \times \mathrm{K}^{\prime} \mathrm{mrem}\right)$, the flat dose (.035 $\mathrm{K}$ ' $x$ TI mrem), and the low hump dose (.050 $\mathrm{K}^{\prime} \times \mathrm{TI}$ mrem). The trim-end-of-draft dose is the simple average of the shove-from-trim-end cases $(.252 \mathrm{~K}$ ' $\mathrm{x}$ TI mrem). The average of these doses is $.097 \mathrm{~K}^{\prime} \times \mathrm{TI}$ mrem, which is rounded to $.10 \mathrm{~K}^{\prime} \times \mathrm{TI}$ mrem per rail cask. It does not include any exposure resulting from set-off time on the dynamite track.

\section{Car repairs}

Car repair facilities at railroad terminals have traditionally consisted of "rip" tracks, to which are switched cars that require repairs more extensive than those which can be performed in train arrival or departure yards. The rip tracks are widely spaced to provide working room for the carmen (see photo in Figure 10). Tools, parts, and machinery are carried as needed to where the cars are spotted. The rip tracks are "set up" or switched periodically, during which time repair work ceases. Between set-ups the cars are usually not moved.

To improve repair facility efficiency, and to cut down on unnecessary detention of "bad order" (defective) cars, many larger terminals have installed "one-spot" repair facilities, so called because all needed tools, parts, and machinery are stocked in one place. The cars to be repaired roll through sequentially rather than being repaired in batches (see photo in Figure 11). The roll-through is performed by off-track hostlers or tractors, and by cable-powered axle-pushing indexers operated by the carmen, who draw from an inventory of bad order cars held outside the one spot. When repaired, 


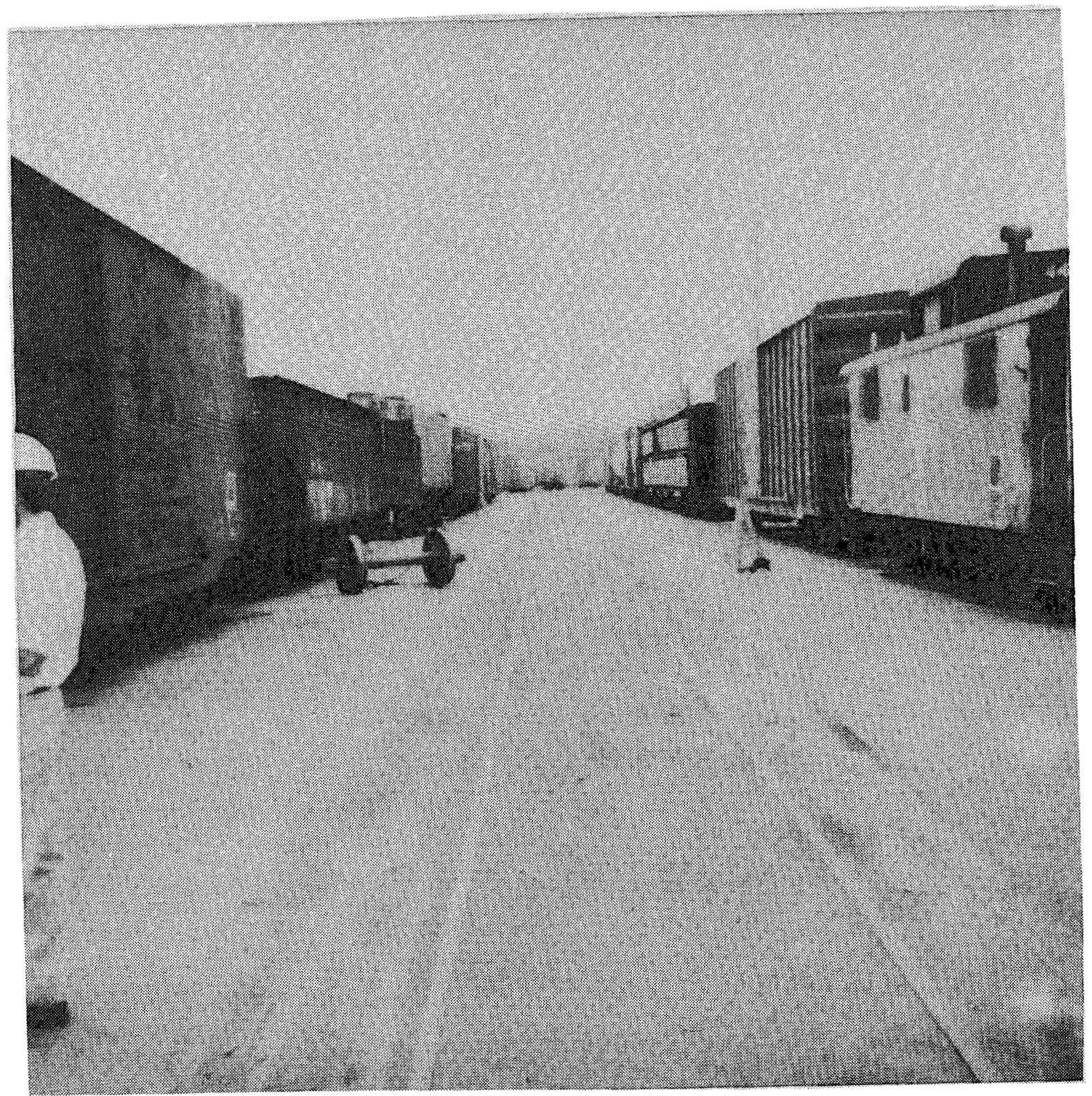

Figure 10. "Rip" Track Photo 
the cars are rolled out of the facility. The facility is roofed over rather than open, as rip tracks are.

Car repair facilities at the smaller intermediate terminal were conventional rip tracks, and the other three had one-spots of different capacities. Two of the latter terminals also performed repairs at locations away from the one-spot. Despite these variations, the potential exposures during repair per car stopping were very similar in three of the four terminals visited.

Unless a large volume of repair work is observed in progress, it is difficult to develop measurements of how many man-hours are spent in close proximity to the cars under repair. The field visits were too short to permit this. After discussion with a "one-spot" manager, it was decided that a reasonable estimate of close exposure time in such facilities would be one-half of the on-duty time of carmen. Of this close exposure time, one-half was assumed to be right next to the cars (within $3 \mathrm{~m}$ )* and the remainder at an average distance of $5 \mathrm{~m}$. The working space between car edge and parts cribs in one-spot facilities is 4-5 $\mathrm{m}$, and the space between tracks on the conventional rip is about $9 \mathrm{~m}$, constituting the work area for two tracks of cars under repair.

The "one-spot" observed most extensively was at the large intermediate terminal, having a repair rate of about 90 cars per week. Each of the three run-through repair tracks has a capacity of three standard cars. The facility uses one fully manned shift (11 carmen) and one-half manned shift (6 carmen) on weekdays, with two carmen available on weekends for urgent repairs. This works out to about one man day per car repaired (involves 4 hrs of exposure) or a $1.07 \mathrm{~K}^{\prime} \times$ TI mrem dose $(2 \mathrm{hrs} / 3 \mathrm{~m}+2 \mathrm{hrs} / 5 \mathrm{~m}) \mathrm{K}^{\prime} \times$ TI mrem. A dose of $0.25 \mathrm{~K}^{\prime} \times \mathrm{TI}$ mrem is added to account for carmen working close to other cars in the facility.**

\footnotetext{
* See photo in Figure 8.

**This includes exposure from cars immediately outside the facility. These cars will be repaired on the next cycle, or were repaired on the previous one.
} 


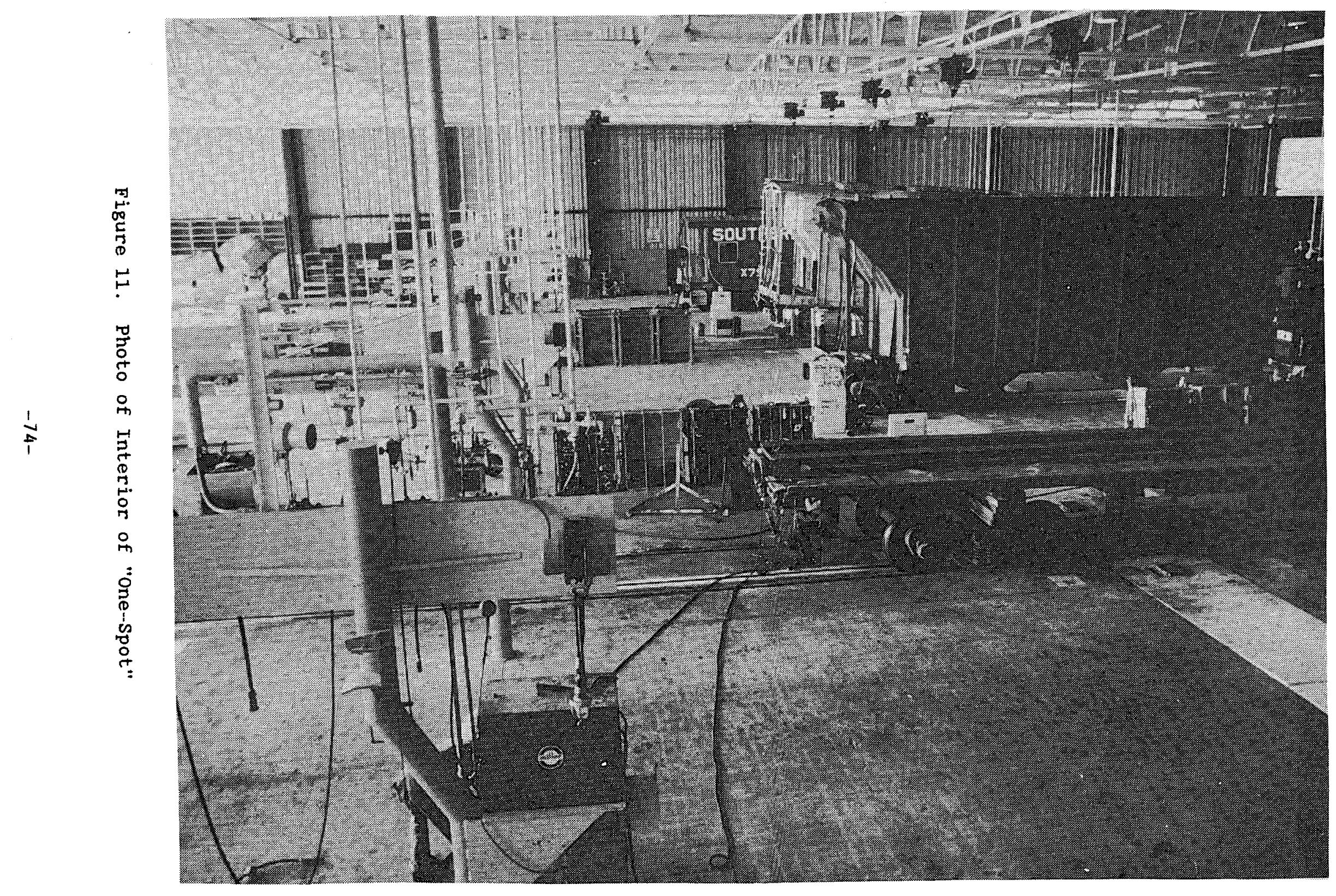


A small number of cars, about 5 per weekday, are repaired on the terminal's cleaning tracks. This keeps the cars from having to spend three days in the one-spot cycle for repairs that require less extensive resources. The close proximity time is assumed to be half that of the one-spot, plus the adjoining car factors. Thus, the dose is $\mathrm{TI} \times \mathrm{K}^{\prime}(1.10 / 3+1.27 / 5)=.62 \times \mathrm{TI} \times \mathrm{K}^{\prime} \mathrm{mrem}$ per rail cask.

Finally, this terminal does a large volume ( 355 cars per week) of repair on cars in the arrival yard. Some tracks in the yard have been removed, and blacktop laid to enable repair trucks to move up and down the trains (see photo in Figure 12). The average repair in these receiving tracks is smaller than those performed in the cleaning tracks, but no such repair activity was observed during the visit. All the carmen time here would be in close proximity, and is assumed to be one-quarter of the one-spot estimate $(0.31 \times$ TI $\left.\times \mathrm{K}^{\prime} \mathrm{mrem}\right)$. The arrival yard tracks where these repairs are made are $8 \mathrm{~m}$ apart (center to center). The carmen repairing cars on the track adjacent to the $\mathrm{RA}$ car would receive exposures at $3 \mathrm{~m}$ and $5 \mathrm{~m}$ while they work on the side next to the RA car, which can be assumed to be half the time ( $4 \mathrm{hrs}$ per man-day). The other half of the time, they would be further away and shielded by the cars being repaired. If the arrival yard has a joint occupancy factor of 40 percent, the adjacent track car repair dose would be one-half of 40 percent, or 20 percent of the dose in repairing the RA car, for a total of .37 K' $x$ TI mrem.

The weighted average of the dose at the three repair locations in the large terminal is

TI $\times K^{\prime}(90 / 470 \times 1.32+25 / 470 \times .62+355 / 470 \times .37)=.57 \times$ TI $\times K^{\prime} \mathrm{mrem}$ per rail cask.

With assuming the 6 percent repair rate for cars yields an average repair dose of $.034 \mathrm{TI} \mathrm{K}$ 'mrem per car.

The one-spot at the very large intermediate terminal has a weekly production about twice that of the previously discussed facility, but a 


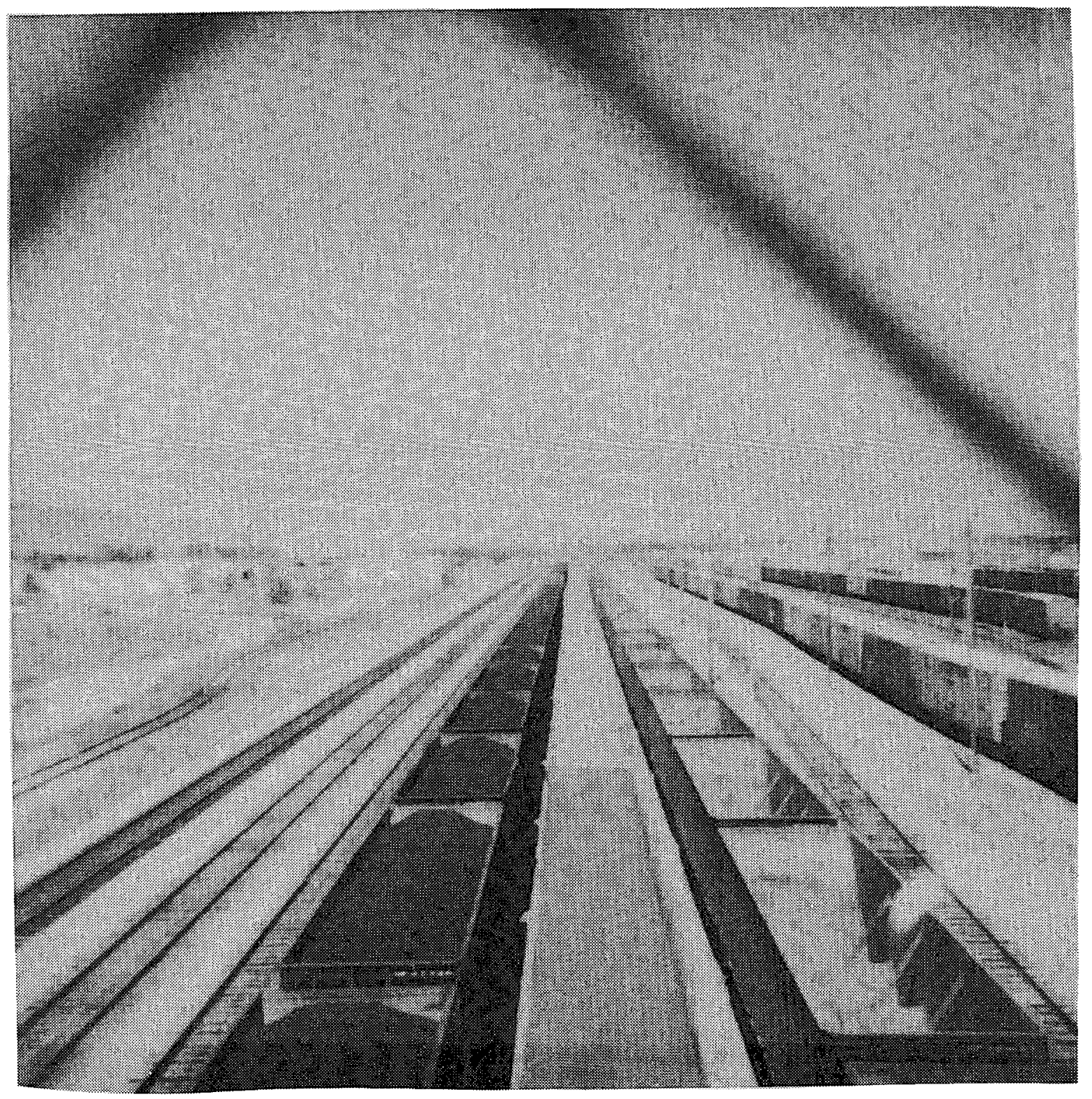

Figure 12. Receiving Yard Repair Tracks Photo 
manning level about three times as large. The nature of the traffic at this high-volume terminal, which is the hub of the system, places an emphasis on avoiding discretionary repairs. As a result, the repairs that are made here are more costly on average than those made at other intermediate terminals. In addition to the one-spot, one-fourth of all cars repaired here are handled at repair locations on the outer edge of the eastward classification yard (most loads move east through this terminal). The average of 1.3 man-days per car at the "mini-rip" tracks is almost as high as at the one-spot. Again, the objective is to avoid delay to loaded cars by repairing them right in the yard. For the terminal as a whole, the dose per car repaired (TI $x K^{\prime}$ $\left.(185 / 250 \times 1.32 \times 1.5+65 / 250 \times .62 \times 2 \times 1.3)=1.88 \times \mathrm{TI} \times \mathrm{K}^{\prime} \mathrm{mrem}\right)$ is higher than at the first terminal, but only $11 / 2$ percent of the cars are repaired, giving an average dose per car of $.028 \mathrm{TI} \times \mathrm{K}$ 'mrem.

The interchange terminal has the third one-spot visited. Man-days per car repaired (1.75) were highest here (a man-day leads to 4 hrs of exposure), one reason being that many empty cars that are sent home for repairs by foreign lines are received here, making this a logical place to repair them. Such repairs tend to be both more extensive than average and discretionary to the foreign line. On the other hand, there is an opportunity to avoid making smaller-than-average repairs to foreign cars about to be delivered offline. With 2 percent of cars handled being repaired at a dose of $2.31 \mathrm{~K}^{\prime} \times \mathrm{TI}$ mrem, the average dose is $.046 \mathrm{~K}^{\prime} \times \mathrm{TI}$ mrem per car stopping over.

During its first shift operation, the rip track observed at the smaller intermediate terminal handled 3 percent of the cars stopping over, which are mostly foreign cars. The average man-days per car repaired is only .6, consistent with predominantly foreign car repair which should average less. The smaller second shift operation handled 1 percent of the cars, but these are almost entirely home empties, averaging 1 man-day per car repaired. The dose to carmen working on a spent fuel car would be

$\mathrm{TI} \times \mathrm{K}^{\prime} .6(2 / 3 \times 1.10+2 / 5 \times 1.27)=.74 \mathrm{TI} \times \mathrm{K}^{\prime} \mathrm{mrem}$.

Except for home cars repaired on the second shift, cars are repaired on three 
tracks with track centers $12 \mathrm{~m}$ apart. Therefore, carmen repairing cars on tracks next to the spent fuel car would receive the same exposure at 7 and $9 \mathrm{~m}$, but half of the exposure time would be on the other side of the car being repaired at greater distances and with shielding. For spent fuel cars, the average dose for all three rip tracks (assuming $100 \%$ joint occupancy on the first shift) is

$\mathrm{TI} \times \mathrm{K}^{\prime} .6(2 / 7 \times 1.46+2 / 9 \times 1.61) \times 1 / 2 \times 4 / 3=.31 \mathrm{TI} \times \mathrm{K}^{\prime} \mathrm{mrem}$.

The average dose per car stopping over would be $.033 \mathrm{~K}^{\prime} \times$ TI mrem $(1.05 \times .03)$.

With three of the four terminals so similar in their calculated doses, and the fourth's experience not relevant to this problem, it is recommended that a repair dose of $.03 \mathrm{TI} \times \mathrm{K}^{\prime} \mathrm{mrem}$ per car be used.

Summary

Pending more definite determination of switch-to-rest dose, the estimated employee close proximity dose at classification points is

Inspection

Classification

Repair
$.03 \mathrm{TI} \times \mathrm{K} \cdot \mathrm{mrem}$

.10

.03

.16 TI $\times k^{\prime}$ mrem per rail cask

\subsection{Employee General Area Exposure at Intermediate Classification Points}

The greatest difficulty in estimating exposures to terminal employees is that the location of the source of radiation, the spent fuel carload, cannot be defined during stopover time. The car will be in the receiving yard for some portion of the time, in the classification yard for another portion, in the departure yard for yet another, and occasionally in the repair facilities. Precisely where the car will be within each of these locations cannot be predicted. This makes it difficult to quantify the exposure distances to various employee groups, even if the locations of the latter are relatively fixed. 
The technique that has been used to surmount this difficulty is based on the assumption that, within each sector of the terminal where the RA car reposes, all possible locations are equally probable, i.e., the actual location will be randomly determined. (This assumption is modified in the measurement of general exposure following shove-to-rest classification, as might be anticipated.)

Each terminal sector is essentially linear, in that it consists of one or more parallel tracks that extend for a measurable distance. The car will repose somewhere within the sector for an estimatable period of time. If the car location within a sector is randomly determined, the probable exposure that will be experienced at a point with a fixed reference to the sector will be the average of the exposures calculated for all the possible car locations within the sector. A possible measure of the average exposure is the integrated dose that would be received if the source (RA car) were to move through the sector at a speed equal to the length of the sector divided by the estimated time of repose.* When the number of parallel tracks within the sector changed, subsectors were created. The estimated repose time in the sector as a whole was apportioned among the subsectors in proportion to the relative length of trackage in each.

Exposures at distances in excess of 400 meters were disregarded, as the dose becomes insignificant.

*In multiple track sectors, the exposure should be calculated separately for each track in the sector and then averaged unless the number of tracks is quite large as in a classification bowl. Then an average distance from an employee work site to the sector was used. 
General employee exposures were also modified for the shielding that would be provided by loaded cars reposing on tracks adjacent to the RA cars. The calculation of shielding factors was based on the estimated occupancy factors for the sectors (including allowance for bunching**), the number of parallel tracks in the sectors, and a loaded car percentage of 50 . The greater the number of tracks, and the higher the occupancy factors, the greater the reduction in dose due to shielding provided by loaded cars.

The large intermediate terminal had the largest number of employee work locations as it was the site of several large shop activities. These locations were closest to the receiving yard trackage, which extended for about $3.3 \mathrm{~km}$. The westernmost portion of the receiving yard $(1.7 \mathrm{~km})$ is 4 tracks wide, then comes an eight-track subsector of $.7 \mathrm{~km}$, followed by 12 tracks extending $.9 \mathrm{~km}$. There is a gap of about $.8 \mathrm{~km}$ between the body of the receiving yard and the bowl of the classification yard to the east. With an estimated average reposal time of 6 hours in the receiving yard, the computed speed for exposure in each of the above subsectors was $1.0 \mathrm{~km} / \mathrm{hr}, 0.5 \mathrm{~km} / \mathrm{hr}$, and $0.3 \mathrm{~km} / \mathrm{hr}$, respectively.

\begin{tabular}{|c|c|c|c|c|c|c|c|}
\hline Subsector & $\begin{array}{l}\text { Subsector } \\
\text { length (km) }\end{array}$ & $\begin{array}{l}\text { No. of } \\
\text { Tracks }\end{array}$ & $\begin{array}{l}\text { Track } \\
\text { Length }\end{array}$ & $(\mathrm{km})$ & $\begin{array}{r}\text { \% Track } \\
\text { Length }\end{array}$ & $\begin{array}{l}\text { Reposal } \\
\text { time }(\mathrm{hr})\end{array}$ & $\begin{array}{l}\text { "Speed" } \\
(\mathrm{km} / \mathrm{hr})\end{array}$ \\
\hline Western & 1.7 & 4 & 6.8 & & 29 & 1.7 & 1.0 \\
\hline Central & .7 & 8 & 5.6 & & 24 & 1.4 & 0.5 \\
\hline \multirow[t]{2}{*}{ Eastern } & .9 & 12 & 10.8 & & 47 & 2.9 & 0.3 \\
\hline & 3.3 & & 23.2 & & 100 & 6.0 & \\
\hline
\end{tabular}

With about 1200 cars passing through the receiving yard per day, the average occupancy is about 20 percent; this was doubled to 40 percent to allow for bunching. Together with the 50-percent loaded car factor, the 40-percent joint occupancy factor results in a shielding factor of 20 percent for adjoining tracks, or an "unshielded" factor of 80 percent. A RA car with one track between it and an employee location would have a probable effective dose rate of 80 percent of its unshielded dose on the track closest to the location.

**Bunching is fluctuation in occupancy rates from hour to hour over the course of the day and week. 
An RA car on a track with two intervening tracks would be 64 percent shielded, etc. The shielding factors for the three receiving yard subsectors were therefore $.75, .5$, and .4 , respectively (averaging the factors over 4,8 , and 12 tracks).

Beginning at the west end of the arrival yard, the following employee work locations were adjacent to the tracks at the distances shown:

\begin{tabular}{|c|c|c|c|c|}
\hline Location & Distance & Employees & $\begin{array}{l}\text { Dose to an } \\
\text { Individual* for } \\
\mathrm{v}=1.0 \mathrm{~km} / \mathrm{hr} \\
\end{array}$ & $\begin{array}{c}\text { Aggregate } \\
\text { Shielded Dose } \\
\end{array}$ \\
\hline $\begin{array}{l}\text { Private car shops } \\
\text { Locomotive service }\end{array}$ & $\begin{array}{l}80 \mathrm{~m} \\
40\end{array}$ & $\begin{array}{r}135 \\
20\end{array}$ & $\begin{array}{l}2.3 \times 10^{-5} \mathrm{KxTI} \text { mrem } \\
5.8\end{array}$ & $\begin{array}{l}.00233 \mathrm{KxTI} \text { mrem } \\
.00087\end{array}$ \\
\hline Wheel shop & 140 & 30 & 1.0 & .00022 \\
\hline System stores & 220 & 60 & 0.5 & .00022 \\
\hline Steel car shop & 250 & 150 & 0.4 & .00053 \\
\hline Signal shop & 330 & 60 & 0.2 & .00012 \\
\hline System shop & 190 & 30 & 0.5 & .00013 \\
\hline offices (depot) & 40 & 95 & 5.8 & .00735 \\
\hline Freight depot & 100 & 4 & 1.7 & .00009 \\
\hline Dispatchers & 50 & 16 & 4.4 & .00094 \\
\hline
\end{tabular}

The locations eastward through system stores are perpendicular to the western subsector of the yard, the steel car shop and system shop are at the boundary of the western and central subsectors (and the doses are calculated at their average), the signal shop is opposite the central subsector, and the last three locations are adjacent to the eastern subsector.

As an example of how the aggregate doses were calculated, that for dispatchers is

$\mathrm{TI} \times .000044 \mathrm{~K} / .3 \times .4 \times 16=.00094 \times \mathrm{K} \times \mathrm{TI}$ mrem.

The aggregate shieldeg* doses would apply to each RA car stopping over in the arrival yard for a period of 6 hours, provided the employees were present around the clock. Onily the locomotive service and dispatchers locations are so manned. All others work one shift only five days per week. Therefore

*from SAND 83-0867, Jigure 6 (Wi-83) 
their aggregate doses must be multiplied by $5 / 21$, and added to those for locomotive service and dispatchers. The adjusted dose is

$\mathrm{K} \times \mathrm{TI}(.01099 \times 5 / 21+.00181)=.0044 \mathrm{~K} \times \mathrm{TI}$ mrem per rail cask

Employees at all the above locations work indoors for the most part, thus doses would be reduced further due to structure shielding.

Employee general exposure while RA cars are in the bowl, or hump yard, is based upon the shove-to-rest mode of classification. Total hump yard detention is about 14 hours in this terminal, but bowl exposures are calculated at 12 hours of repose in the bowl, the other two hours are consumed by the classification (humping with RA car switched to rest) and outgoing train assembly processes. With shove-to-rest handling, the RA car will repose either at the trim end or randomly through the bowl. The probability of each alternative is assumed to be equal.

Cars are cleaned on two tracks adjacent to the north side of the bowl. The cleaners work primarily in the area between the two cleaning tracks and in the cars themselves. The closest exposure distance from the edge of the cars being cleaned to the centerline of the outer bowl track is about $10 \mathrm{~m}$. Allowing for a $3 \mathrm{~m}$ car width and a $5 \mathrm{~m}$ space between cars on the two cleaning tracks, the greatest exposure distance is about $21 \mathrm{~m}$. There is only minor shielding from the cars in the cleaning track as they are empty. The cleaning track personnel work one shift 5 days per week. Each track holds about 30 cars; this means that the men move at a rate of $60 \mathrm{~m} / \mathrm{hr}$ relative to cars in the bowl. If we assume that a RA car in the bowl has an equal probability of being classified into each of the 40 bowl tracks, the chance of the RA car being in the northernmost bowl track closest to the cleaning tracks is .025 . If it is switched to rest into that track, it will be located at the trim end (50\%) or randomly along the track $(50 \%)$. Based on its being there throughout the eight-hour shift for the cleaning track, the exposure of the car cleaners

*Shielding only by adjacent loaded cars, not buildings. 
to the RA car can be represented by $65 \%(50 \% \times 1 / 2+80 \% \times 1 / 2)$ of the integrated exposure at a speed of $.06 \mathrm{Km} / \mathrm{hr}$ for the employees relative to the $\mathrm{RA}$ car. The exposure distance would be from $10 \mathrm{~m}$ to $21 \mathrm{~m}$. Thus, the dose is

TI $\times \mathrm{K} \times .00028 / .06=.0047 \mathrm{~K} \times \mathrm{TI}$ mrem at 10 meter; TI $\times \mathrm{K} \times$ $.00012 / .06=.0020 \mathrm{~K} \times \mathrm{TI}$ mrem at 21 meter;

and an average of about $\mathrm{TI} \times \mathrm{K}(.0033 \mathrm{~K} \times .65 \times .025)=.000055 \mathrm{TI}$ $\mathrm{K}$ mrem.*

There is an equal probability that the RA car would be classified into the bowl track next to the northernmost track. In this event it would be $4 \mathrm{~m}$ farther away from the cleaning tracks, and shielded from these tracks to some extent by the presence of cars on the intervening track. On average, the bowl has a 40-percent occupiancy, so shielding might reduce exposure by 20 percent at distances between $14 \mathrm{~m}$ and $25 \mathrm{~m}$. The dose is

$\mathrm{TI} \times \mathrm{K} \times .00020 / .06=.0033 \mathrm{~K} \times \mathrm{TI} \mathrm{mrem}$ at $14 \mathrm{~m} ; \mathrm{K} \times \mathrm{TI} \times .00010 / .06=$ $.0017 \mathrm{~K} \times \mathrm{TI}$ mrem at $25 \mathrm{~m}$;

and an average of TI $\times \mathrm{K}(.0025 \mathrm{~K} \times .65 \times .025 \times .8)=.000033 \mathrm{~K} \times \mathrm{TI}$ mrem.

The next farther bowl track would have the exposure reduced to 64 percent due to shielding. The dose for this case is

$\mathrm{TI} \times \mathrm{K} \times .0001 \mathrm{~h} / .06=.0023 \mathrm{~K} \times \mathrm{TI}$ mrem at 18 meter; TI K $\times .00009 / .06$ $=.0015 \mathrm{~K} \times \mathrm{TI}$ mrem at $29 \mathrm{~m}$;

and an average of $.0019 \mathrm{~K} \times \mathrm{TI} \times .025 \times .65 \times .64=.000020 \mathrm{~K} \times \mathrm{TI}$ mrem, etc.

*These doses were der:Lved using data from Figure 6 in wi-83. 
The sum of all doses would be approximately .00014 $\mathrm{K} \times \mathrm{TI}$ mrem per rail cask. (If the RA car were not switched to rest, it would have a $100 \%$ uniform probability of being anywhere along the occupiable length of its bowl track. This would raise the above dose to about 80 percent of the full integrated dose rather than $65 \%$ or $.00018 \mathrm{~K} \times \mathrm{TI}$ mrem.)

The above is the dose that would be experienced by each car cleaner if there were a RA car in the bowl during the entire eight hour shift. Ten men work each shift, but only five shifts are worked per week. The average dose rate per hour over the week would be

$\mathrm{TI} \times .00014 \mathrm{~K} \times(10 \times 5) /(24 \times 7)=.000042 \mathrm{~K} \times \mathrm{TI} \mathrm{mrem} / \mathrm{hr}$, which at 12 hours per car in the bowl $=.00050 \mathrm{~K} \times \mathrm{TI}$ mrem per car.

A RA car reposing at the trim end of the bowl would lead to exposures to trim-end crews performing their functions, and to employees in both the one-spot and the yard offices, which are about $250 \mathrm{~m}$ from the trim end of drafts of cars in the bowl.

Trim engine crews would be at varying distances from the ends of the drafts of cars as they go about shoving together and pulling back drafts in the process of assembling outbound trains. The distances could be shortest with the crewmen on the ground (two or three) in particular, but even the crew in the engine ( $t$ wo or one) would come as close as $10 \mathrm{~m}$ to a $\mathrm{RA}$ car on an adjoining track. The throat of the yard is about $250 \mathrm{~m}$ away, in between the one-spot and the yard office. Moreover, while this is a hump yard, some flat classification does take place from the trim end, which also exposes the ground crew. It is reasonable to assume that there would be one trim engine working between the throat and the body of cars in the yard at all times, and that there would be a loaded cover car in place 25 percent of the time.

More time will be spent by trim end crews at greater distances from the RA car than at lesser distances. This offsets the exponential decline in dose with distance, and makes a median distance of $130 \mathrm{~m}$ a reasonable basis for 
calculating dose. This dose is

$\mathrm{TI} \times \mathrm{K} \times 12 / 2 \times .65 /(130 \times 130) \times 4 \times .75=.00069 \mathrm{~K} \times \mathrm{TI}$ mrem per car.

There are 89 employees per week working in the one-spot, and 99 in the yard office. Their dose (largely indoors) is

$\mathrm{TI} \times \mathrm{K} \times 12 / 2 \times .44 /(250 \times 250) \times(188 \times 8) /(24 \times 7) \times .75=.00028 \mathrm{~K}$ $x$ TI mrem.

In addition to RA cars in the trim end of the bowl and in the departure yard, yard office employees and employees in the one-spot are also exposed to RA cars awaiting repairs on the tracks outside the one-spot, undergoing repairs inside, or awajting removal after repair.

With three tracks through the one-spot spaced $15 \mathrm{~m}$ apart, and the track closest to the yard office being about $50 \mathrm{~m}$ away, the dose rate per day would be

$\mathrm{TI} \times \mathrm{K} \times 99 \times 8 / 7 \times[(.85 /(50 \times 50) \times 1 / 3+.81 /(65 \times 65) \times 1 / 3$ $\times 1 / 2+.76 /(80 \times 80) \times 1 / 3 \times 1 / 4)]=.0176 \mathrm{~K} \times \mathrm{TI}$ mrem per day.

The average detention of a car repaired in the one-spot is $21 / 2$ days, for a total of $.044 \mathrm{~K} \times \mathrm{TI}$ mrem.

The general exposure of one-spot employees to RA cars in the facility, over and beyond what they receive while actually in close proximity to the cars they are repairing (which has been estimated earlier) is difficult to estimate. The close-proximity exposures are spaced out within the building, and the cars that are the source are either within it or within $40 \mathrm{~m}$ of its perimeter (those further away are effectively shielded). Since half of the carmen's time is accounted for by close proximity repair activities, the other half constitutes the general exposure. A reasonable estimate is that the general dose would equal the dose experienced while in close proximity to cars being repaired (other than the RA car itself), or $.072 \mathrm{~K} \times \mathrm{TI}$ mrem. Adding this dose to the yard office general dose, and multiplying by the 1-percent 
frequency of one-spot repairs yields an estimate of $.0012 \mathrm{~K} \times \mathrm{TI}$ mrem. The employee general exposure estimated thus far is

$\begin{array}{ll}\text { Receiving yard (indoors) } & .0044 \mathrm{~K} \times \mathrm{TI} \mathrm{mrem} \\ \begin{array}{l}\text { Classification \& } \\ \text { departure yard } \\ \text { Indoors }\end{array} & .0003 \\ \text { Outdoors } & .0012 \\ \text { Subtotal } & .0059 \mathrm{~K} \times \mathrm{TI} \mathrm{mrem} \\ \text { One-spot (indoors) } & .0012 \mathrm{~K} \times \mathrm{TI} \mathrm{mrem} .\end{array}$

There are several groups of employees whose general exposure has not been estimated because their locations are not easily specified due to the variability and mobility of their activities. Sixty-eight yard crews per week of 4 men each perform classification, train makeup, switching of industries, and are at other locations, repair facility, cleaning track, shops and stores, intermodal terminal, pick up and set off cars from roll-by trains, etc. We have accounted for general exposure of 21 crews (trim end). The remaining 47 crews $\times 4$ men $\times 8$ hours, or 1504 man-hours per week has not had any general exposure attributed. Similarly, 350 road crews averaging $41 / 2$ men arrive and depart from this terminal per week. Allowing one hour exposure for each crew, the exposure time amounts to 1575 man-hours per week.

Twenty-six carmen per week (other than the one-spot) perform inspections and minor repairs to roll-by trains and in yards. We have accounted for much of their exposure in arrival and departure inspections, but not roll-bys, travelling to and from assignments, etc.

This latter estimate of man-hours is about 10 percent of the man-hours for which general dose has been estimated (excluding general dose originating at the one-spot). Therefore, 10 percent of the subtotal, or .0006 TI $\times \mathrm{K}$ mrem, will be added to cover the latter exposures resulting in a grand total of $.0077 \mathrm{~K} \times \mathrm{TI}$ mrem, of which $.0059 \mathrm{~K} \times \mathrm{TI}$ mrem is to employees who work largely indoors. If the attenuation due to structure shielding is assumed to reduce dose by a factor of seven, the total effective dose would be only $.0026 \mathrm{~K} \times$ TI mrem, or $.00011 \mathrm{~K} \times \mathrm{TI}$ mrem per stop time hour. 


\subsection{Population Exposur'e at Intermediate Classification Points}

In the case of non-rail population exposure, the population is spread over an extended area, and cannot be well represented by an "average" or centroidal location point as is general employee exposure. The dosage must be integrated over strips on either side of the terminal. The analogous concept is the integrated population dose over strips alongside the route of moving trains. The methodology applies as well to stationary RA cars which repose at determinable locations in a rail terminal. When the integrated dose is multiplied by the number of hours the car remains in the terminal and the population density surrounding the terminal, the integrated population dose results.

In the case of non-rail population dose at terminals (as distinct from population exposures along lines of road), the minimum distance from the population to the RA shipment is not uniform throughout the length of the terminal. The perimeter of the terminal is at varying distances from the centerline of the yard trackage from place to place within the terminal. Moreover, the existence of multiple tracks within the terminal introduces shielding of the population by loaded cars on adjoining tracks.

Figure 6 of Wi-83, p. 32, gives "linear" integrated doses for specific distances from 10 to $1000 \mathrm{~m}$ perpendicular to the shipment path. These data were used to estimate "area" integrated exposures over distance intervals ("strips") up to $400 \mathrm{~m}$ perpendicular distance from the source, beyond which the doses become negligible. The strip integrated exposures could be combined or accumulated to make up the population exposure rate for a strip beginning at selected distances from the source out to 400 meters away. The cumulative integrated dose rates are given in Table 1 . 
TABLE 1. Integrated Dose Rates to Areas Adjacent to Railroad Perimeters

\begin{tabular}{|c|c|c|c|}
\hline $\begin{array}{l}\text { Distance from } \\
\text { source (d) }\end{array}$ & $\begin{array}{l}\text { Linear } \\
\text { integrated dose } \\
\text { rate at distance(d) } \\
\text { for } \mathrm{V}=1 \mathrm{~km} / \mathrm{hr} \\
\left(10^{-8} \mathrm{TI} \times \mathrm{K} \text { mrem }\right)\end{array}$ & $\begin{array}{l}\text { Approximate area } \\
\text { integrated dose } \\
\text { rate from (d) to } \\
\left(\mathrm{d}_{2}\right)\left(10^{-8} \mathrm{TI} \times\right. \\
\left.\mathrm{m} \text { mem } \cdot \mathrm{km}^{2} / \mathrm{hr}\right)\end{array}$ & $\begin{array}{l}\text { Approximate area } \\
\text { integrated dose rate } \\
\text { from (d) to } 400 \mathrm{~m} \\
\left(10^{-8} \mathrm{TI} \times \mathrm{K} \text { mrem }\right. \\
\left.\mathrm{km}^{2} / \mathrm{hr}\right)\end{array}$ \\
\hline \multirow[t]{2}{*}{$10 \mathrm{~m}$} & 28.44 & & \\
\hline & & 189.4 & 679 \\
\hline \multirow[t]{2}{*}{20} & 13.18 & & \\
\hline & & 103.6 & 490 \\
\hline \multirow[t]{2}{*}{30} & 8.212 & & \\
\hline & & 68.2 & 386 \\
\hline \multirow[t]{2}{*}{40} & 5.781 & & \\
\hline & & 50.1 & 318 \\
\hline \multirow[t]{2}{*}{50} & 4.355 & & \\
\hline & & 38.5 & 268 \\
\hline \multirow[t]{2}{*}{60} & 3.425 & & \\
\hline & & 30.5 & 230 \\
\hline \multirow[t]{2}{*}{70} & 2.776 & & \\
\hline & & 25.8 & 199 \\
\hline \multirow[t]{2}{*}{80} & 2.301 & & \\
\hline & & 20.6 & 173 \\
\hline \multirow[t]{2}{*}{90} & 1.939 & & \\
\hline & & 18.1 & 153 \\
\hline \multirow[t]{2}{*}{100} & 1.657 & & \\
\hline & & 87.0 & 135 \\
\hline \multirow[t]{2}{*}{200} & .5116 & & \\
\hline & & 32.6 & 48 \\
\hline \multirow[t]{2}{*}{300} & .2187 & & \\
\hline & & 15.0 & 15 \\
\hline 400 & .1072 & & \\
\hline
\end{tabular}

In the case of the large intermediate terminal, a RA car stopping over is estimated to repose in the receiving sector for 6 hours, in the classification yard 12 hours, and in the departure sector for 4 hours. The one percent incidence of $21 / 2$ days in the one-spot repair facility is disregarded.

*Derived from Figure 6 in SAND83-0867 (Wi-83)

**Equivalent to one half of Equation (5), SAND80-1943 (Ta-82), p. B 
The receiving sector ( 3300 meters in length) has numbers of receiving tracks varying from four to twelve, and the distance from the centerline of these tracks to the perimeter of the terminal, the point at which exposure to the population begins, also varies, as shown in Figure 13. The perimeter on either side of the tracks has been divided into segments which have a uniform number of receiving tracks and a uniform distance from the centerline of those tracks. This is necessary because the exposure rate for the populated area changes with both of these characteristics. The "reposal time" of a RA car adjacent to each sector of perimeter has been determined by the "speeds" that were developed for the analysis of general employee exposure. The shielding effect of other loaded cars in the yard is from the same source. Using these characteristics, the breakdown of the dose factors for the receiving yard eastward from its western end is shown in Table 2.

TABLE 2. Dose Factors for Receiving Yard

\begin{tabular}{|c|c|c|c|c|c|c|}
\hline $\begin{array}{l}\text { Track } \\
\text { length }\end{array}$ & $\begin{array}{c}\text { Distance to } \\
\text { perimeter }\end{array}$ & $\begin{array}{l}\text { Integrated } \\
\text { area dose } \\
\text { rate } 10^{-6} \\
\text { TIxK mrem } \\
\text { - } \mathrm{km}^{2} / \mathrm{hr} \\
\end{array}$ & $\begin{array}{l}\text { Reposal } \\
\text { time } \\
\end{array}$ & $\begin{array}{l}\text { Shielding } \\
\text { factor }\end{array}$ & $\begin{array}{c}\text { Integrated } \\
\text { Area } \\
\text { Dose } \\
\left(10^{-7} \mathrm{TI} \mathrm{x}\right. \\
\left.\mathrm{K} \mathrm{mrem} \cdot \mathrm{km}^{2}\right) \\
\end{array}$ & $\begin{array}{l}\text { Population } \\
\text { zone type }\end{array}$ \\
\hline $700 \mathrm{~m}$ & $\mathrm{~s}-80 \mathrm{~m}$ & 1.73 & $.7 \mathrm{hr}$ & .75 & 9.0 & urban' \\
\hline 900 & $N-120$ & 1.13 & .9 & .75 & 7.6 & residential \\
\hline 1000 & $s-20$ & 4.90 & 1.0 & .75 & 36.8 & " \\
\hline 800 & $N-800 / 400$ & negligible & .8 & .75 & - & \\
\hline 200 & $S-80$ & 1.73 & .4 & .5 & 3.5 & $\begin{array}{l}\text { business/ } \\
\text { residential }\end{array}$ \\
\hline 600 & $N-400 / 120$ & .33 & 1.2 & .5 & 2.0 & 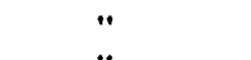 \\
\hline 500 & $s-120$ & 1.13 & 1.0 & .5 & 5.6 & " \\
\hline 100 & $N-120$ & 1.13 & .2 & .5 & 1.1 & $"$ \\
\hline 900 & $N-120$ & 1.13 & 2.9 & .4 & 13.1 & " \\
\hline 500 & $S-120$ & 1.13 & 1.6 & .4 & 7.2 & $"$ \\
\hline 400 & $S-80$ & 1.73 & 1.3 & .4 & $\frac{9.0}{95.0}$ & $"$ \\
\hline
\end{tabular}

Note that total track length for south perimeter and for north perimeter both equal $3300 \mathrm{~m}$, the length of the receiving yard sector. 


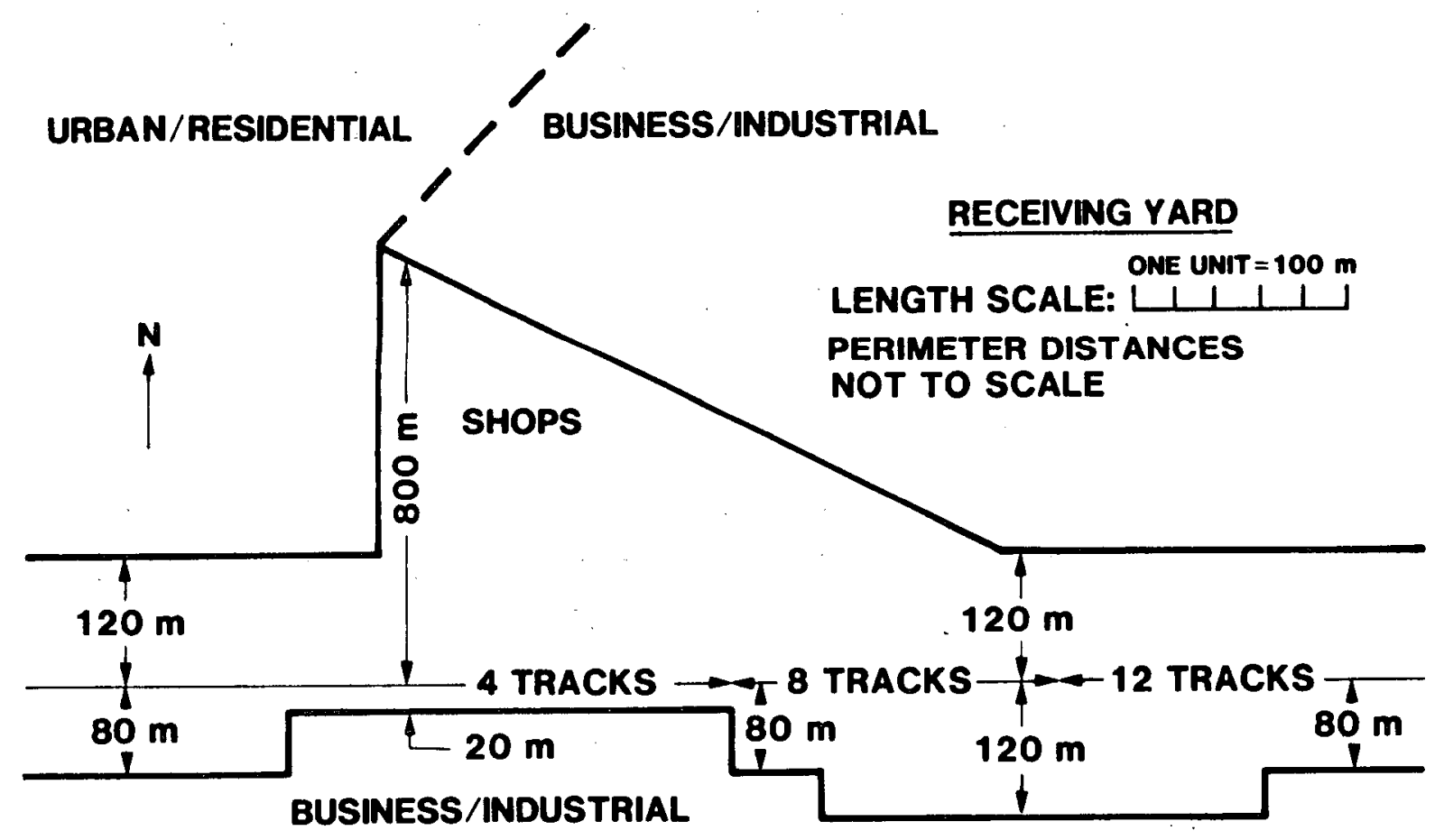

Figure 13: Receiving Yard Diagram (Note: Number of tracks and centerline is for receiving tracks only. There are other tracks in this sector as well. 
The classification yard is an automated hump with a dynamite track, which will be assumed to be used for all spent fuel carloads. For the switch-torest mode, cars would repose in the bowl either at the trim end of the classification tracks or randomly through the bowl. Loaded cars in adjacent tracks would shield the population in a perpendicular direction. The perimeter of the terminal is about $50 \mathrm{~m}$ from the outermost bowl tracks on either side (see Figure 14). With 20-percent loaded car occupancy, and 40 bowl tracks, the dose out to 400 meters for 12 hours will be $3.28 \times 10^{-6} \mathrm{PD} \times \mathrm{x}$ TI $\times \mathrm{K}$ mrem to each side or $6.56 \times 10^{-6} \mathrm{PD} \times \mathrm{TI} \times \mathrm{K}$ mrem. The population density is entirely suburban to rural to the south and also to the north from the trim end of the bowl. From the hump end on the north side, the area is urban residential from about $150 \mathrm{~m}$ beyond the perimeter or 200 meters from the edge of the bowl. The boundary is irregular but would constitute no more than 5 percent of the total bowl track dose or about . $3 \times 10^{-7} \mathrm{PD} \times \mathrm{K} \times \mathrm{TI}$ mrem.

Cars will repose on departure tracks for four hours. The perimeter to the south is $100 \mathrm{~m}$ distant across a small river, and the area is suburban to rural, and includes a golf course. A public highway is $20 \mathrm{~m}$ from the departure tracks to the north, in an area with a rural population density. There are 13 departure tracks, three of which extend about $600 \mathrm{~m}$ eastward from the other tracks. Average occupancy is less than that at the receiving yard, but bunching is a greater factor, so the 40-percent effective occupancy is assumed.

With shove-to-rest handling from the dynamite track, and three classification drafts in the typical train, the probability that the RA car will be in the three-track extension of the yard is $3 / 13 \times 1 / 3$, or 8 percent. The remaining probability $(92 \%)$ is that the RA car will be in the 13-track body of the departure yard. Based on shielding factors for adjacent loaded cars in 3-vs 13-track locations, the population dose for the north (rural) side is $6.29 \times 10^{-6} \mathrm{PD} \times \mathrm{K} \times \mathrm{TI}$ mrem, and to the south (suburban-rural) is $1.96 \times 10^{-6} \mathrm{PD} \times \mathrm{K} \times \mathrm{TI} \mathrm{mrem}$.

ॠPD is the population density (person $/ \mathrm{km}^{2}$ ) for the area outside of the railyard. 


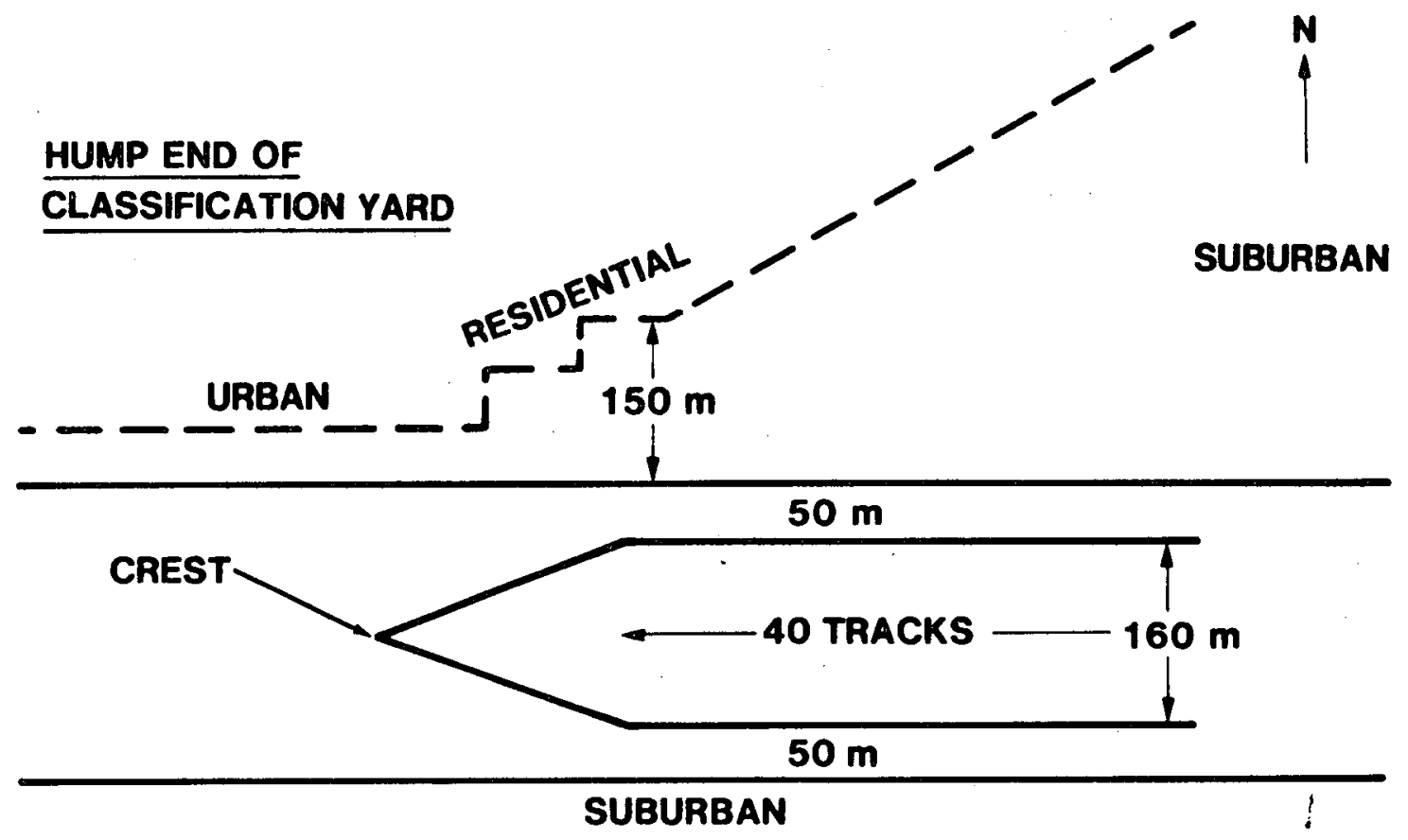

Figure 14. Classification Yard Diagram 
The sum of population exposures is:

$\begin{array}{lll}\text { Receiving yard } & 4.15 \times 10^{-6} \text { PDXKXTI mrem } & \text { businesss-industrial } \\ & 5.35 & \text { urban-residential } \\ \text { Classification } & .30 & \text { urban-residential } \\ \text { Departure yard } & 6.26 & \text { suburban } \\ & 1.96 & \text { suburban-rural } \\ & \frac{6.29}{24.31 \times 10^{-6} \text { PDXKXTImrem }} & \text { rural }\end{array}$

In addition to 22 hours per car reposal time in the three zones above, another two hours per car is spent moving between them. If we assume that the exposure during these two, 1-hour periods is at the same rates as during the 22 reposal hours, $2.37 \times 10^{-6} \mathrm{PD} \times \mathrm{K} \times \mathrm{TI}$ mrem will be added, making $\mathrm{a}$ complete population dose for the entire stop of

Business-industrial Urban residential Suburban suburban-rural Rural
4.49
6.13
6.78
2.20
7.08
$26.68 \times 10^{-6} \mathrm{PD} \times \mathrm{K} \times \mathrm{TI}$ mrem

Divided by the 24-hour stop time in this terminal, the hourly population dose rate is $1.11 \times 10^{-6} \mathrm{PD} \times \mathrm{K} \times \mathrm{TI} \mathrm{mrem} / \mathrm{hr}$ per rail cask. The population density (PD), is weighted to reflect the population characteristics at the terminal.

\subsection{Frequency of Classification}

Having established crew dose per classification, an estimate of how often classification occurs is needed to determine shipment dose. There are no statistics collected on the number of cars classified, so a study was conducted for this purpose. The study consisted of the following steps:

1. Developing a compilation of routes which represent the prospective movements of spent fuel.

2. Railroads included in those routes were requested to identify the locations where classification typically takes place. 
3. The number of classifications on each route was counted and related to the length of the route.

4. A statistical analysis was made of these data to derive a general expression of classification frequency.

The relationship derived is

Classifications per shipment $=2+0.055 \times \mathrm{km}^{0.55}$.

This relationship expresses the average number of classifications for a large number of shipments over different routes having a common length. Individual shipments and individual route averages will vary from the number predicted by this relationship. A more detailed description of each step is given below.

\subsubsection{The route base}

The Highway and Railroad Routing Section of the Oak Ridge National Laboratory was requested to provide from their computerized rail network one representative rail route from each present or proposed reactor site accessible by rail service to each of the candidate repository sites. The computer listings showed the names of the carriers, the classification points along the route and the mileage. The computer selected routes over the best quality main lines ("A" main) whenever feasible. Two routes were furnished for each movement to Hanford, WA, as there are two serving carriers.* since there were 57 reactor sites considered to be rail-accessible, Oak Ridge's analyses furnished over 330 routes.

\subsubsection{Railroad requests and responses}

The railroad industry is very sensitive to inquiries about proprietary information. Therefore, it was decided that requests would be made for classification information only from those roads where a personal contact was

*Except when the reactor site was local to one of the two Hanford roads. 
available, so that the nature and purpose of the information request could be well presented. After an initial telephone contact, a letter was sent with the route detail desired, a retyped copy of the letter is contained in Appendix E.

Some roads were not contacted, because they had only a small involvement in the routing base (e.g., only one reactor site, bridge movement only). In the end, 12 roads participated. Only one major originator was not included, and only one road contacted declined to participate.

\subsubsection{Route analysis}

Aside from those routes which could not be analyzed because of missing carrier information, there were a number of other routes which were omitted for different reasons: site considered too impractical to reach from existing rail lines; line abandoned, no alternative available, junction specified no longer used, not serviceable, or not customary; and, route not commercially realistic. In many such cases, alternative routes were developed, with or without the help of the carriers, this enabled the movement to be included in the study.

It was possible to identify classification points for 211 routes. It frequently happened that the identity of the classification points that were furnished indicated that the route of movement (i.e., the rail segments that the trains actually would traverse) differed in some detail from the route provided by the Oak Ridge computer. This happened for operational reasons: after being picked up at the reactor site, the shipment would be back-hauled to the terminal where it would be placed in the next train, rather than proceed forward as the computer assumed; trains operate into and out of terminals that are of $f$ of the line of the direct route; trains operate over longer, more roundabout routes where service is more frequent, and track quality may be better because traffic is denser. These deviations from the direct routes furnished by the computer added mileage, sometimes substantially.

The classification characteristics of the 211 routes are summarized in Table 3. For convenience the routes have been grouped into 100-mile blocks 
(50-149, 150-249, etc). Even with this grouping, it is evident that the classification experience of the different hypothetical routes is widely scattered with respect to mileage. If individual shipments actually traveling over the routes were to be studied, they would be scattered around the route averages as well. Nonetheless, a definite trend of more classifications with distance is discernable in Table 3. This trend was characterized by 1 ) averaging the number of classifications per route within each mileage block, 2) disregarding all averages that were based on fewer than four routes, 3) subtracting two classifications from each average as the minimum, and 4) fitting a least squares curve to these reduced averages. The resulting equation, converted to metric, is

Classifications per shipment $=2+.055 \times \mathrm{km}^{0.55} \cdot *$

\subsection{Exposure of Passengers and Crew of Other Trains Sharing Route}

The total dose per mile consists of two components; dose to persons aboard Amtrak passenger trains (passengers and crew) and dose to crews of passing freight trains. Exposure to passengers and crews of non-Amtrak commuter trains is disregarded. Commuter trains operate in very limited and selected large metropolitan zones (New York, Philadelphia, Boston, etc.) which spent fuel cars will traverse very infrequently. The only relevant commuter zone might be Chigago, which is an important gateway for freight traffic between east and west.

\subsubsection{Amtrak Trains}

Amtrak operates about 30 million train miles per year. Both Amtrak service and spent fuel shipments are concentrated on the rail routes having in excess of 1 million gross tons of freight traffic per year (i.e., they don't run on B branch lines) of which there were about 140,000 miles in 1977 . This equates to an average of 210 Amtrak train miles per route mile per year, or .024 route miles per hour, one half of which can be assumed to operate in each

*This equation may be appropriate for much long haul, general merchandise traffic, but not for bulk, short haul, or intermodal shipments. 
TABLE 3. Number of Routes v8. Number of Classifications by Hileage Blocks

\begin{tabular}{|c|c|c|c|c|c|c|c|c|c|c|c|}
\hline Mileage & & & & & & of & 100 & cat & & & \\
\hline$\frac{\text { Block }}{\text { (center) }}$ & $\underline{2}$ & $\underline{3}$ & 4 & $\underline{5}$ & 6 & 1 & $\underline{8}$ & 9 & 10 & 11 & $\underline{12}$ \\
\hline 200 & & & 1 & & & & & & & & \\
\hline 300 & & 2 & & 1 & & & & & & & \\
\hline 400 & & 1 & & & & 1 & & & & & \\
\hline 500 & 1 & & & 3 & & & & & & & \\
\hline 600 & & & & & 1 & 1 & & & & & \\
\hline 700 & & & & 1 & 1 & 1 & & & & & \\
\hline 800 & & & & 1 & 2 & 1 & 1 & & & & \\
\hline 900 & & 1 & 1 & 2 & 3 & & & & & & \\
\hline 1000 & & 1 & 3 & 3 & 1 & & & & & & \\
\hline 1100 & & 1 & 2 & 3 & 2 & 3 & 1 & & & & \\
\hline 1200 & 1 & 1 & 1 & 3 & 2 & 2 & & 1 & & & \\
\hline 1300 & & & 2 & 1 & 3 & 1 & & & & & \\
\hline 1400 & & & & 4 & & 1 & 4 & 1 & & & \\
\hline 1500 & & 1 & & 6 & 3 & 2 & 2 & & & & \\
\hline 1600 & 1 & 1 & 1 & 1 & & 1 & & & & & \\
\hline 1700 & & 1 & & 1 & 2 & 2 & 1 & & & & \\
\hline 1800 & & & & 1 & 6 & 2 & 2 & & & & \\
\hline 1900 & & & & 1 & 3 & 1 & & & & & \\
\hline 2000 & & & & 6 & 3 & 1 & 1 & & 2 & & \\
\hline 2100 & & & 2 & 3 & 2 & 1 & 1 & 1 & & & \\
\hline 2200 & & & & 2 & 1 & 5 & 2 & & & & \\
\hline 2300 & & & & 1 & & 1 & & 1 & & & \\
\hline 2400 & & & & 3 & 1 & 1 & & 2 & & & \\
\hline 2500 & & & & 1 & 1 & & 1 & 1 & & & \\
\hline 2600 & & & & 2 & 1 & & & 1 & & & \\
\hline 2700 & & & & 2 & 2 & 1 & 3 & 2 & 1 & 1 & 1 \\
\hline 2800 & & & & & 2 & 1 & & 3 & 1 & & 1 \\
\hline 2900 & & & & & & 1 & & & 2 & 1 & 2 \\
\hline 3000 & & & & & 2 & 1 & & 2 & 1 & & 1 \\
\hline 3100 & & & & 1 & & 1 & & 2 & & 1 & 1 \\
\hline 3200 & & & & 1 & & & & 1 & & & \\
\hline
\end{tabular}


direction. Amtrak trains average about $45 \mathrm{mph}$ and thus a freight train operating at an average velocity of $20 \mathrm{mph}$ will not only meet Amtrak and freight trains in the opposite direction, but be overtaken by Amtrak trains in the same direction. At .024 Amtrak trains per hour, a freight train containing a spent fuel car will pass or be passed by .00075 Amtrak trains per $\mathrm{km} . \star$

Amtrak trains have an average of about 160 passengers and crew. Thus, 0.12 persons will be exposed to the passing RA shipment for each $\mathrm{km}$ on its route of movement. This population exposure will be considered jointly with that of passing freight train crews.

\subsubsection{Other Ereight Trains}

Freight train crew dose is more complex to calculate because, unlike Amtrak, an even distribution of freight trains over the rail network is not an acceptable assumption. As freight density increases on routes, the number of trains per hour increases in both directions, so the frequency of encountering opposing freight trains goes up. At the same time, the probability of a spent fuel shipment being handled over a high-density route is also higher. Using an average freight train incidence per route mile, as assumed for Amtrak trains, would result in an underestimate of exposure.

If it is assumed that the freight train density increases in proportion to the gross tonnage density per route mile (an overstatement, as freight trains are longer on heavy-density lines), then $A$ main lines (over 20 million gross ton per year) have a freight train density 10 times that of A branch lines (1-5 million gross ton per year). The probability is also 10 times greater that the RA shipment will be moving over A main lines than over A branch lines. As a result of this differential weighting, the average train moves over a line having about 5500 freight trains per year, whereas the average

*This factor is overstated due to the highest frequency of Amtrak trains being in the Boston-Washington corridor, which will have less than average use for spent fuel shipments. 
line (excluding B branches) has about 2900 trains per year.

A freight train density of 5500 trains per year equates to .63 trains per hour, half in each direction. At $32 \mathrm{~km}$ per hour, the trains in each direction will, on average, be $102 \mathrm{~km}$ apart. Thus a shipment with an average velocity of $32 \mathrm{~km} / \mathrm{h}$ will pass one train in the opposite direction every $51 \mathrm{~km}$, or .02 trains per $\mathrm{km}$. With an average crew of $41 / 2$ per freight train, the freight train crews will be passed at the rate of .09 persons per $\mathrm{km}$.

\subsubsection{Passing train exposure}

It is assumed that the relative speeds of trains passing spent fuel shipments will be $30 \mathrm{mph}$ ( $48 \mathrm{kmph}$ ). With a cask car length of $16.5 \mathrm{~m}$, direct exposure time per person (immediately opposite car) is $.00034 \mathrm{hr}$. Passengers and crew are assumed to be either three or five meters from the linear source. Including adjoining car factors, dose per $\mathrm{km}$ is then

$\mathrm{TI} \times .00034 \mathrm{~K}^{\prime}(1.10 / 3+1.27 / 5) \times 1 / 2 \times(.12+.09)=.000022 \mathrm{TI} \times$ $\mathrm{K}$ 'mrem/km per rail cask.

\subsection{Rail Accident Rates}

\subsubsection{The data base}

Characterization of the accident rate for rail transport of irradiated fuel is based on train accident data compiled by the FRA from accident reports filed by railroads. The AAR has performed certain editing and adjustment of this base, and the AAR version is employed here. The AAR editing consisted of excluding grade crossing accidents, merging joint and multiple reports, adjusting reporting thresholds and reported damages to 1981 cost levels, and correcting obvious coding errors. The data base compiles accident data by track type: main track (which includes branches); sidings; yards; and industry. Only the data for the first two track types was utilized. The reason for this is that carloads of spent fuel would be handled in yards in such a way as to virtually eliminate the risk of severe accidents. The only 
risk would be from a large explosion or fire occurring in the yard near the spent fuel shipment. The handling over industry tracks from the reactor to the rail line, and from the rail line to the repository will entail negligible accident risk.

The accident characterization does not consider all rail accidents. Minor accidents are excluded from the data base because reporting of accidents by railroads is subject to threshholds defined in terms of the estimated damage to track and rolling stock ( $\$ 3700$ per accident in 1981). The damage estimates do not include other costs (wreck clearing, liability for personal injuries, cargo loss and damage, or deaths, third-party property losses, etc.) and are not subject to revision when the actual value of damages is realized later.

\subsubsection{Superiority of using only severe accidents}

As well as the minor accidents which are not in the data base, the characterization also excludes a large number of the less severe accidents that are in the data base. Abnormal radiation exposures will occur from accidents only if the integrity of the cask is compromised by impact, fire, and/or explosion. Only the more severe accidents could involve enough energy to affect the integrity of the cask.

Within the train accident data base is a subset of accidents which serve to characterize more severe accidents. These are accidents in which a release of hazardous cargo material is reported to have occurred. A release of contents of a "hazmat" car virtually always involves a puncture or rupture of the carbody. About 1 percent of all reported accidents involve a release of hazardous materials.

It should be appropriate to attribute this subset of more severe accidents to the rail transport of spent fuel and to disregard the less severe accidents, rather than consider all accidents. In addition to eliminating accidents of little or no relevance to spent fuel shipment (other than to delay the shipments, and to increase "normal" exposures on account of wreck clearing and repair personnel), the hazmat-release accidents are more appropriate in that 
hazmat shipments move in a train environment more similar to that of spent fuel than does the average shipment, which includes a large proportion of bulk traffic moving in low-speed, high-tonnage trains or in unit trains of uniform consistency. In addition, eliminating less severe accidents will improve the correlation between train speed as reported at the time of the accident and the impact speed experienced by the cars under study. Cars derailed or damaged but not punctured or ruptured will not be counted. This will improve the realism of the accident severity distribution that is derived from reported train accident speeds.

The rationale for studying "hazmat" release accidents is not that spent fuel cars would also be expected to release radioactivity under like accident conditions. Rather, the purpose is to focus on a set of cars which clearly have experienced more severe than average forces in an accident.* The accident itself may not have been more severe than the average accident, although statistical comparisons show that as a group such accidents are. The "severe" accident rate is lower than the overall rate; however, the severity distribution is higher.

\subsubsection{Severe accident rate}

Road haul accidents are those that occur in train movement over main track (which includes branch lines) and sidings. The road haul severe accident rate has been determined from the number of "hazmat" cars having accidental releases per "hazmat" car mile** in 1980-81, which is .17 per million. It would be preferable to use a longer period, as the reported accident rates can vary from one year to another (1981 was only half 1980). The car release count for 1982 is available, but the loaded car miles are not. However, the 1982 rate would appear to have been very close to the 1980-81 average.

\footnotetext{
*It is merely fortuitous that hazmat cars are the ones that permit this. Nonhazmat cars also experience levels of kinetic and thermal energy severe enough to puncture or rupture them, but in their case this event is not reported; they are undistinguished from cars merely derailed or damaged.

**Car miles of hazmat loads were estimated by AAR using the FRA network model and the FRA 1-percent Waybill Sample (all STCC 49000 commodities).
}

$$
-101-
$$


Years before 1980 are not comparable with years since. Before 1978, "hazmat" shipments (predominantly in tank cars) were more vulnerable to puncture due to vertical separation of couplers during accidents, and to releases from valves broken off the tank undersides when carbodies were separated from trucks. From 1978 to 1980 , tank cars handing hazmat commodities were retrofitted with head and valve shields and shelf couplers, which shifted the speed distribution of hazmat release accidents upward.

At the same time that the hazmat accident environment was changing for the foregoing reasons, the overall accident rate was declining. This may have been partly due to the cost levels of the accident damage estimates not keeping pace with the rising reporting thresholds. If this were the case, accidents which would have been reported during the late 1970 s might not have been reported after 1979. This too would have shifted the severity profile upward. Both reasons underlie the decision to disregard years before 1980 in determining both accident rates and severity distributions for hazmat release accidents. 


\section{References for Section 4.0}

Wi-83 E. L. Wilmot, M. M. Madsen, J. W. Caswell, and D. S. Joy, A Preliminary Analysis of the Cost and Rise of Transporting Nuclear Waste to Potential Candidate Commerical Repository Sites, SAND83-0867, TTC-0434, Sandia National Laboratories, Albuquerque, NM, June 1983.

Ma-83 M. M. Madsen and E. L. Wilmot, "Truck Transportation of Radioactive Materials," proceedings of PATRAM '83, New Orleans, 1983.

Ta-82 J. M. Taylor and S. L. Daniel, RADTRAN II: Revised Computer Code to Analyze Transportation of Radioactive Material, SAND80-1943, Sandia National Laboriatories, Albuquerque, NM, 1982. 


\subsection{Summary of Incident--Free Exposure Models}

The dose factors for each railcask can be summarized as follows:

Dose while in train service

Road crews on shipments

Occupants of passing trains

Population along route

Dose while not in trains

Terminal crews handling shipments

Other employees at stops

Population at stops

Classifications $=2+0.055(\mathrm{~km}) 0.55$

Stop time $(\mathrm{hr})=60+0.02$ per $\mathrm{km}+0.86(\mathrm{~km}) 0.46$

To compare the relative contributions to accident-free transport risk of the above dose components, doses were calculated for a short-haul movement $(500 \mathrm{~km})$ and a long-haul movement $(5000 \mathrm{~km})$. Doses expressed in $\mathrm{K}$ ' have been converted to $K$ on the basis that $K=3.5 \mathrm{~K}^{\prime}$ (see Appendix A). Population density for this comparison has been taken as 119 equivalent persons per square $\mathrm{km}$ along the route, and as 340 equivalent persons at stop locations. The derivation of these population densities is discussed in Appendix $C$.

Total incident free dose is as follows per trip:

Short haul

Employees handling shipment

other persons on link

Population alongside link

Long haul

Employees handling shipment

Other persons on link***

Population alongside link

\begin{tabular}{|c|c|c|}
\hline Trains** & Stops & Total \\
\hline$\overline{500 \mathrm{~km}}$ & $\overline{85 \mathrm{hr}}$ & \\
\hline $.001 \mathrm{KxT}$ Imrem & $.168 \mathrm{KxTImrem}$ & $.169 \mathrm{~K} \times T$ Imrem \\
\hline .003 & .009 & .012 \\
\hline .026 & .032 & .058 \\
\hline .030 & $\overline{.209}$ & .239 \\
\hline $5000 \mathrm{~km}$ & $203 \mathrm{hr}$ & \\
\hline .012 & .364 & .376 \\
\hline .031 & .022 & .053 \\
\hline .258 & .076 & .334 \\
\hline $.301 \mathrm{~K} \times \mathrm{T}$ Imrem & $.462 \mathrm{~K} \times \mathrm{TImrem}$ & $.763 \mathrm{~K} \times \mathrm{TImrem}$ \\
\hline
\end{tabular}

\footnotetext{
* See Ta-82 in Section 4.0 .

$* *$ Includes stop time while in trains. $\star \star \star$ Based on model in $\mathrm{Ta}-82$.
}

$2.4 \mathrm{TI} \times \mathrm{K} 10^{-6} \mathrm{mrem} / \mathrm{km}$

$2.2 \mathrm{TI} \times \mathrm{K}, 10^{-5} \mathrm{mrem} / \mathrm{km}$

4.3XPD* $\times 10^{-7} \mathrm{~K}$ TI $\mathrm{mrem} / \mathrm{km}$

$1.6 \times 10^{-1} \mathrm{~K}^{\prime} \times \mathrm{TI}$ mrem/ classification

$1.1 \times 10^{-4} \mathrm{~K} \times \mathrm{TI} \mathrm{mrem} / \mathrm{stop}$ time hour time hour 
As would be expected, exposure in train service is proportional to length of haul. Exposure at stops doubles as haul distance increases tenfold. In addition, population exposure is the main component ( 85 percent) over the road, whereas employee exposure predominates at stops. Also, other persons on link is a minor factor ( 10 percent or less) throughout. 


\section{APPENDIX A. Units of Calculations}

The basic formulation for the assessment of population does is based upon an expression for total body dose-rate as a function of distance from a point source of external penetrating radiation. This point source approximation is acceptable for distances between the receptor and the source of more than twice the largest physical dimension of the source. At smaller distances, the point source approximation overpredicts exposure and, therefore, an alternative approach to estimating dose is used. The point source dose-rate formula is given by

$$
D R(r)=\frac{S_{p}}{4 \pi r^{2}} \cdot \exp (-\mu r) \cdot B(\mu r) \cdot A
$$

where

$$
\begin{aligned}
s_{p} & =\text { particle or photon enission rate } \\
r & =\text { distance from source } \\
\frac{s_{p}}{4 \pi r^{2}} & =\text { flux at distance } r \\
\mu= & \text { absorption coefficient for surrounding medium } \\
\exp (-\mu r)= & \text { attenuation in medium at distance } r \\
B(\mu r)= & \text { Berger dose-rate buildup factor for surrounding medium at } \\
& \text { distance } r \\
A & =\text { flux-to-dose-rate conversion factor }
\end{aligned}
$$


For all values of $\mu$ and $r$ the product $\exp (-\mu r) \times B(\mu r)$ is $\leq 1.0$. Thus, dose rate can be expressed conservatively as

$$
\begin{aligned}
& D R(r)=\frac{J}{r^{2}} \\
& \text { where } \quad J=\frac{S_{p} A}{4 \pi}
\end{aligned}
$$

Using the regulatory definition of transport index as the dose-rate in mrem/hr at a distance of $1 \mathrm{~m}$ from the surface of the package, the factor $\mathrm{J}$ in the above equation can also be given by

$$
\mathrm{J}=\mathrm{K} \times \mathrm{T} \mathrm{T} .
$$

The new parameter, $K$, serves to extrapolate the dose-rate value given at $1 \mathrm{~m}$ from the package surface back to the actual center of the package such that a true point source configuration is achieved.

For exposure distances less than 10 meters from the package, a line source approximation is applied. The dose is proportional to $1 / \mathrm{r}$ rather than $1 / \mathrm{r}^{2}$ and $\mathrm{K}$ is replaced by $\mathrm{K}^{\prime}$.

While close proximity doses calculated in this study were accumulated separately from the more distant doses, it may be desirable to combine them for some analytical purposes. This study used a factor of

$$
\mathbf{K}=3.5 \mathbf{K}^{\cdot} .
$$




\section{APPENDIX B. Factors for Exposure From Adjoining Cars}

When an employee proceeds parallel to a draft of cars, such as when performing car inspection, or when the draft is passing him at a measured rate, such as during classification, the employee's exposure to a RA car in the draft has been calculated from his distance from the centerline and the length of time directly adjacent to or opposite the car. In addition to this immediately adjacent exposure, he will also receive exposure as he approaches the RA car (or it approaches him), such as while inspecting the cars adjoining the RA car, and also while retreating from it. This exposure will be less than the immediately adjacent exposure due to the greater distance, and also because of shielding that may be provided by the adjoining cars if they are loaded. To allow for this "adjoining" exposure, a set of factors has been developed to increase adjacent exposure values. The factors are based on the assumption that the employee remains at the same distance from the centerline of the adjoining cars as from the $R A$ car, and proceeds at the same relative speed (or spends the same length of time per adjoining car), as with the RA car. It is assumed that the $\operatorname{car}(s)$ next to the $R A$ car are loaded, and thus provide a shielding "shadow" that eliminates the adjoining exposure at some distance from the RA car. The distance that the next adjoining car provides shielding increases as the perpendicular distance of the employee from the draft of cars becomes greater. The correction as a function of perpendicular distance is

Perpendicular distance

$3 \mathrm{~m}$
4
5
6
7
8
9

\section{Correction factor}

for both directions

1.10

1.18

1.27

1.37

1.46

1.54

1.61 


\section{APPENDIX C. Generic Population Density Estimates}

The distribution of population density zones along the line of road is taken from Table 23 of: SAND 83-0867 (see reference wi-83 in Section 4.0) (p. 39) and is the avarage of those for the five repository sites shown. The distribution adjacent to terminals is taken from the field study of the large intermediate terminal. It is not simply the distribution of areas adjacent to the terminal by population zone, as is the coad distribution. It is a distribution of integrated area exposure rates by population zone, in which are reflected 1) the varying distances of the source (spent fuel car) from the terminal property line, 2) the complementary variations in the width of the populated zone exposed, and 3 ) the variations in shielding from loaded cars in the terminal. Unlike the road population zone distribution, the terminal population distribution is not symmetrical on both sides of the railroad.

\section{Population Zone}

rural

suburban

urban
Percent of Travel

80

18

2
Percent Stops

The population density of each zone is taken from Table 23 of SAND 83-0867 (p. 39). The population density in each zone has been reduced by the shielding effectiveness factors in Table 1 of SAND 80-1943 (p. 12) (see reference Ta-82 in Section 4.0 ).

As a result, equivalent (to unshielded) population densities are as follows.

\begin{tabular}{|c|c|c|c|c|c|}
\hline Zone & $\begin{array}{l}\text { Density } \\
\text { (persons/ } \\
\text { sq km) }\end{array}$ & $\begin{array}{c}\text { Shielding } \\
\text { factor } \\
\end{array}$ & $\begin{array}{l}\text { Equivalent } \\
\text { density }\end{array}$ & $\begin{array}{l}\text { Along } \\
\text { route }\end{array}$ & $\begin{array}{c}\text { At } \\
\text { stops }\end{array}$ \\
\hline Rural & 6 & 1.00 & 6 & 5 & 2 \\
\hline Suburban & 719 & .87 & 626 & 113 & 338 \\
\hline \multirow[t]{2}{*}{ Urban } & 3861 & .018 & 69 & 1 & 12 \\
\hline & & & & 119 & 340 \\
\hline
\end{tabular}




\section{APPENDIX D. Classification Frequency Study Letter}

As part of a project on the characteristics of rail transportation for the Transportation Technology Center of Sandia National Laboratories, I have made a selection of hypothetical movements. I shall appreciate your help in identifying the locations on your system at which cars would receive classification enroute.

The movements originate at present or potential reactor sites and terminate at sites of candidate repositories for irradiated fuel. However, the classification points should be those where a typical carload of merchandise would be handled. This will enable TTC to evaluate the population exposure under "normal" railroad service conditions.

Let me emphasize that I shall keep confidential the information I receive from individual railroads. I shall use it only to derive composite characteristics, and not apply or disclose it in disaggregate form.

Thank you for accepting this request, and for expending time and effort in responding to it. 


\section{APPENDIX E. Study of the Incidence of Classification in}

\section{Eail Shipments of Merchandise}

Information is being sought from a number of large U. S. railroads. The purpose for which the information will be used is twofold:

- To develop relationships between the number of times a loaded car is classified enroute as compared to the distance it travels and the number of rail carriers that participate;

- To establish a profile of the populuation density of the areas adjacent to representative classification points.

A list of hypothetical movements over your railroad is attached. Some are local, and some interline. The connecting carrier(s) is shown where the on-line origin and/or destination is an interchange point.

Please indicate the locations at which a single car shipment would most likely be classified between trains/transfers/industry switchers for each of these movements. If different connecting carriers result in different handlings, please report on each individually.

If a shipment would normally receive more than one handling at a particular location, indicate the number. If a classification at an interchange point is performed in a yard jointly serving both carriers, such as Potomac yard, please indicate this. If an interchange is usually made via switching roads, indicate them also, and the locations of handings on such roads (or their absence) if you happen to know them.

An example of the information sought might look as follows on a movement originating on Conrail at Oswego, NY for delivery to the BN at Chicago:

Oswego

Syracuse (2)

Rochester 
Elkhart

Gibson (joint with IHB)

IHB: Blue Island

delivery to $B N$ at LaGrange

Total: 7 classifications

Please correct the names of junctions which are used predominantly with a given connection, and indicate wherever the junction specified is little used or impractical.

It is not essential that this information conform precisely with your present operating plan. Responses reflecting any actual operations in the recent past will be satisfactory. The routings chosen do not in all cases conform with the most recent mergers and affiliations, but if they were realistic previously, please respond in that context. 
DISTRIBUTION :

U. S. Department of Inergy

office of Scientific \& Technical Information (226)

Oak Ridge, TN 37830

Attn: DOE/OSTI-4500-R74 UC-71

U. S. Department of Einergy

Routing DP 123

Washington, DC 20545

Attn: T. Hindman

R. Heusser

F. Falci

U. S. Department of Energy

Idaho Operations office

550 second street

Idaho Falls, ID 83401

Attn: C. P. Gertz

W. W. Bixby

U. S. Department of Energy

Albuquerque Operations of $f$ ice

2201 San Pedro, NE, Bldg. 3

Albuquerque, NM 87110

Attn: J. McGough

K. Golliher

E. C. Hardin

Joint Integration of $f$ ice

2201 San Pedro, NE; Bldg. 3

Albuquerque, NM 87110

Attn: J. Roll, Westinghouse

K. McKinley, Rockwell

R. M. Jefferson

U.S. Department of Energy

Routing RW-33

1000 Independence SW

Washington, DC 20585

Attn: L. Barrett (1)

R. Philpott (1)

E. Wilmot (10)

S. Denny (1)

Office of Security Evaluations

Attn: Dr. Julio L. Torres, Acting Director

Defense Programs - DP-4, GTN

Washington, DC 20545

Environmental Evaluation Group

Attn: D. L. Shomaker, Librarian

P.0. Box 968

Santa Fe, NM 87503 
3141 S. A. Landenberger (5)

3151 W. L. Garner (3)

6000 E. H. Beckner

6300 R. W. Lynch

6320 J. E. Stiegler

Attn: TTC Master File

6320 TTC Library (25)

6321 R. E. Luna

6322

6323

6324

W. E. Wowak

G. C. Allen

B. D. Zak

8024

P. W. Dean (1) 